\title{
Discovery of Novel Non-Peptidic PAR2 Ligands
}

\author{
Ilona Klösel, ${ }^{1}$ Maximilian F. Schmidt,${ }^{1}$ Jonas Kaindl, ${ }^{1}$ Harald Hübner, ${ }^{1}$ Dorothee Weikert, ${ }^{1}$ \\ Peter Gmeiner ${ }^{*}$
}

\begin{abstract}
${ }^{1}$ Department of Chemistry and Pharmacy, Medicinal Chemistry, Friedrich-Alexander University Erlangen-Nürnberg (FAU), Nikolaus-Fiebiger-Str. 10, 91058 Erlangen, Germany
\end{abstract}

\section{SUPPORTING INFORMATION}

Supplementary Figure S1. Modeling and refinement of trypsin activated PAR2 model....

Supplementary Figure S2. Docking of $\mathbf{4 b}$ and $\mathbf{5 a}$ to PAR2 .................................... 4

Supplementary Figure S3. Investigation of potential antagonist properties........................... 5

Supplementary Table 1. PAINS screening of target and reference compounds......................... 6

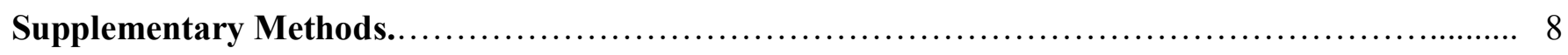

Supplementary Data. Supplementary Data. ${ }^{1} \mathrm{H}$ and ${ }^{13} \mathrm{C}$ NMR spectra of the key compounds.............28

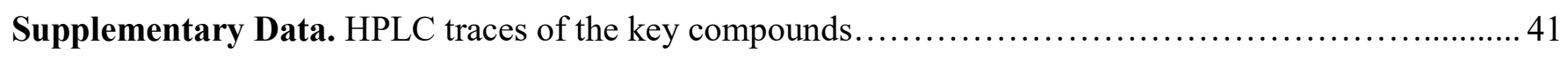

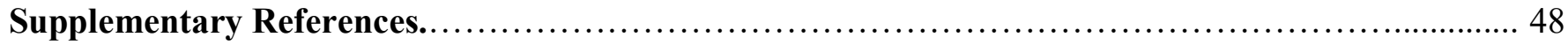




\section{Supplementary Figure S1. Modeling and refinement of trypsin activated PAR2 model.}

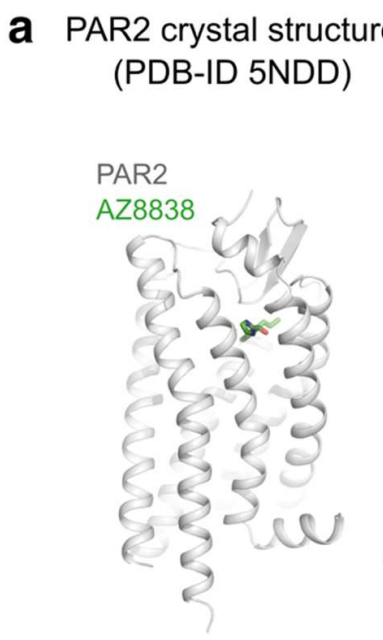

$$
\begin{aligned}
& \text { model of trypsin activated N-terminus bound } \\
& \text { to transmembrane segment of PAR2 }
\end{aligned}
$$

1. removing $A Z 8838$

2. modeling of $\mathrm{N}$-terminus up to Ser37 to simulate trypsin cleavage

3. metadynamics simulations to capture binding of

$\mathrm{N}$-terminus to receptor core 4. refinement by unbiased MD

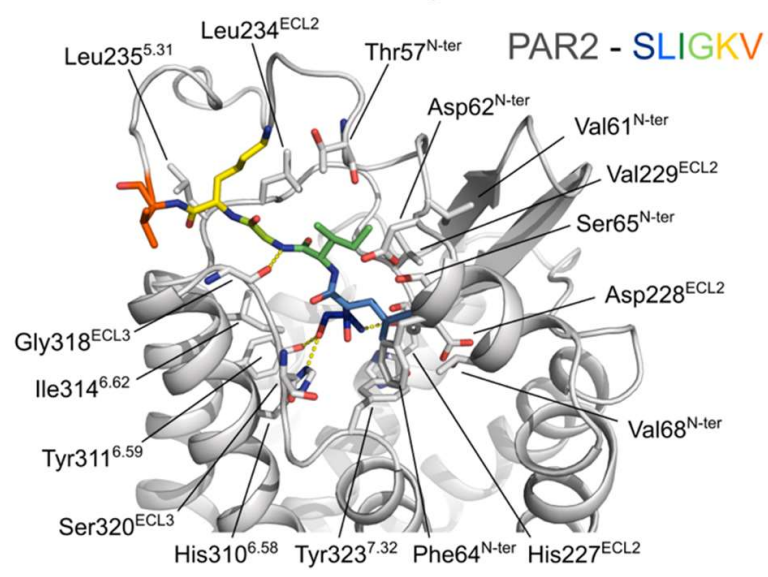

b

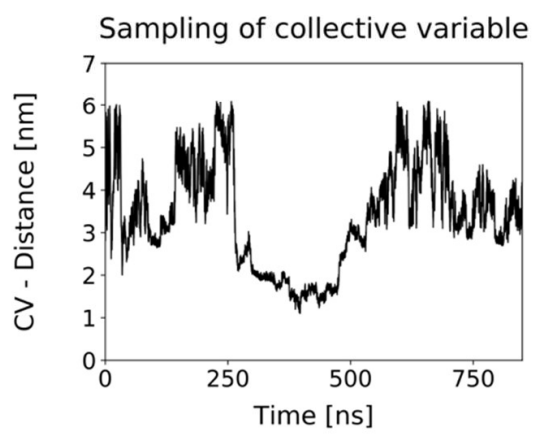

C

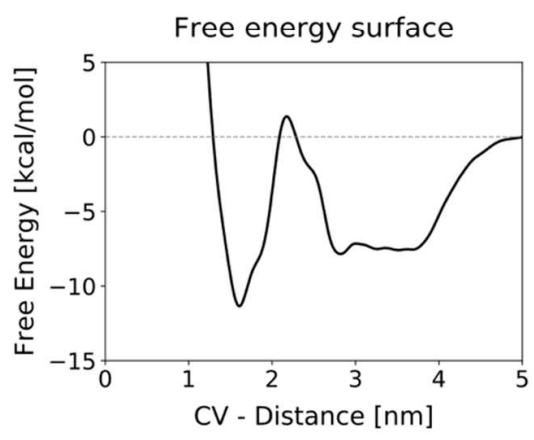

d Stability of SLIGKV binding in MD

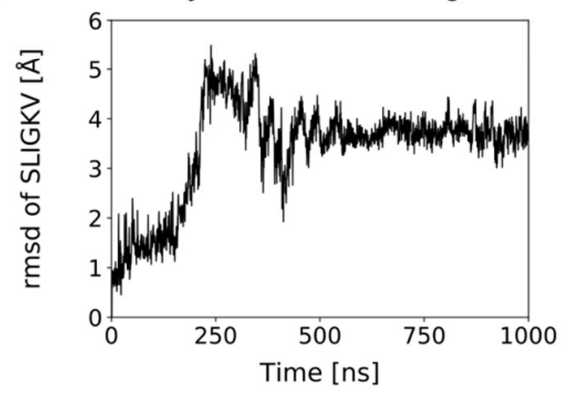

e

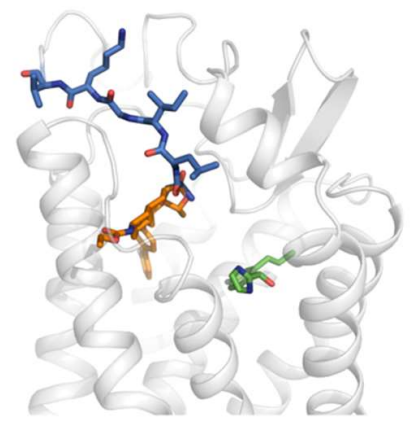

PAR2 SLIGKV Vorapaxar AZ8838

(a) Applied workflow producing the model of trypsin-activated N-terminus bound to the transmembrane segment of PAR2. Starting from the crystal structure of PAR2 in complex with AZ8838, the coordinates of AZ8838 were removed and N-terminal residues added up to Ser37, to simulate activation by trypsin. After equilibration by unbiased $\mathrm{MD}$, metadynamics simulations were used to sample binding of the tethered ligand to the transmembrane helix bundle. The lowest energy conformation shows the N-terminus bound to the extracellular part of the helix bundle. This conformation was further refined by $1 \mu$ s of unbiased MD. (b) The trace plot depicts the sampling of the collective variable during the metadynaimcs docking simulations. Panel (c) shows the free-energy surface reconstructed from the metadynamics simulations. This has to be considered a rough estimate of the enegry profil and needs to be refined to draw further conclusions. (d) The trace plot 
depicts the rmsd of the heavy atoms of the tethered ligand (SLIGKV) to the starting conformation during unbiased MD performed to refine the model of PAR2. After an initial equilibration of about $500 \mathrm{~ns}$, the tethered ligand maintains 1 conformation with constant interactions to the receptor (e) Comparison of ligand binding locations of the tethered ligand in our model, Vorapaxar in the PAR1 crystal structure (PDB-ID 3VW7), ${ }^{1}$ and AZ8838 in the PAR2 crystal structure (PDB-ID 5NDD). ${ }^{2}$ The binding site of the tethered ligand in our model partially overlaps with the pocket occupied by the competitive antagonist Vorapaxar in the PAR1. Although Vorapaxar is selective for the PAR1, the location of the location of the binding pocket can be considered to be comparable over the PAR subtypes, as it is for other families of class A GPCRs. The tethered ligand does not overall with the binding site of AZ8838. This agrees with the fact that AZ8838 is considered an allosteric antagonist, ${ }^{2}$ presumably not addressing the orthosteric pocket. 


\section{Supplementary Figure S2. Docking of 4b and 5a to PAR2.}
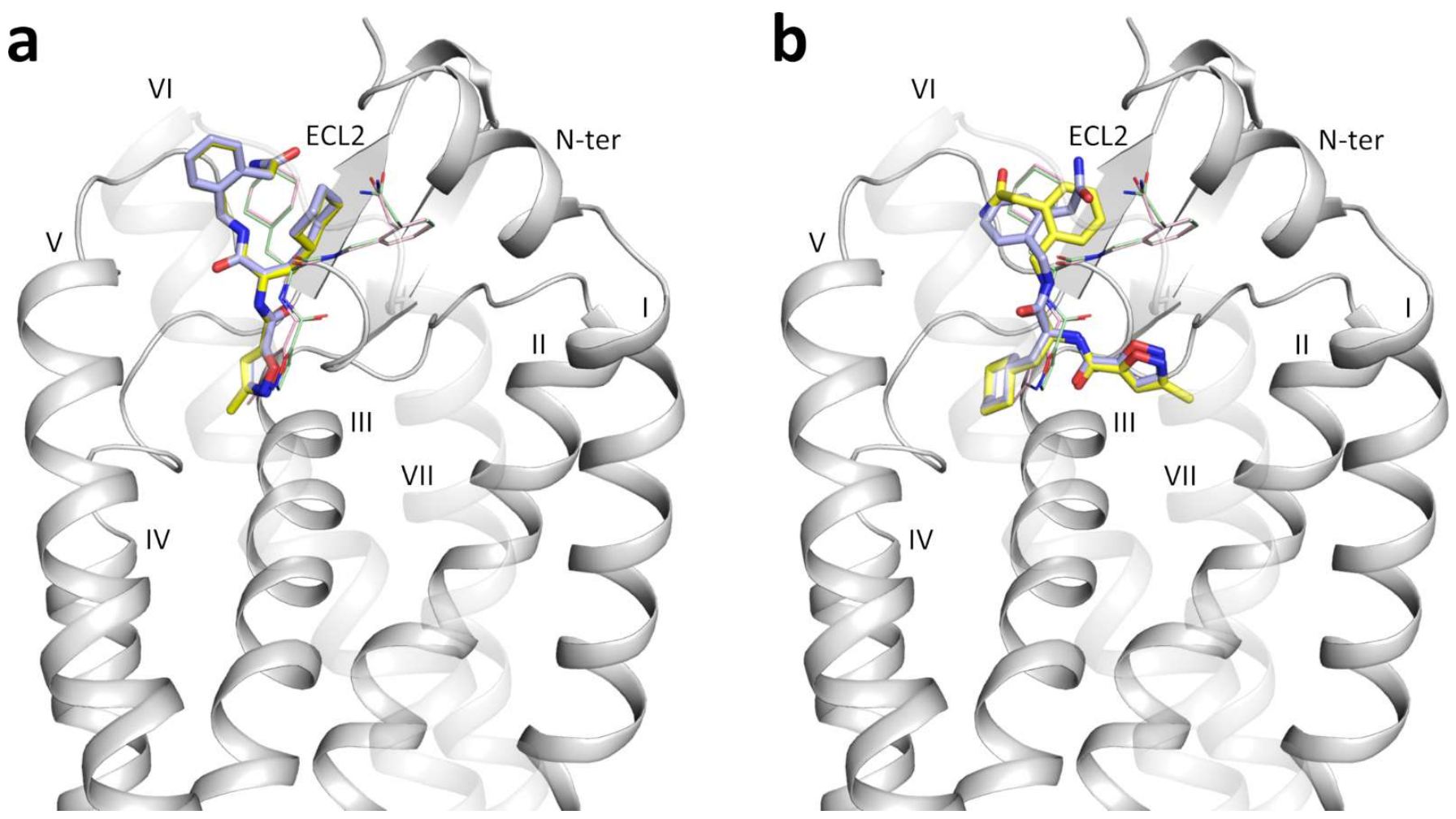

Molecular Docking results for 4b (blue sticks) and 5a (yellow sticks) at the PAR2 model of Kennedy et al. (grey) ${ }^{3}$. Two different clusters (a) and (b) of ligand orientations were observed. For both compounds one representative docking pose is shown. The respective docking poses of $\mathbf{4 b}$ (green lines) and $\mathbf{5 a}$ (pink lines) in the metadynamic model are shown in comparison. 
Supplementary Figure S3. Investigation of potential antagonist properties for ligands 6, 9 and 13.

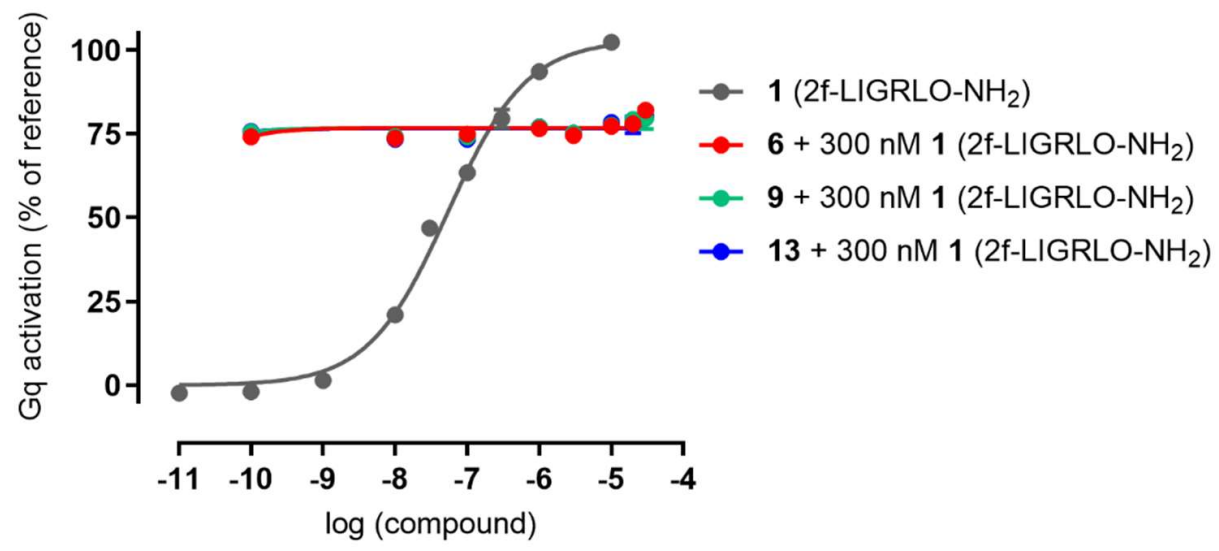

Ligands 6, 9 and 13 were investigated for antagonist properties at PAR2 in the IP ${ }_{1}$ accumulation assays. None of the ligands was able to inhibit the effect of the reference agonist 1 (2f-LIGRLO-NH ${ }_{2}$ ) used at a concentration of $300 \mathrm{nM}$. Data show mean \pm SEM of eight independent experiments, each performed in duplicate. 


\section{Supplementary Table 1. PAINS screening of target and reference compounds. ${ }^{\text {a }}$}

\begin{tabular}{|c|c|c|}
\hline Compound & Structure & PAINS/Aggregation liability detected \\
\hline 1 & & no problems found \\
\hline $4 a$ & & no problems found \\
\hline $4 b$ & & no problems found \\
\hline $4 c$ & & no problems found \\
\hline 4d & & no problems found \\
\hline $4 e$ & & no problems found \\
\hline $4 f$ & & no problems found \\
\hline $4 \mathrm{~g}$ & & no problems found \\
\hline $4 h$ & & no problems found \\
\hline 5a & & no problems found \\
\hline $5 \mathbf{b}$ & & no problems found \\
\hline 6 & & no problems found \\
\hline
\end{tabular}

a PAINS screening was performed using the ZINC15 database as described in the methods section. ${ }^{\mathrm{b}}$ Classification according to ZINC15. 


\begin{tabular}{|c|c|c|}
\hline Compound & Structure & PAINS/Aggregation liability detected \\
\hline 7 & & no problems found \\
\hline $8 a / 8 b$ & & no problems found \\
\hline 9 & & no problems found \\
\hline $10 a / 10 b$ & & no problems found \\
\hline 11 & & no problems found \\
\hline $12 a / 12 b$ & & no problems found \\
\hline 13 & & no problems found \\
\hline
\end{tabular}

${ }^{a}$ PAINS screening was performed using the ZINC15 database as described in the methods section. ${ }^{b}$ Classification according to ZINC15. 


\section{Supplementary Methods.}

General chemistry methods. Reagents and solvents were purchased in their purest grade from abcr, Acros, Alfa Aesar, Sigma Aldrich and TCI and used as without further purification. Compounds were characterized by NMR spectroscopy, IR spectroscopy, high-resolution mass spectra (HRMS) and purity was assessed by rpHPLC. All assayed compounds were $\geq 95 \%$ pure. HPLC-MS was run on a BRUKER amaZon SL mass spectrometer using ESI as ionization source. HRMS-ESI was performed on a Bruker Daltonic microTOF II focus TOF-MS spectrometer using ESI or MALDI as ionization source or on a AB Sciex Triple TOF660 SCiex using ESI as ionization source. NMR spectra were obtained on a Bruker Avance 360, Bruker Avance 400 or a Bruker Avance 600 spectrometer at $300 \mathrm{~K} \cdot{ }^{1} \mathrm{H}$ and ${ }^{13} \mathrm{C}$ chemical shifts are given in ppm $(\delta)$ relative to TMS in the solvents indicated. In case rotamers were observed, integrals are given as sum over both rotamer signals if not indicated otherwise. IR spectra were performed on a Jasco FT/IR 4100 spectrometer using a film of substance on a $\mathrm{NaCl}$ plate. Purification by column chromatography was conducted using silica gel 60 (40-63 $\mu \mathrm{m}$ mesh, Merck) and eluents as binary mixtures with the volume ratios and modifiers indicated. Preparative HPLC was performed on an Agilent 1100 preparative series HPLC system or on an Agilent HPLC 1260 Infinity system combined with a VWD detector. As HPLC column, a ZORBAX-ECLIPSE XDB-C8 PrepHT $(21.2 \times 150 \mathrm{~mm}, 5 \mu \mathrm{m}$, flow rate $10-12 \mathrm{~mL} / \mathrm{min}, \lambda=254 \mathrm{~nm})$ or a ZORBAX-ECLIPSE XDB-C8 PrepHT (30 x $150 \mathrm{~mm}, 5 \mu \mathrm{m}$, usual flow $12 \mathrm{~mL} / \mathrm{min}, \lambda=254 \mathrm{~nm})$ with a BDSpher PUR C8-E (30 x $20 \mathrm{~mm}$, $10 \mu \mathrm{m})$ pre-column was used. TLC analyses were performed using Merck $60 \mathrm{~F}_{254}$ aluminum sheets and analyzed by UV light (254 nm). Analytical HPLC was performed on an AGILENT 1200 series HPLC system employing a DAD detector. As HPLC column, a ZORBAX ECLIPSE XDB-C8 (4.6 x $150 \mathrm{~mm}, 5 \mu \mathrm{m})$ was used. HPLC purity was measured using the following binary solvent systems: 1) $10 \%$ methanol in $0.1 \%$ aq. formic acid for $3 \mathrm{~min}$, from $10 \%$ to $100 \%$ methanol in $15 \mathrm{~min}, 100 \%$ methanol for $6 \mathrm{~min}$, from $100 \%$ to $10 \%$ methanol in $3 \mathrm{~min}$ and $10 \%$ methanol for $3 \mathrm{~min}$. 2) $10-65 \%$ acetonitrile in $0.1 \%$ trifluoroacetic acid for 24 min, $65 \%$ to $95 \%$ acetonitrile in $2 \mathrm{~min}, 95 \%$ acetonitrile for $2 \mathrm{~min}$, from $95 \%$ to $10 \%$ acetonitrile in $2 \mathrm{~min}$, $10 \%$ acetonitrile for $2 \mathrm{~min}$. For all systems, a flow rate of $0.5 \mathrm{~mL} / \mathrm{min}$ and a detection wavelength of $\lambda=220$ $\mathrm{nm}, 254 \mathrm{~nm}$ or $280 \mathrm{~nm}$ was employed. The purity of all test compounds was determined to be $>95 \%$. Chiral 
semi-preparative HPLC was conducted on an AGILENT 1100 series preparative HPLC equipped with a VWD and detection at 220 and $254 \mathrm{~nm}$. As chiral column a DAICEL Chiralpak IC semiprep column (5 $\mu \mathrm{M}, 10 \times 250$ $\mathrm{mm}$ ) was used at flow rates from $3-6 \mathrm{~mL} / \mathrm{min}$ with the solvent system indicated. Chiral analytical HPLC was run on a AGILENT series 1100 system equipped with a VWD or DAD and detection at 220 and $254 \mathrm{~nm}$. As chiral column a DAICEL Chiralpak IC column $(5 \mu \mathrm{M}, 4.6 \times 250 \mathrm{~mm})$ was used at $20{ }^{\circ} \mathrm{C}$ and flow rates from $0.7 \mathrm{~mL} / \mathrm{min}$ with the solvent system as indicated. Optical rotation values were obtained from a Jasco P2000 polarimeter with the solvents indicated. Melting points were determined in open capillaries using a Büchi 510 melting point apparatus or a MEL-TEMP II apparatus (Laboratory Devices, U.S.A.) and are given uncorrected.

Solid Phase Synthesis. Standard Fmoc SPPS procedures were performed on a Rink amide resin (100 - $200 \mathrm{mesh}, 0.66 \mathrm{mmol} / \mathrm{g})$ or on a 2-chlorotrityl chloride resin $(200-400 \mathrm{mesh}, 1.52 \mathrm{mmol} / \mathrm{g})$ in analogy to previously described protocols ${ }^{4}$. In brief, the reactions were carried out in silanized glassware loosely sealed with a silicon septum using a microwave-assisted protocol (Discover microwave oven, CEM Corp.). The corresponding starting material was loaded on the unprotected resin applying a $2-5$-fold excess, PyBOP, HOBt and DIPEA as coupling reagents and 30 cycles of microwave irradiation $(50 \mathrm{~W} ; 10 \mathrm{~s})$. DMF was used as a solvent and the reaction mixture was cooled in an ethanol-ice bath intermittently. If not indicated otherwise, the corresponding amino acids were commercially available and used Fmoc-protected. If present, sidechainamines were Boc- or Pbf-protected, respectively. Fmoc protective groups were cleaved applying a 25\% (v/v) solution of piperidine in DMF and 5 cycles of microwave irradiation $(100 \mathrm{~W} ; 5 \mathrm{~s})$. Coupling reactions were performed using the coupling reagents indicated and 20 to 30 cycles of microwave irradiation $(50 \mathrm{~W} ; 10 \mathrm{~s})$. Amino acids were used in 5-fold excess and routinely activated by (benzotriazol-1-yloxy)tripyrrolidinophosphonium hexafluorophosphate (PyBOP, 5 equivalents) and 1-hydroxybenzotriazole (HOBt, 7.5 equivalents) in presence of DIPEA (5 equivalents). For couplings to primary aromatic amines the corresponding carboxylic acids were activated with HATU (5 equivalents) and DIPEA (10 equivalents) and 30 cycles of microwave irradiation were performed. Cleavage was achieved by treating the resin with a 44:1:3:2 
mixture of TFA/TIS/phenol liquefactum ${ }^{1} /$ water for $2 \mathrm{~h}$ at ambient temperature (Rink amide resin) or with a 1:4 mixture of HFIP and dichloromethane for $16 \mathrm{~h}$ at ambient temperature (Chlorotrityl resin). The crude products were purified by preparative reversed phase HPLC to $>95 \%$ purity, and characterized by high resolution MS and NMR spectroscopy.

2-Furoyl-Leu-Ile-Gly-Arg-Leu-Orn-NH2 $\left(\right.$ TFA salt, 1). ${ }^{5} 1$ was synthesized applying standard SPPS methods on a Rink amide resin in analogy to previously described protocols. ${ }^{5}$ ESI-MS: $m / z 778.53[\mathrm{M}+\mathrm{H}]^{+}$, $m / z 389.8[\mathrm{M}+2 \mathrm{H}]^{2+}$. HRMS-ESI: calcd. for $\mathrm{C}_{36} \mathrm{H}_{65} \mathrm{~N}_{11} \mathrm{O}_{8}, m / z \quad 389.7504[(\mathrm{M}+2 \mathrm{H}) / 2]^{2+}$; found: 389.7503 . HPLC (system 1): $t_{\mathrm{R}}=13.9 \mathrm{~min}$, purity $96 \%$; (system 2$): t_{\mathrm{R}}=15.6 \mathrm{~min}$, purity $95 \%$.

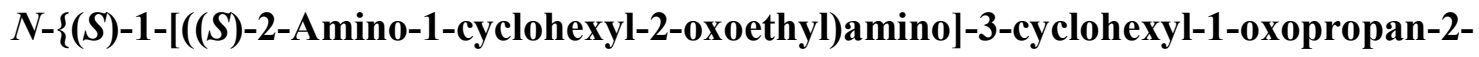

yl isoxazole-5-carboxamide $\left(\mathrm{AY77,2)}{ }^{6} \mathbf{2}\right.$ was synthesized applying standard SPPS methods on a Rink amide resin in analogy to previously described protocols ${ }^{6}$ and purified by preparative HPLC. ESI-MS: $\mathrm{m} / z$ 405.3 $[\mathrm{M}+\mathrm{H}]^{+}$. HRMS-ESI: calcd. for $\mathrm{C}_{21} \mathrm{H}_{32} \mathrm{~N}_{4} \mathrm{O}_{4} \mathrm{Na}, m / z$ 427.2316 [M+Na] $]^{+}$; found: 427.2306. HPLC (system 1): $t_{\mathrm{R}}=19.9 \mathrm{~min}$, purity $95 \% ;($ system 2$): t_{\mathrm{R}}=22.6 \mathrm{~min}$, purity $96 \%$.

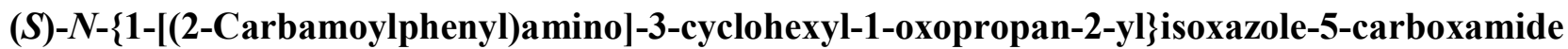

(4a). In analogy to previously described protocols, ${ }^{7}$ to a solution of 2 -amino-benzoic acid (750 $\left.\mathrm{mg}, 5.50 \mathrm{mmol}\right)$ in 1,4-dioxane $(20.0 \mathrm{~mL})$ was added a $10 \mathrm{wt} \%$ solution of sodium carbonate $(15.7 \mathrm{~mL})$. Chloroformic acid $9 \mathrm{H}$ fluoren-9-ylmethyl ester $(1.68 \mathrm{~g}, 6.50 \mathrm{mmol})$ was added and the suspension was stirred at ambient temperature for $2 \mathrm{~h}$. The mixture was acidified with $1 \mathrm{M} \mathrm{HCl}$ and extracted with ethyl acetate. The combined organic layers were washed with $1 \mathrm{M} \mathrm{HCl}$ and brine, dried over $\mathrm{Na}_{2} \mathrm{SO}_{4}$ and evaporated. 2-(\{[(9H-Fluoren-9yl)methoxy]carbonyl \}amino)benzoic acid was obtained as beige solid (1.90 g, 96\%) and used without further purification. 4a was synthesized on a Rink amide resin, loading the resin with 2-(\{[(9H-fluoren-9yl)methoxy]carbonyl \}amino)benzoic acid and applying standard SPPS methods. Purification by preparative RP-HPLC (40 - 95\% $\mathrm{CH}_{3} \mathrm{CN} / 0.1 \%$ aq. trifluoroacetic acid) yielded $4 \mathrm{a}$ as white solid. IR (NaCl): 3280, 2917 , 1671, 1526, 1283, $\mathrm{cm}^{-1} .{ }^{1} \mathrm{H}$ NMR (DMSO-d $\left., 600 \mathrm{MHz}, \delta\right): 12.29(\mathrm{~s}, 1 \mathrm{H}), 9.41(\mathrm{~d}, J=7.6 \mathrm{~Hz}, 1 \mathrm{H}), 8.77$ (d,

\footnotetext{
${ }^{1}$ phenol liquefactum $=$ phenol $/$ water $17: 3$
} 
$J=1.9 \mathrm{~Hz}, 1 \mathrm{H}), 8.53(\mathrm{dd}, J=7.8,1.4 \mathrm{~Hz}, 1 \mathrm{H}), 8.24(\mathrm{~s}, 1 \mathrm{H}), 7.81(\mathrm{dd}, J=8.0,1.4 \mathrm{~Hz}, 1 \mathrm{H}), 7.70(\mathrm{~s}, 1 \mathrm{H}), 7.50$ (ddd, $J=8.0,7.6,1.4 \mathrm{~Hz}, 1 \mathrm{H}), 7.21(\mathrm{~d}, J=1.9 \mathrm{~Hz}, 1 \mathrm{H}), 7.13$ (ddd, $J=7.8,7.6,1.3 \mathrm{~Hz}, 1 \mathrm{H}), 4.51$ (ddd, $J=7.6 \mathrm{~Hz}, 1 \mathrm{H}), 1.83-1.71(\mathrm{~m}, 3 \mathrm{H}), 1.71-1.51(\mathrm{~m}, 4 \mathrm{H}), 1.42-1.28(\mathrm{~m}, 1 \mathrm{H}), 1.25-1.04(\mathrm{~m}, 3 \mathrm{H}), 1.04-0.82$ $(\mathrm{m}, 2 \mathrm{H}) .{ }^{13} \mathrm{C}$ NMR (DMSO-d $\left., 151 \mathrm{MHz}, \delta\right): 170.6,170.4,162.2,156.1,151.6,139.4,132.3,128.6,122.6$, 119.8, 119.3, 106.4, 52.3, 38.0, 33.7, 33.2, 31.4, 26.0, 25.7, 25.5. ESI-MS: $m / z 385.2[\mathrm{M}+\mathrm{H}]^{+}$. HRMS-ESI: calcd. for $\mathrm{C}_{20} \mathrm{H}_{24} \mathrm{~N}_{4} \mathrm{O}_{4} \mathrm{Na}, 407.1690[\mathrm{M}+\mathrm{Na}]^{+}$; found: 407.1693. [ $\left.\alpha\right]^{22}{ }_{\mathrm{D}}-15.5\left(\mathrm{C} 0.43, \mathrm{CH}_{3} \mathrm{OH}\right)$. HPLC (system 1 ): $t_{\mathrm{R}}=18.9 \mathrm{~min}$, purity $97 \%$; (system 2$): t_{\mathrm{R}}=20.2 \mathrm{~min}$, purity $98 \%$.

\section{(S)-N-(1-\{[2-(2-Amino-2-oxoethyl)benzyl]amino\}-3-cyclohexyl-1-oxopropan-2-yl)isoxazole-5-}

carboxamide (4b). 4b was synthesized applying standard SPPS methods on Rink amide resin. Purification by preparative RP-HPLC ( $40-65 \% \mathrm{CH}_{3} \mathrm{CN} / 0.1 \%$ aq. trifluoroacetic acid) yielded $4 \mathbf{b}$ as white solid. IR $(\mathrm{NaCl})$ : 3382, 3280, 3200, 2915, 2849, 1665, 1634, 1530, 1422, 1254, $1219 \mathrm{~cm}^{-1} .{ }^{1} \mathrm{H}$ NMR (DMSO- $d_{6}, 400 \mathrm{MHz}, \delta$ ): $8.97(\mathrm{~d}, J=8.1 \mathrm{~Hz}, 1 \mathrm{H}), 8.73(\mathrm{~d}, J=1.9 \mathrm{~Hz}, 1 \mathrm{H}), 8.56(\mathrm{t}, J=5.7 \mathrm{~Hz}, 1 \mathrm{H}), 7.49(\mathrm{br} \mathrm{s}, 1 \mathrm{H}), 7.25-7.17(\mathrm{~m}, 4 \mathrm{H})$, $7.17(\mathrm{~d}, J=1.9 \mathrm{~Hz}, 1 \mathrm{H}), 6.95(\mathrm{br} \mathrm{s}, 1 \mathrm{H}), 4.52(\mathrm{ddd}, J=10.0,8.1,5.2 \mathrm{~Hz}, 1 \mathrm{H}), 4.33(\mathrm{~d}, J=5.7 \mathrm{~Hz}, 2 \mathrm{H}), 3.47$ $(\mathrm{s}, 2 \mathrm{H}), 1.76-1.50(\mathrm{~m}, 7 \mathrm{H}), 1.37-1.22(\mathrm{~m}, 1 \mathrm{H}), 1.22-1.01(\mathrm{~m}, 3 \mathrm{H}), 1.01-0.78(\mathrm{~m}, 2 \mathrm{H}) .{ }^{13} \mathrm{C}$ NMR (DMSO$\left.d_{6}, 101 \mathrm{MHz}, \delta\right): 172.1,171.2,162.3,155.5,151.5,137.4,134.4,130.0,127.4,126.7,126.4,106.0,50.8,40.1$, 39.0, 38.6, 33.6, 33.0, 31.6, 25.9, 25.6, 25.5. ESI-MS: $m / z$ 413.3 [M+H] $]^{+}$. HRMS-ESI: calcd for $\mathrm{C}_{22} \mathrm{H}_{29} \mathrm{~N}_{4} \mathrm{O}_{4}$, 413.2183 [M+H] $]^{+}$; found: 413.2190. $[\alpha]^{26}{ }_{\mathrm{D}}+1.6(\mathrm{c} 0.43, \mathrm{DMSO})$. HPLC (system 1): $t_{\mathrm{R}}=18.8$ min, purity $99 \%$; (system 2$): t_{\mathrm{R}}=20.3 \mathrm{~min}$, purity $99 \%$.

\section{(S)-N-\{1-[(2-Carbamoylbenzyl)amino]-3-cyclohexyl-1-oxopropan-2-yl\}isoxazole-5-carboxamide}

(4c). 4c was synthesized applying standard SPPS methods on Rink amide resin. Purification by preparative RP-HPLC (40 - 65\% $\mathrm{CH}_{3} \mathrm{CN} / 0.1 \%$ aq. trifluoroacetic acid) yielded $4 \mathbf{c}$ as white solid. IR (NaCl): 3298, 3198, 2920, 2851, 1642, 1628, $1541 \mathrm{~cm}^{-1} .{ }^{1} \mathrm{H}$ NMR (DMSO- $\left.d_{6}, 400 \mathrm{MHz}, \delta\right): 9.03(\mathrm{~d}, J=8.1 \mathrm{~Hz}, 1 \mathrm{H}), 8.74(\mathrm{~d}, J=$ $1.9 \mathrm{~Hz}, 1 \mathrm{H}), 8.52(\mathrm{t}, J=6.1 \mathrm{~Hz}, 1 \mathrm{H}), 7.89(\mathrm{~s}, 1 \mathrm{H}), 7.45(\mathrm{~s}, 1 \mathrm{H}), 7.43(\mathrm{dd}, J=7.8,1.5 \mathrm{~Hz}, 1 \mathrm{H}), 7.39(\mathrm{ddd}, J=$ 7.6, 7.5, $1.5 \mathrm{~Hz}, 1 \mathrm{H}), 7.34-7.25(\mathrm{~m}, 2 \mathrm{H}), 7.17(\mathrm{~d}, J=1.9 \mathrm{~Hz}, 1 \mathrm{H}), 4.53$ (ddd, $J=9.8,8.1,5.3 \mathrm{~Hz}, 1 \mathrm{H}), 4.43$ $(\mathrm{d}, J=6.0 \mathrm{~Hz}, 2 \mathrm{H}), 1.76-1.53(\mathrm{~m}, 7 \mathrm{H}), 1.36-1.24(\mathrm{~m}, 1 \mathrm{H}), 1.22-1.02(\mathrm{~m}, 3 \mathrm{H}), 1.00-0.80(\mathrm{~m}, 2 \mathrm{H}) .{ }^{13} \mathrm{C}$ NMR (DMSO- $\left.d_{6}, 101 \mathrm{MHz}, \delta\right): 171.5,170.5,162.4,155.6,151.6,137.1,135.4,129.6,127.4,127.3,126.5$, 
106.1, 50.9, 40.2, 38.6, 33.7, 33.1, 31.6, 26.0, 25.7, 25.6. ESI-MS: $m / z$ 399.2 [M+H] $]^{+}$. HRMS-ESI: calcd. for $\mathrm{C}_{21} \mathrm{H}_{27} \mathrm{~N}_{4} \mathrm{O}_{4}, 399.2027[\mathrm{M}+\mathrm{H}]^{+}$; found: 399.2014. [ $\left.\alpha\right]^{23} \mathrm{D}-17.0\left(\mathrm{c} 0.28, \mathrm{CH}_{3} \mathrm{OH}\right)$. HPLC (system 1): $t_{\mathrm{R}}=17.9$ min, purity $96 \%$; (system 2$): t_{\mathrm{R}}=19.9 \mathrm{~min}$, purity $96 \%$.

(S)-N-(1-((2-(2-Amino-2-oxoethyl)phenyl)amino)-3-cyclohexyl-1-oxopropan-2-yl)isoxazole-5-

carboxamide (4d). 4d was synthesized applying standard SPPS methods on Rink amide resin. Purification by preparative RP-HPLC (50 - 65\% $\mathrm{CH}_{3} \mathrm{CN} / 0.1 \%$ aq. trifluoroacetic acid) yielded $\mathbf{4 d}$ as white solid. IR $(\mathrm{NaCl})$ : $3302,3198,2924,2852,1659,1531,1448,1288 \mathrm{~cm}^{-1} .{ }^{1} \mathrm{H}$ NMR (DMSO- $d_{6}, 600 \mathrm{MHz}, \delta$ ): 8.86 (d, $J=8.3 \mathrm{~Hz}$, 1H), $8.73(\mathrm{~d}, J=1.9 \mathrm{~Hz}, 1 \mathrm{H}), 7.49($ br s, $1 \mathrm{H}), 7.19-7.12(\mathrm{~m}, 3 \mathrm{H}), 7.16(\mathrm{~d}, J=1.9 \mathrm{~Hz}, 1 \mathrm{H}), 7.05(\mathrm{br}, 1 \mathrm{H})$, $6.78-6.74(\mathrm{~m}, 1 \mathrm{H}), 4.44(\mathrm{ddd}, J=10.5,8.3,4.7 \mathrm{~Hz}, 1 \mathrm{H}), 4.16(\mathrm{br} \mathrm{s}, 2 \mathrm{H}), 1.73(\mathrm{br} \mathrm{d}, J=12.7 \mathrm{~Hz}, 1 \mathrm{H}), 1.70-$ $1.53(\mathrm{~m}, 6 \mathrm{H}), 1.36-1.26(\mathrm{~m}, 1 \mathrm{H}), 1.22-1.05(\mathrm{~m}, 3 \mathrm{H}), 0.97-0.90(\mathrm{~m}, 1 \mathrm{H}), 0.87$ (dddd, $J=12.7,12.0,12.0$, $4.0 \mathrm{~Hz}, 1 \mathrm{H}$ ), CONH-phenyl was not detected. ${ }^{13} \mathrm{C}$ NMR (DMSO- $d_{6}, 101 \mathrm{MHz}, \delta$ ): 173.5, 162.5, 155.5, 151.6, 129.4 (2C), 118.8, 115.2 (2C), 106.1, 50.6, 40.2, 38.8, 33.7, 33.2, 31.6, 26.1, 25.8, 25.6, two quarterny carbons could not be detcted. ESI-MS: m/z $399.2[\mathrm{M}+\mathrm{H}]^{+}$. HRMS-ESI: calcd. for $\mathrm{C}_{21} \mathrm{H}_{27} \mathrm{~N}_{4} \mathrm{O}_{4}, 399.2027[\mathrm{M}+\mathrm{H}]^{+}$; found: 399.2018. $[\alpha]^{23} \mathrm{D}-9.2\left(\mathrm{c} 0.73, \mathrm{CH}_{3} \mathrm{OH}\right)$. HPLC (system 1): $t_{\mathrm{R}}=17.8 \mathrm{~min}$, purity $99 \%$; (system 2): $t_{\mathrm{R}}=$ 17.2 min, purity $97 \%$.

(S)-N-\{1-[(3-Carbamoylphenyl)amino]-3-cyclohexyl-1-oxopropan-2-yl\}isoxazole-5-carboxamide (4e). In analogy to previously described protocols, ${ }^{7}$ to a solution of 3 -amino-benzoic acid (850 mg, $6.20 \mathrm{mmol}$ ) in 1,4-dioxane $(20.0 \mathrm{~mL})$ was added a $10 \mathrm{wt} \%$ solution of sodium carbonate $(17.8 \mathrm{~mL})$. Chloroformic acid $9 H$ fluoren-9-ylmethyl ester $(1.91 \mathrm{~g}, 7.40 \mathrm{mmol})$ was added and the suspension was stirred at ambient temperature for $3 \mathrm{~h}$. The mixture was acidified with $1 \mathrm{M} \mathrm{HCl}$ and extracted with ethyl acetate. The combined organic layers were washed with $1 \mathrm{M} \mathrm{HCl}$ and brine, dried over $\mathrm{Na}_{2} \mathrm{SO}_{4}$ and evaporated. 3-(\{[(9H-Fluoren-9yl)methoxy]carbonyl \}amino)benzoic acid was obtained as beige solid (2.11 g, 95\%) and used without further purification. 4e was synthesized on a Rink amide resin, loading the resin with $3-(\{[(9 H-$ fluoren-9yl)methoxy]carbonyl $\}$ amino)benzoic acid and applying standard SPPS methods. Purification by preparative RP-HPLC (40-95\% $\mathrm{CH}_{3} \mathrm{CN} / 0.1 \%$ aq. trifluoroacetic acid) yielded 4e as white solid. IR (NaCl): 3293, 2924, 1662, 1546, 1205, $\mathrm{cm}^{-1} .{ }^{1} \mathrm{H}$ NMR (DMSO-d $\left.6,600 \mathrm{MHz}, \delta\right): 10.26(\mathrm{~s}, 1 \mathrm{H}), 9.12$ (d, $\left.J=7.9 \mathrm{~Hz}, 1 \mathrm{H}\right), 8.76(\mathrm{~d}, J$ 
$=1.9 \mathrm{~Hz}, 1 \mathrm{H}), 8.05(\mathrm{dd}, J=1.9,1.9 \mathrm{~Hz}, 1 \mathrm{H}), 7.94(\mathrm{~s}, 1 \mathrm{H}), 7.79(\mathrm{ddd}, J=8.1,1.9,1.3 \mathrm{~Hz}, 1 \mathrm{H}), 7.55(\mathrm{ddd}, J=$ 7.8, 1.9, $1.3 \mathrm{~Hz}, 1 \mathrm{H}), 7.38(\mathrm{dd}, J=8.1,7.9 \mathrm{~Hz}, 1 \mathrm{H}), 7.33(\mathrm{~s}, 1 \mathrm{H}), 7.19(\mathrm{~d}, J=1.9 \mathrm{~Hz}, 1 \mathrm{H}), 4.67$ (ddd, $J=10.5$, 7.9, $4.8 \mathrm{~Hz}, 1 \mathrm{H}), 1.84-1.55(\mathrm{~m}, 7 \mathrm{H}), 1.44-1.33(\mathrm{~m}, 1 \mathrm{H}), 1.26-1.05(\mathrm{~m}, 3 \mathrm{H}), 1.02-0.88(\mathrm{~m}, 2 \mathrm{H}) .{ }^{13} \mathrm{C}$ NMR (DMSO-d $\left.d_{6}, 151 \mathrm{MHz}, \delta\right): 170.7,167.8,162.3,155.7,151.7,138.8,135.1,128.5,122.2,122.1,119.1,106.2$, 51.7, 38.5, 33.7, 26.0, 25.8, 33.1, 31.6, 25.5. ESI-MS: $m / z$ 385.2 $[\mathrm{M}+\mathrm{H}]^{+}$. HRMS-ESI: calcd. for $\mathrm{C}_{20} \mathrm{H}_{24} \mathrm{~N}_{4} \mathrm{O}_{4} \mathrm{Na}, 407.1690[\mathrm{M}+\mathrm{Na}]^{+}$; found: 407.1683. HPLC (system 1): $t_{\mathrm{R}}=18.5$ min, purity 98\%; (system 2): $t_{\mathrm{R}}=20.1 \mathrm{~min}$, purity $98 \%$.

(S)-N-\{1-[(3-Carbamoylbenzyl)amino]-3-cyclohexyl-1-oxopropan-2-yl $\}$ isoxazole-5-carboxamide (4f). 4f was synthesized on a Rink amide resin applying standard SPPS methods. Purification by preparative RP-HPLC (40 - 75\% $\mathrm{CH}_{3} \mathrm{CN} / 0.1 \%$ aq. trifluoroacetic acid) yielded $\mathbf{4 f}$ white solid. IR (NaCl): 3408, 2951, 2842, 1656, 1649, 1402, $1020 \mathrm{~cm}^{-1} .{ }^{1} \mathrm{H}$ NMR (DMSO-d $\left.6,400 \mathrm{MHz}, \delta\right): 9.03$ (d, $\left.J=8.0 \mathrm{~Hz}, 1 \mathrm{H}\right), 8.74(\mathrm{~d}, J=$ $1.9 \mathrm{~Hz}, 1 \mathrm{H}), 8.65$ (t, $J=5.9 \mathrm{~Hz}, 1 \mathrm{H}), 7.91($ br s, $1 \mathrm{H}), 7.77(\mathrm{~s}, 1 \mathrm{H}), 7.78-7.69(\mathrm{~m}, 1 \mathrm{H}), 7.41-7.37$ (m, 2H), 7.37 (br s, 1H), $7.17(\mathrm{~d}, J=1.9 \mathrm{~Hz}, 1 \mathrm{H}), 4.52(\mathrm{ddd}, J=10.1,8.0,5.1 \mathrm{~Hz}, 1 \mathrm{H}), 4.32(\mathrm{~d}, J=5.9 \mathrm{~Hz}, 2 \mathrm{H})$, $1.79-1.51(\mathrm{~m}, 7 \mathrm{H}), 1.39-1.25(\mathrm{~m}, 1 \mathrm{H}), 1.22-1.03(\mathrm{~m}, 3 \mathrm{H}), 1.02-0.79(\mathrm{~m}, 2 \mathrm{H}) .{ }^{13} \mathrm{C}$ NMR (DMSO- $d_{6}, 101$ $\mathrm{MHz}, \delta): 171.5,167.8,162.4,155.7,151.6,139.5,134.3,129.9,128.1,126.4,125.8,106.2,51.0,42.0,38.6$, 33.7, 33.1, 31.7, 26.1, 25.7, 25.6. ESI-MS: $m / z 399.3[\mathrm{M}+\mathrm{H}]^{+}$. HRMS-ESI: calcd. for $\mathrm{C}_{21} \mathrm{H}_{27} \mathrm{~N}_{4} \mathrm{O}_{4}, 399.2027$ $[\mathrm{M}+\mathrm{H}]^{+}$; found: 399.2026. $[\alpha]^{23} \mathrm{D}+11.9\left(\mathrm{c} 0.97, \mathrm{CH}_{3} \mathrm{OH}\right) . \mathrm{HPLC}($ system 1$): t_{\mathrm{R}}=18.5$ min, purity $99 \%$; (system 2): $t_{\mathrm{R}}=19.5 \mathrm{~min}$, purity $99 \%$.

(S)-N-(1-\{[3-(2-Amino-2-oxoethyl)phenyl]amino\}-3-cyclohexyl-1-oxopropan-2-yl)isoxazole-5-

carboxamide (4g). To a solution of 2-(3-aminophenyl)acetic acid (600 $\mathrm{mg}, 3.97 \mathrm{mmol})$ in 1,4-dioxane $(20.0 \mathrm{~mL})$ a $10 \mathrm{wt} \%$ solution of sodium carbonate $(11.3 \mathrm{~mL})$ was added. Chloroformic acid $9 H$-fluoren-9ylmethyl ester $(1.23 \mathrm{~g}, 4.75 \mathrm{mmol})$ was added and the suspension was stirred at ambient temperature for $4 \mathrm{~h}$. The mixture was acidified with $1 \mathrm{M} \mathrm{HCl}$ and extracted with ethyl acetate. The combined organic layers were washed with $1 \mathrm{M} \mathrm{HCl}$ and brine, dried over $\mathrm{Na}_{2} \mathrm{SO}_{4}$ and evaporated. Purification by flash chromatography (ethyl acetate/hexane 1:6 $+0.1 \%$ glacial acetic acid to $100 \%$ ethyl acetate $+0.1 \%$ glacial acetic acid) yielded 2-[3-(\{[(9H-fluoren-9-yl)methoxy]carbonyl $\}$ amino $)$ phenyl]acetic acid as greyish solid $(1.03 \mathrm{~g}, 69 \%)$, which 
was loaded in a Rink amide resin. $\mathbf{4 g}$ was synthesized on a Rink amide resin applying standard SPPS methods. Purification by preparative RP-HPLC $\left(40-65 \% \mathrm{CH}_{3} \mathrm{CN} / 0.1 \%\right.$ aq. trifluoroacetic acid) yielded $\mathbf{4 g}$ as white solid. IR (NaCl): 3279, 2924, 2852, 1660, 1614, 1555, 1492, 1447, 1300, $1205 \mathrm{~cm}^{-1} .{ }^{1} \mathrm{H}$ NMR (DMSO-d6, 400 $\mathrm{MHz}, \delta): 10.11(\mathrm{~s}, 1 \mathrm{H}), 9.08(\mathrm{~d}, J=7.9 \mathrm{~Hz}, 1 \mathrm{H}), 8.75(\mathrm{~d}, J=1.9 \mathrm{~Hz}, 1 \mathrm{H}), 7.52(\mathrm{ddd}, J=7.9,2.1,1.8 \mathrm{~Hz}, 1 \mathrm{H})$, 7.49 (dd, $J=1.9,1.9 \mathrm{~Hz}, 1 \mathrm{H}), 7.45$ (br s, 1H), 7.22 (dd, $J=7.9,7.8 \mathrm{~Hz}, 1 \mathrm{H}), 7.19$ (d, $J=1.9 \mathrm{~Hz}, 1 \mathrm{H}), 6.95$ (ddd, $J=7.6,2.1,1.8 \mathrm{~Hz}, 1 \mathrm{H}), 6.87($ br s, $1 \mathrm{H}), 4.66(\mathrm{ddd}, J=10.4,7.9,4.8 \mathrm{~Hz}), 3.34(\mathrm{~s}, 2 \mathrm{H}), 1.80-1.69$ (m, 3H), $1.69-1.57(\mathrm{~m}, 4 \mathrm{H}), 1.43-1.34(\mathrm{~m}, 1 \mathrm{H}), 1.25-1.08(\mathrm{~m}, 3 \mathrm{H}), 1.01-0.88(\mathrm{~m}, 2 \mathrm{H}) .{ }^{13} \mathrm{C}$ NMR (DMSO$\left.d_{6}, 151 \mathrm{MHz}, \delta\right): 171.9,170.4,162.2,155.6,151.5,138.6,136.9,128.3,124.2,120.0,117.4,106.0,51.6,42.1$, 38.5, 33.6, 33.0, 31.6, 25.9, 25.7, 25.5. ESI-MS: $m / z 399.3[\mathrm{M}+\mathrm{H}]^{+}$. HRMS-ESI: calcd. for $\mathrm{C}_{21} \mathrm{H}_{26} \mathrm{~N}_{4} \mathrm{O}_{4} \mathrm{Na}$, 421.1852 $[\mathrm{M}+\mathrm{Na}]^{+}$; found: 421.1842. $[\alpha]^{23} \mathrm{D}+2.2\left(\mathrm{c} 0.95, \mathrm{CH}_{3} \mathrm{OH}\right)$. HPLC (system 1$): t_{\mathrm{R}}=18.2$ min, purity $100 \%$; (system 2$): t_{\mathrm{R}}=20.2 \mathrm{~min}$, purity $100 \%$.

(S)-N-(1-\{[3-(2-Amino-2-oxoethyl)benzyl]amino\}-3-cyclohexyl-1-oxopropan-2-yl)isoxazole-5-

carboxamide (4h). 4h was synthesized on a Rink amide resin applying standard SPPS methods. Purification by preparative RP-HPLC (40 - 65\% $\mathrm{CH}_{3} \mathrm{CN} / 0.1 \%$ aq. trifluoroacetic acid) yielded $\mathbf{4 h}$ as white solid. IR (NaCl): 3312, 3275, 2916, 2850, 1666, 1630, 1543, 1525, $1215 \mathrm{~cm}^{-1} .{ }^{1} \mathrm{H}$ NMR (DMSO- $d_{6}, 400 \mathrm{MHz}, \delta$ ): 8.97 $(\mathrm{d}, J=8.1 \mathrm{~Hz}, 1 \mathrm{H}), 8.74(\mathrm{~d}, J=1.9 \mathrm{~Hz}, 1 \mathrm{H}), 8.59(\mathrm{t}, J=6.0 \mathrm{~Hz}, 1 \mathrm{H}), 7.42($ br s, $1 \mathrm{H}), 7.23(\mathrm{dd}, J=7.8,7.7 \mathrm{~Hz}$, 1H), $7.17(\mathrm{~d}, J=1.9 \mathrm{~Hz}, 1 \mathrm{H}), 7.14-7.11(\mathrm{~m}, 2 \mathrm{H}), 7.09$ (ddd, $J=7.7,1.5,1.5 \mathrm{~Hz}, 1 \mathrm{H}), 6.85$ (br s, 1H), 4.53 (ddd, $J=10.1,8.1,5.1 \mathrm{~Hz}, 1 \mathrm{H}), 4.26(\mathrm{~d}, J=6.0 \mathrm{~Hz}, 2 \mathrm{H}), 3.34(\mathrm{~s}, 2 \mathrm{H}), 1.75-1.55(\mathrm{~m}, 7 \mathrm{H}), 1.37-1.26(\mathrm{~m}$, 1H), $1.24-1.04(\mathrm{~m}, 3 \mathrm{H}), 0.99-0.81(\mathrm{~m}, 2 \mathrm{H}) .{ }^{13} \mathrm{C}$ NMR (DMSO-d $\left., 151 \mathrm{MHz}, \delta\right): 172.0,171.4,162.4,155.6$, $151.6,139.2,136.4,129.3,128.1,127.5,125.0,106.1,50.9,42.2,42.1,38.7,33.7,33.1,31.6,26.0,25.7,25.6$. ESI-MS: $m / z$ 413.3 [M+H] $]^{+}$. HRMS-ESI: calcd. for $\mathrm{C}_{22} \mathrm{H}_{29} \mathrm{~N}_{4} \mathrm{O}_{4}, 413.2183[\mathrm{M}+\mathrm{H}]^{+}$; found: 413.2180. $[\alpha]^{22}{ }_{\mathrm{D}}^{-}$ $1.8\left(\mathrm{c} 0.67, \mathrm{CH}_{3} \mathrm{OH}\right.$ ). HPLC (system 1): $t_{\mathrm{R}}=18.3 \mathrm{~min}$, purity $97 \%$; (system 2 ): $t_{\mathrm{R}}=19.3 \mathrm{~min}$, purity $97 \%$.

(S)-N-(1-\{[2-(2-Amino-2-oxoethyl)benzyl]amino)-3-cyclohexyl-1-oxopropan-2-yl\}-3-

methylisoxazole-5-carboxamide (5a). 5a was synthesized applying standard SPPS methods on a Rink amide resin. Purification by preparative RP-HPLC $\left(40-65 \% \mathrm{CH}_{3} \mathrm{CN} / 0.1 \%\right.$ aq. trifluoroacetic acid) yielded $\mathbf{5 a}$ as white solid. IR (NaCl): 3309, 321 1, 2922, 2850, 1653, 1558, 1541, $1089 \mathrm{~cm}^{-1} .{ }^{1} \mathrm{H}$ NMR (DMSO- $d_{6}, 400 \mathrm{MHz}$, 


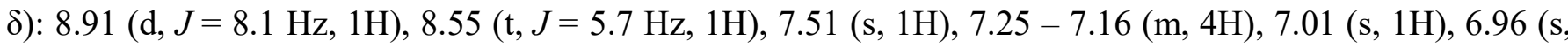
1H), $4.50(\mathrm{ddd}, J=10.1,8.0,4.9 \mathrm{~Hz}, 1 \mathrm{H}), 4.32(\mathrm{~d}, J=5.7 \mathrm{~Hz}, 2 \mathrm{H}), 3.47(\mathrm{~s}, 2 \mathrm{H}), 2.30(\mathrm{~s}, 3 \mathrm{H}), 1.77-1.52(\mathrm{~m}$, 7H), $1.30-1.21(\mathrm{~m}, 1 \mathrm{H}), 1.22-1.02(\mathrm{~m}, 3 \mathrm{H}), 0.99-0.77(\mathrm{~m}, 2 \mathrm{H}) .{ }^{13} \mathrm{C}$ NMR (DMSO-d6, $\left.101 \mathrm{MHz}, \delta\right): 172.09$, $171.21,162.62,160.29,155.67,137.38,134.33,130.02,127.38$ (2C), 126.64, 126.39, 107.13, 50.71, 39.96, 39.03, 38.71, 33.54, 33.01, 31.49, 25.92, 25.64, 25.47, 10.91. ESI-MS: $m / z$ 427.1 [M+H] ${ }^{+}$. HRMS-ESI: calcd. for $\mathrm{C}_{23} \mathrm{H}_{30} \mathrm{NaN}_{4} \mathrm{O}_{4}, 449.2159[\mathrm{M}+\mathrm{Na}]^{+}$; found: 449.2165. [ $\left.\alpha\right]^{23} \mathrm{D}^{-4.323}$ (c 0.54, $\mathrm{CH}_{3} \mathrm{OH}$ ). HPLC (system 1): $t_{\mathrm{R}}=19.4 \mathrm{~min}$, purity $96 \%$; (system 2$): t_{\mathrm{R}}=21.3 \mathrm{~min}$, purity $97 \%$.

(S)-N-(1-\{[2-(2-Amino-2-oxoethyl)benzyl]amino\}-3-cyclohexyl-1-oxopropan-2-yl)-3ethylisoxazole-5-carboxamide (5b). 5b was synthesized applying standard SPPS methods on Rink amide resin. Purification by preparative RP-HPLC $\left(40-65 \% \mathrm{CH}_{3} \mathrm{CN} / 0.1 \%\right.$ aq. trifluoroacetic acid) yielded $\mathbf{5 b}$ as white solid. IR (NaCl): 3308, 2920, 2850, 1654, 1558, 1541, $1088 \mathrm{~cm}^{-1} .{ }^{1} \mathrm{H}$ NMR (DMSO- $d_{6}, 400 \mathrm{MHz}, \delta$ ): $8.91(\mathrm{~d}, J=8.1 \mathrm{~Hz}, 1 \mathrm{H}), 8.56(\mathrm{t}, J=5.7 \mathrm{~Hz}, 1 \mathrm{H}), 7.51(\mathrm{~s}, 1 \mathrm{H}), 7.29-7.15(\mathrm{~m}, 4 \mathrm{H}), 7.09(\mathrm{~s}, 1 \mathrm{H}), 6.97(\mathrm{~s}, 1 \mathrm{H})$, $4.51(\mathrm{ddd}, J=10.2,8.1,4.9 \mathrm{~Hz}, 1 \mathrm{H}), 4.33(\mathrm{~d}, J=5.7 \mathrm{~Hz}, 2 \mathrm{H}), 3.47(\mathrm{~s}, 2 \mathrm{H}), 2.70(\mathrm{q}, J=7.6 \mathrm{~Hz}, 2 \mathrm{H}), 1.76-$ $1.54(\mathrm{~m}, 7 \mathrm{H}), 1.36-1.26(\mathrm{~m}, 1 \mathrm{H}), 1.22(\mathrm{t}, J=7.6 \mathrm{~Hz}, 3 \mathrm{H}), 1.17-1.03(\mathrm{~m}, 3 \mathrm{H}), 1.03-0.81(\mathrm{~m}, 2 \mathrm{H}) .{ }^{13} \mathrm{C}$ NMR (DMSO-d $\left.d_{6}, 101 \mathrm{MHz}, \delta\right): 172.09,171.22,165.47,162.65,155.71,137.39,134.32,130.02,127.36$ (2C), $126.64,126.39,105.96,50.72,39.96,39.03,33.52,33.02,31.49,25.93,25.63,25.46,18.80,12.34$. ESI-MS: $m / z$ 441.2 [M+H] $]^{+}$. HRMS-ESI: calcd. for $\mathrm{C}_{24} \mathrm{H}_{32} \mathrm{NaN}_{4} \mathrm{O}_{4}, 463.2316[\mathrm{M}+\mathrm{Na}]^{+}$; found: 463.2318. [ $\left.\alpha\right]^{23} \mathrm{D}-9.2(\mathrm{c}$ $\left.0.25, \mathrm{CH}_{3} \mathrm{OH}\right)$. HPLC (system 1): $t_{\mathrm{R}}=20.0 \mathrm{~min}$, purity $97 \%$; (system 2$): t_{\mathrm{R}}=22.6 \mathrm{~min}$, purity $98 \%$.

$N$-[2-(2-\{[2-(2-Amino-2-oxoethyl)benzyl]amino\}-2-oxoethyl)benzyl]isoxazole-5-carboxamide (6). 6 was synthesized applying standard SPPS methods on Rink amide resin. Purification by preparative RP-HPLC (40-75\% $\mathrm{CH}_{3} \mathrm{CN} / 0.1 \%$ aq. trifluoroacetic acid) yielded 6 as white solid. IR (NaCl): 3302, 2921, 2851, 1658, 1538, $1422 \mathrm{~cm}^{-1} .{ }^{1} \mathrm{H}$ NMR (DMSO- $\left.d_{6}, 600 \mathrm{MHz}, \delta\right): 9.45(\mathrm{t}, J=5.8 \mathrm{~Hz}, 1 \mathrm{H}), 8.73(\mathrm{~d}, J=1.9 \mathrm{~Hz}, 1 \mathrm{H}), 8.63(\mathrm{t}$, $J=5.7 \mathrm{~Hz}, 1 \mathrm{H}), 7.49$ (br s, 1H), $7.31-7.17(\mathrm{~m}, 8 \mathrm{H}), 7.08$ (d, $J=1.9 \mathrm{~Hz}, 1 \mathrm{H}), 6.97$ (br s, 1H), 4.55 (d, $J=5.8 \mathrm{~Hz}, 2 \mathrm{H}), 4.33(\mathrm{~d}, J=5.6 \mathrm{~Hz}, 2 \mathrm{H}), 3.66(\mathrm{~s}, 2 \mathrm{H}), 3.49(\mathrm{~s}, 2 \mathrm{H}) .{ }^{13} \mathrm{C}$ NMR (DMSO-d $\left., 101 \mathrm{MHz}, \delta\right): 172.2$, $170.1,162.5,155.3,151.6,137.3,136.7,134.5,134.5,130.1,130.1,128.2,127.8,127.1,126.8,126.7,126.5$, 105.7, 40.3, 40.2, 39.8, 39.0. ESI-MS: $m / z$ 407.2 [M+H] $]^{+}$. HRMS-ESI: calcd. for $\mathrm{C}_{22} \mathrm{H}_{23} \mathrm{~N}_{4} \mathrm{O}_{4}, 407.1714$ 
$[\mathrm{M}+\mathrm{H}]^{+}$; found: 407.1709 . HPLC (system 1$): t_{\mathrm{R}}=16.1 \mathrm{~min}$, purity $100 \%$; (system 2$): t_{\mathrm{R}}=15.7$ min, purity $99 \%$.

(S)-N-(1-\{[2-(2-Amino-2-oxoethyl)benzyl]amino\}-1-oxo-3-phenylpropan-2-yl)isoxazole-5-

carboxamide (7). 7 was synthesized applying standard SPPS methods on Rink amide resin. Purification by preparative RP-HPLC ( $40-65 \% \mathrm{CH}_{3} \mathrm{CN} / 0.1 \%$ aq. trifluoroacetic acid) yielded 7 as white solid. IR ( $\mathrm{NaCl}$ ): 3314, 3182, 2927, 1646, 1528, $1214 \mathrm{~cm}^{-1} .{ }^{1} \mathrm{H}$ NMR (DMSO- $d_{6}, 400 \mathrm{MHz}, \delta$ ): 9.11 (d, $\left.J=8.4 \mathrm{~Hz}, 1 \mathrm{H}\right), 8.70$ $(\mathrm{d}, J=1.9 \mathrm{~Hz}, 1 \mathrm{H}), 8.66(\mathrm{t}, J=5.7 \mathrm{~Hz}, 1 \mathrm{H}), 7.50(\mathrm{br} \mathrm{s}, 1 \mathrm{H}), 7.35-7.13(\mathrm{~m}, 9 \mathrm{H}), 7.09(\mathrm{~d}, J=1.9 \mathrm{~Hz}, 1 \mathrm{H}), 6.95$ (br s, 1H), $4.72(\mathrm{ddd}, J=10.3,8.4,4.5 \mathrm{~Hz}, 1 \mathrm{H}), 4.36(\mathrm{~d}, J=5.7 \mathrm{~Hz}, 2 \mathrm{H}), 3.47$ (s, 2H), 3.16 (dd, $J=13.7,4.6$ $\mathrm{Hz}, 1 \mathrm{H}), 3.01(\mathrm{dd}, J=13.7,10.4 \mathrm{~Hz}, 1 \mathrm{H}) .{ }^{13} \mathrm{C} \mathrm{NMR}\left(\mathrm{DMSO}-d_{6}, 101 \mathrm{MHz}, \delta\right): 172.2,170.3,162.3,155.5$, $151.6,137.9,137.3,134.5,130.1,129.1(2 \mathrm{C}), 128.1(2 \mathrm{C}), 127.6,126.8,126.6,126.4,106.0,54.7,40.2,40.2$, 37.0. ESI-MS: $m / z$ 407.1 [M+H] $]^{+}$. HRMS-ESI: calcd. for $\mathrm{C}_{22} \mathrm{H}_{23} \mathrm{~N}_{4} \mathrm{O}_{4}, 407.1714[\mathrm{M}+\mathrm{H}]^{+}$; found: 407.1710 . $[\alpha]^{22} \mathrm{D}-115.6\left(\mathrm{c} 0.14, \mathrm{CH}_{3} \mathrm{OH}\right)$. HPLC (system 1$): t_{\mathrm{R}}=17.3 \mathrm{~min}$, purity $95 \%$; (system 2$): t_{\mathrm{R}}=17.7$ min, purity $96 \%$.

\section{$N$-(3-Cyclohexyl-1-((2-methylbenzyl)amino)-1-oxopropan-2-yl)isoxazole-5-carboxamide (8a and} 8b). (S)-3-Cyclohexyl-2-(isoxazole-5-carboxamido)propanoic acid was prepared on a 2-chlorotrityl chloride resin applying standard Fmoc SPPS methods and used without further purification. To a solution of $(S)$-3cyclohexyl-2-(isoxazole-5-carboxamido)propanoic acid $(88.0 \mathrm{mg}, 33.0 \mu \mathrm{mol})$, PyBOP (172 mg, $33.0 \mu \mathrm{mol})$ and HOBT $(66.9 \mathrm{mg}, 50.0 \mu \mathrm{mol})$ in dichloromethane $(4.00 \mathrm{~mL})$ and DMF $(0.5 \mathrm{~mL})$ was added DIPEA $(60.0 \mu \mathrm{L}, 33.0 \mu \mathrm{mol})$ and 2-methylbenzylamine $(200 \mu \mathrm{L}, 1.65 \mathrm{mmol})$. The mixture was irradiated in the microwave reactor $(50 \mathrm{~W}, 10 \mathrm{~s})$ for 30 times, cooling the reaction tube in an ethanol/ice bath between each irradiation step. The solvent was evaporated, and the racemic mixture was purified by preparative HPLC (40 $-65 \% \mathrm{CH}_{3} \mathrm{CN} / 0.1 \%$ aq. trifluoroacetic acid). The enantiomers were separated by chiral, semipreparative HPLC (DAICEL Chiralpak IC column, hexane/isopropanol + 0.1\% EDA 9:1), referring to the first eluent as a and to the second eluent as $\mathbf{b}$, to yield $\mathbf{8 a}(12.1 \mathrm{mg}, 10 \%)$ and $\mathbf{8 b}(17.0 \mathrm{mg}, 14 \%)$ as white powder. IR $(\mathrm{NaCl})$ : $3285,3065,2924,2852,1648,1543,1449,1253,1211,824,742 \mathrm{~cm}^{-1} .{ }^{1} \mathrm{H}$ NMR (DMSO- $d_{6}, 400 \mathrm{MHz}, \delta$ ): $8.97(\mathrm{~d}, J=8.2 \mathrm{~Hz}, 1 \mathrm{H}), 8.74(\mathrm{~d}, J=1.9 \mathrm{~Hz}, 1 \mathrm{H}), 8.46(\mathrm{t}, J=5.7 \mathrm{~Hz}, 1 \mathrm{H}), 7.17(\mathrm{~d}, J=1.9 \mathrm{~Hz}, 1 \mathrm{H}), 7.24-7.10$ 
(m, 4H), $4.55(\mathrm{ddd}, J=10.1,8.1,5.0 \mathrm{~Hz}, 1 \mathrm{H}), 4.26(\mathrm{dd}, J=15.4,5.7 \mathrm{~Hz}, 1 \mathrm{H}), 4.24(\mathrm{dd}, J=15.6,5.7 \mathrm{~Hz}, 1 \mathrm{H})$, $2.25(\mathrm{~s}, 3 \mathrm{H}), 1.76-1.54(\mathrm{~m}, 7 \mathrm{H}), 1.38-1.24(\mathrm{~m}, 1 \mathrm{H}), 1.23-1.04(\mathrm{~m}, 3 \mathrm{H}), 0.99-0.80(\mathrm{~m}, 2 \mathrm{H}) .{ }^{13} \mathrm{C}$ NMR (DMSO- $\left.d_{6}, 151 \mathrm{MHz}, \delta\right): 171.3,162.4,155.5,151.6,136.8,135.6,129.8,127.5,126.8,125.6,106.0,50.9$, 40.4, 38.8, 33.7, 33.1, 31.7, 26.0, 25.7, 25.6, 18.6. ESI-MS: $m / z$ 370.2 [M+H] $]^{+}$HRMS-ESI: calcd. for $\mathrm{C}_{21} \mathrm{H}_{28} \mathrm{~N}_{3} \mathrm{O}_{3}, 370.2125[\mathrm{M}+\mathrm{H}]^{+}$; found: 370.2123. $[\alpha]^{27}$ D $\left(8 \mathrm{a}, \mathrm{c} 0.076, \mathrm{CH}_{3} \mathrm{OH}\right)-6.5 ;[\alpha]^{27}$ ( $\left(8 \mathrm{~b}, \mathrm{c} 0.13, \mathrm{CH}_{3} \mathrm{OH}\right)$ +5.5. HPLC (system 1): $t_{\mathrm{R}}=20.6 \mathrm{~min}$, purity $100 \%$; (system 2$): t_{\mathrm{R}}=27.2 \mathrm{~min}$, purity $100 \%$. Chiral HPLC (hexane/isopropanol $+0.1 \%$ EDA 9:1) $(8 \mathrm{a}), t_{\mathrm{R}}=17.5 \mathrm{~min}$, ee $98 \% ;(8 \mathrm{~b}) t_{\mathrm{R}}=20.4$, ee $94 \%$.

(S)-N-(1-\{[2-(2-Amino-2-oxoethyl)benzyl]amino\}-3-cyclohexyl-1-oxopropan-2-yl)benzamide (9). 9 was synthesized applying standard SPPS methods on Rink amide resin. Purification by preparative RP-HPLC (40-65\% $\mathrm{CH}_{3} \mathrm{CN} / 0.1 \%$ aq. trifluoroacetic acid) yielded 9 as white solid. IR (NaCl): 3389, 3280, 2913, 2850, 1664, 1624, 1392, $1254 \mathrm{~cm}^{-1} .{ }^{1} \mathrm{H}$ NMR (DMSO- $\left.d_{6}, 400 \mathrm{MHz}, \delta\right): 8.45(\mathrm{~d}, J=8.0 \mathrm{~Hz}, 1 \mathrm{H}), 8.43(\mathrm{t}, J=5.7 \mathrm{~Hz}$, 1H), $7.94-7.88(\mathrm{~m}, 2 \mathrm{H}), 7.58-7.41(\mathrm{~m}, 4 \mathrm{H}), 7.27-7.14(\mathrm{~m}, 4 \mathrm{H}), 6.95$ (br s, 1H), 4.55 (ddd, $J=10.1,8.0$, $5.1 \mathrm{~Hz}, 1 \mathrm{H}), 4.33(\mathrm{~d}, J=5.7 \mathrm{~Hz}, 2 \mathrm{H}), 3.48(\mathrm{~s}, 2 \mathrm{H}), 1.78-1.53(\mathrm{~m}, 7 \mathrm{H}), 1.40-1.29(\mathrm{~m}, 1 \mathrm{H}), 1.26-1.02(\mathrm{~m}$, 3H), $1.00-0.81(\mathrm{~m}, 2 \mathrm{H}) .{ }^{13} \mathrm{C}$ NMR (DMSO-d6, $\left.101 \mathrm{MHz}, \delta\right): 172.2(2 \mathrm{C}), 166.4,137.7,134.4,134.2,131.2$, $130.1,128.2$ (2C), $127.6(2 \mathrm{C}), 127.5,126.7,126.5,51.3,40.0,39.2,39.0,33.8,33.2,31.8,26.1,25.8,25.7$. ESI-MS: $m / z$ 422.2 [M+H] $]^{+}$. HRMS-ESI: calcd. for $\mathrm{C}_{25} \mathrm{H}_{32} \mathrm{~N}_{3} \mathrm{O}_{3}, 422.2438[\mathrm{M}+\mathrm{H}]^{+}$; found: 422.2436. $[\alpha]^{22}{ }_{\mathrm{D}}$ $29.6\left(\mathrm{c} 0.44, \mathrm{CH}_{3} \mathrm{OH}\right)$. HPLC (system 1): $t_{\mathrm{R}}=20.0 \mathrm{~min}$, purity $95 \%$; (system 2$): t_{\mathrm{R}}=23.2 \mathrm{~min}$, purity $97 \%$.

\section{$N-[(2 S)-1-(\{[2-(2-A m i n o-2-o x o e t h y l) c y c l o h e x y l]$ methyl\}amino)-3-cyclohexyl-1-oxopropan-2-}

yl]isoxazole-5-carboxamide (10a and 10b). In analogy to previously described protocols, ${ }^{8}$ 2-(2(aminomethyl)phenyl)acetic acid (1.0 g, $6.1 \mathrm{mmol})$ and rhodium on alumina (5 wt. \%, $30 \mathrm{mg}, 0.05$ equivalents $\mathrm{Rh})$ were suspended in distilled water $(15 \mathrm{ml})$. The mixture was transferred into a laboratory autoclave and stirred at $100{ }^{\circ} \mathrm{C}$ and 18 bar $\mathrm{H}_{2}$ for $24 \mathrm{~h}$. The crude mixture was filtered through a syringe filter which was washed with distilled water two times. Lyophilization yielded 2-[2-(aminomethyl)cyclohexyl]acetic acid as white solid $(0.96 \mathrm{~g}, 92 \%)$, which was used without further purification. To a solution of 2-[2(aminomethyl)cyclohexyl]acetic acid $(250 \mathrm{mg}, 1.46 \mathrm{mmol})$ in 1,4-dioxane $(10.0 \mathrm{~mL})$ was added a $10 \mathrm{wt} \%$ solution of sodium carbonate $(4.00 \mathrm{~mL})$. Chloroformic acid $9 H$-fluoren-9-ylmethyl ester $(453 \mathrm{mg}$, 
$1.75 \mathrm{mmol}$ ) was added and the suspension was stirred at ambient temperature for $3 \mathrm{~h}$. The solvent was removed in vacuo and the residue taken up in ethyl acetate $(30.0 \mathrm{~mL})$, which was washed with $1 \mathrm{M} \mathrm{HCl}$ and brine. The organic layer was dried over $\mathrm{Na}_{2} \mathrm{SO}_{4}$ and evaporated. Purification by preparative RP-HPLC $\left(40-65 \% \mathrm{CH}_{3} \mathrm{CN} /\right.$ $0.1 \%$ aq. trifluoroacetic acid $) \quad$ yielded $2-\{2-[(\{[(9 H$-fluoren-9-yl $)$ methoxy $]$ carbonyl $\}$ amino $)$ methyl $]$ cyclohexyl acetic acid as white solid (148 mg, 26\%), which was loaded on a Rink amide resin to synthesize compounds 10a and 10b applying standard SPPS methods. The corresponding ( $Z$ )-diastereomers were separated and purified by preparative RP-HPLC $\left(40-65 \% \mathrm{CH}_{3} \mathrm{CN} / 0.1 \%\right.$ aq. trifluoroacetic acid), referring to the first eluent as $\mathbf{a}$ and to the second one as $\mathbf{b}$, to yield $\mathbf{1 0 a}$ and $\mathbf{1 0 b}$ as white solids. IR (10a, $\mathrm{NaCl}): 3208$, 3057, 2923, 2849, 1646, 1557, 1442, 1254, $1176 \mathrm{~cm}^{-1} .{ }^{1} \mathrm{H}$ NMR (10a, DMSO- $\left.d_{6}, 400 \mathrm{MHz}, \delta\right): 8.89$ (d, $J=8.2$ $\mathrm{Hz}, 1 \mathrm{H}), 8.73(\mathrm{~d}, J=1.9 \mathrm{~Hz}, 1 \mathrm{H}), 8.01(\mathrm{t}, J=5.7 \mathrm{~Hz}, 1 \mathrm{H}), 7.24(\mathrm{br} \mathrm{s}, 1 \mathrm{H}), 7.16(\mathrm{~d}, J=1.9 \mathrm{~Hz}, 1 \mathrm{H}), 6.72(\mathrm{br} \mathrm{s}$, 1H), $4.45(\mathrm{ddd}, J=9.7,8.1,5.5 \mathrm{~Hz}, 1 \mathrm{H}), 3.06-2.89(\mathrm{~m}, 2 \mathrm{H}), 2.13-1.96(\mathrm{~m}, 3 \mathrm{H}), 1.79-1.03(\mathrm{~m}, 19 \mathrm{H}), 1.01$ $-0.78(\mathrm{~m}, 3 \mathrm{H}) .{ }^{13} \mathrm{C}$ NMR (10a, DMSO- $\left.d_{6}, 151 \mathrm{MHz}, \delta\right): 174.0,171.2,162.4,155.4,151.6,106.0,50.9,40.1$, 39.9, 38.9, 33.7, 33.0 (2C), 31.8, 28.7, 26.0 (2C), 25.9, 25.7 (2C), 25.6 (2C). ESI-MS (10a): m/z 419.2 [M+H]. HRMS-ESI (10a): calcd. for $\mathrm{C}_{22} \mathrm{H}_{35} \mathrm{~N}_{4} \mathrm{O}_{4}, 419.2653[\mathrm{M}+\mathrm{H}]^{+}$; found: 419.2635 . $[\alpha]^{24}{ }_{\mathrm{D}}+1.5(10 \mathrm{a}$, c 0.068 , $\left.\mathrm{CH}_{3} \mathrm{OH}\right)$. HPLC (10a) (system 1): $t_{\mathrm{R}}=19.7 \mathrm{~min}$, purity 96\%; (system 2): $t_{\mathrm{R}}=21.0 \mathrm{~min}$, purity $97 \%$.

IR (10b, NaCl): 3234, 3067, 2922, 2849, 1646, 1572, 1536, 1453, $1260 \mathrm{~cm}^{-1} .{ }^{1} \mathrm{H}$ NMR (10b, DMSO- $d_{6}, 400$ MHz, $\delta): 8.90(\mathrm{~d}, J=8.1 \mathrm{~Hz}, 1 \mathrm{H}), 8.73(\mathrm{~d}, J=1.9 \mathrm{~Hz}, 1 \mathrm{H}), 8.01(\mathrm{t}, J=5.8 \mathrm{~Hz}, 1 \mathrm{H}), 7.23(\mathrm{br} \mathrm{s}, 1 \mathrm{H}), 7.16(\mathrm{~d}, J$ $=1.9 \mathrm{~Hz}, 1 \mathrm{H}), 6.73(\mathrm{br} \mathrm{s}, 1 \mathrm{H}), 4.45(\mathrm{ddd}, J=9.0,8.1,6.1 \mathrm{~Hz}, 1 \mathrm{H}), 3.10(\mathrm{ddd}, J=13.3,8.8,5.7 \mathrm{~Hz}, 1 \mathrm{H}), 2.88$ $(\mathrm{ddd}, J=13.3,5.7,5.6 \mathrm{~Hz}, 1 \mathrm{H}), 2.09-1.96(\mathrm{~m}, 3 \mathrm{H}), 1.77-1.04(\mathrm{~m}, 20 \mathrm{H}), 0.99-0.80(\mathrm{~m}, 2 \mathrm{H}) .{ }^{13} \mathrm{C}$ NMR (10b, DMSO-d6, $151 \mathrm{MHz}, \delta): 173.9,171.0,162.3,155.4,151.5,105.9,50.9,40.0,39.8,38.8,33.6,32.9$ (2C), 31.8, 28.5, 25.9 (2C), 25.8, 25.6 (2C), 25.5 (2C). ESI-MS (10b): $m / z$ 419.2 [M+H] $]^{+}$. HRMS-ESI (10b): calcd. for $\mathrm{C}_{22} \mathrm{H}_{35} \mathrm{~N}_{4} \mathrm{O}_{4}, 419.2653[\mathrm{M}+\mathrm{H}]^{+}$; found: 419.2640. $[\alpha]^{24}{ }_{\mathrm{D}}-2.9$ (10b, c 0.086, $\mathrm{CH}_{3} \mathrm{OH}$ ). HPLC (10b) (system 1): $t_{\mathrm{R}}=20.0 \mathrm{~min}$, purity $98 \%$; (system 2$): t_{\mathrm{R}}=21.3 \mathrm{~min}$, purity $98 \%$.

\section{$N$-[(S)-1-((S)-3-Carbamoyl-3,4-dihydroisoquinolin-2(1H)-yl)-3-cyclohexyl-1-oxopropan-2-}

yl]isoxazole-5-carboxamide (11). 11 was synthesized applying standard SPPS methods on Rink amide resin. Purification by preparative RP-HPLC (40-75\% $\mathrm{CH}_{3} \mathrm{CN} / 0.1 \%$ aq. trifluoroacetic acid) yielded 11 as white 
solid. IR (NaCl): 3282, 2923, 2852, 1674, 1645, 1538, 1447, 1436, $1209 \mathrm{~cm}^{-1} .{ }^{1} \mathrm{H}$ NMR (DMSO-d, $600 \mathrm{MHz}$, two rotamers were observed, $\delta): 9.13$ and $9.11(\mathrm{~d}, J=8.2 \mathrm{~Hz}, 1 \mathrm{H}), 8.75$ and $8.71(\mathrm{~d}, J=1.9 \mathrm{~Hz}, 1 \mathrm{H}), 7.36$ and $7.31(\mathrm{br} \mathrm{s}, 1 \mathrm{H}), 7.20-7.16(\mathrm{~m}, 4 \mathrm{H}), 7.16$ and $7.14(\mathrm{~d}, J=1.9 \mathrm{~Hz}, 1 \mathrm{H}), 6.92(\mathrm{br} \mathrm{s}, 1 \mathrm{H}), 5.11$ and 4.94 (ddd, $J=$ 9.8, 8.1, $4.5 \mathrm{~Hz}, 1 \mathrm{H}), 4.88$ and $4.85(\mathrm{~d}, J=15.0 \mathrm{~Hz}, 1 \mathrm{H}), 4.85$ and $4.80(\mathrm{dd}, J=5.9,2.5 \mathrm{~Hz}, 1 \mathrm{H}), 4.64$ and 4.36 $(\mathrm{d}, J=15.2 \mathrm{~Hz}, 1 \mathrm{H}), 3.33$ and $3.10(\mathrm{dd}, J=13.8,2.4 \mathrm{~Hz}, 1 \mathrm{H}), 3.11$ and $3.06(\mathrm{dd}, J=13.9,5.8 \mathrm{~Hz}, 1 \mathrm{H}), 1.91$ and $1.84(\mathrm{br} \mathrm{d}, J=12.7 \mathrm{~Hz}, 1 \mathrm{H}), 1.76-1.48(\mathrm{~m}, 6 \mathrm{H}), 1.44-1.35$ and $1.35-1.28(\mathrm{~m}, 1 \mathrm{H}), 1.27-1.08(\mathrm{~m}$, 3H), $1.04-0.86(\mathrm{~m}, 2 \mathrm{H}) .{ }^{13} \mathrm{C}$ NMR (DMSO- $d_{6}, 101 \mathrm{MHz}$, two rotamers were observed, $\delta$ ): $172.2,170.8$ and 170.7, 162.0 and 161.9, 155.4 and 155.3, 151.6 and 151.5, 133.4 and 132.3, 133.2 and 132.1, 128.1 and 127.7, 126.8, 126.3 and 126.2, 125.7, 106.2 and 106.0, 54.3 and 52.7, 47.4 and 47.3, 45.0 and 43.1, 38.7 and 37.8, 33.5, 33.3 and 33.2, 31.7 and 31.6, 31.0, 26.0 and 25.9, 25.7 and 25.7, 25.6 and 25.5. ESI-MS: $m / z$ 425.2 $[\mathrm{M}+\mathrm{H}]^{+}$. HRMS-ESI: calcd. for $\mathrm{C}_{23} \mathrm{H}_{28} \mathrm{~N}_{4} \mathrm{O}_{4} \mathrm{Na}, 447.1997[\mathrm{M}+\mathrm{Na}]^{+}$; found: 447.1991. [ $\left.\alpha\right]^{23} \mathrm{D}-27.5$ (c 0.69, $\left.\mathrm{CH}_{3} \mathrm{OH}\right)$. HPLC (system 1): $t_{\mathrm{R}}=19.5 \mathrm{~min}$, purity $100 \%$; (system 2$): t_{\mathrm{R}}=22.4 \mathrm{~min}$, purity $99 \%$.

\section{$N$-[(2S)-1-(4-Carbamoyl-3,4-dihydroisoquinolin-2(1H)-yl)-3-cyclohexyl-1-oxopropan-2-}

yl]isoxazole-5-carboxamide (12a and 12b). To a solution of 1,2,3,4-tetrahydroisoquinoline-4-carboxylic acid $(250 \mathrm{mg}, 1.41 \mathrm{mmol})$ in $1,4-$ dioxane $(10.0 \mathrm{~mL})$ was added a $10 \mathrm{wt} \%$ solution of sodium carbonate $(4.00 \mathrm{~mL})$. Chloroformic acid 9H-fluoren-9-ylmethyl ester (438 mg, $1.69 \mathrm{mmol})$ was added and the suspension was stirred at ambient temperature for $3 \mathrm{~h}$. The mixture was acidified with $1 \mathrm{M} \mathrm{HCl}$ and extracted with ethyl acetate. The combined organic layers were washed with $1 \mathrm{M} \mathrm{HCl}$ and brine, dried over $\mathrm{Na}_{2} \mathrm{SO}_{4}$ and evaporated. (RS)-2$\{[(9 H$-Fluoren-9-yl)methoxy]carbonyl $\}-1,2,3,4-$ tetrahydroisoquinoline-4-carboxylic acid was obtained as beige solid (650 mg, 98\%) and used without further purification. 12a and 12b were synthesized on a Rink amide resin, loading the resin with $(R S)-2-\{[(9 H-$ Fluoren-9-yl)methoxy $]$ carbonyl $\}-1,2,3,4-$ tetrahydroisoquinoline-4-carboxylic acid and applying standard SPPS methods. Purification was done by preparative RP-HPLC $\left(40-65 \% \mathrm{CH}_{3} \mathrm{CN} / 0.1 \%\right.$ aq. trifluoroacetic acid). Diastereomer separation was achieved by RP-HPLC (60 - 68\% methanol/ $0.1 \%$ aq. trifluoroacetic acid in $10 \mathrm{~min} ; 68-100 \%$ in $10 \mathrm{~min}$ ), referring to the first eluent as $\mathbf{a}$ and to the second one as $\mathbf{b}$, to yield 12a and 12b as white solids. IR (12a, $\mathrm{NaCl}): 3298$, 2924, 2852, 1671, 1637, 1535, 1448, 1284, 1205, $740 \mathrm{~cm}^{-1} .{ }^{1} \mathrm{H}$ NMR (12a, DMSO- $d_{6}, 400 \mathrm{MHz}$, two rotamers 
were observed $\delta): 9.16$ and $9.05(\mathrm{~d}, J=8.1 \mathrm{~Hz}, 1 \mathrm{H}), 8.73(\mathrm{~d}, J=1.9 \mathrm{~Hz}, 1 \mathrm{H}), 7.68$ and $7.56(\mathrm{~s}, 1 \mathrm{H}), 7.27-$ $7.19(\mathrm{~m}, 5 \mathrm{H}), 7.18$ and $7.14(\mathrm{~d}, J=1.9 \mathrm{~Hz}, 1 \mathrm{H}), 5.08$ and $5.04(\mathrm{ddd}, J=11.1,8.2,3.7 \mathrm{~Hz}, 1 \mathrm{H}), 4.78$ and 4.64 $(\mathrm{d}, J=17.2 \mathrm{~Hz}, 1 \mathrm{H}), 4.72$ and $4.56(\mathrm{~d}, J=17.2 \mathrm{~Hz}, 1 \mathrm{H}), 4.18-4.13(\mathrm{~m}, 1 \mathrm{H}) 4.10$ and $3.82(\mathrm{dd}, J=13.3,4.6$ $\mathrm{Hz}, 1 \mathrm{H}), 3.74$ and $3.55(\mathrm{dd}, J=13.3,4.6 \mathrm{~Hz}, 1 \mathrm{H}) 1.89-1.47(\mathrm{~m}, 7 \mathrm{H}), 1.45-0.74(\mathrm{~m}, 6 \mathrm{H}) .{ }^{13} \mathrm{C}$ NMR $(12 \mathrm{a}$, DMSO- $d_{6}, 151 \mathrm{MHz}$, two rotamers were observed, $\left.\delta\right): 172.9$ and 172.8, 170.2 and 169.9, 162.0, 155.3 and $155.2,151.5,133.6$ and 133.5, 133.1 and 133.0, 128.0 and 127.8, 126.8 and 126.7, 126.5, 126.4 and 126.1, 106.0, 47.1 and 46.6, 44.9 and 44.5, 44.1 and 42.6, 40.0 and 39.9, 38.1 and 37.9, 33.6 and 33.5, 33.2 and 33.0, 31.8 and 31.4, 25.9 and 25.8, 25.7, 25.5 and 25.4. ESI-MS (12a): $m / z 425.3$ [M+H] $]^{+}$. HRMS-ESI (12a): calcd. for $\mathrm{C}_{23} \mathrm{H}_{28} \mathrm{~N}_{4} \mathrm{O}_{4} \mathrm{Na}: 447.1997[\mathrm{M}+\mathrm{Na}]^{+}$, found: 447.1991. [ $\left.\alpha\right]^{23} \mathrm{D}(12 \mathrm{a})+26.7$ (c 0.67, $\left.\mathrm{CH}_{3} \mathrm{OH}\right)$ HPLC (12a, system 2): $t_{\mathrm{R}}=21.4 \mathrm{~min}$, purity $99 \%$.

IR (12b, NaCl): 3267, 2924, 2853, 1671, 1637, 1535, 1448, 1283, 1205, $741 \mathrm{~cm}^{-1} .{ }^{1} \mathrm{H}$ NMR (12b, DMSO- $d_{6}, 400 \mathrm{MHz}$, two rotamers were observed, $\delta$ ): 9.08 and $8.98(\mathrm{~d}, J=7.9 \mathrm{~Hz}, 1 \mathrm{H}), 8.74$ and $8.72(\mathrm{~d}$, $J=1.9 \mathrm{~Hz}, 1 \mathrm{H}), 7.64$ and $7.60(\mathrm{~s}, 1 \mathrm{H}), 7.28-7.20(\mathrm{~m}, 4 \mathrm{H}), 7.18$ and $7.13(\mathrm{~d}, J=1.9 \mathrm{~Hz}, 1 \mathrm{H}$, isoxazole-H4), 7.18 and $7.10(\mathrm{~s}, 1 \mathrm{H}), 5.07$ and $4.99(\mathrm{ddd}, J=11.2,7.9,3.7 \mathrm{~Hz}, 1 \mathrm{H}), 4.81$ and $4.72(\mathrm{~d}, J=16.2 \mathrm{~Hz}, 1 \mathrm{H}), 4.71$ and $4.50(\mathrm{~d}, J=16.2 \mathrm{~Hz}, 1 \mathrm{H}), 3.94-3.68(\mathrm{~m}, 3 \mathrm{H}), 1.93-1.78(\mathrm{~m}, 1 \mathrm{H}), 1.78-1.43(\mathrm{~m}, 6 \mathrm{H}), 1.42-1.27(\mathrm{~m}$, 1H), $1.26-1.03(\mathrm{~m}, 3 \mathrm{H}), 1.03-0.78(\mathrm{~m}, 2 \mathrm{H}) .{ }^{13} \mathrm{C}$ NMR $\left(12 \mathrm{~b}\right.$, DMSO- $d_{6}$, two rotamers were observed, 151 $\mathrm{MHz}, \delta$ ): 172.9 and $172.4,170.2$ and 170.1, 162.1 and 162.0, 155.3 and 155.1, 151.6 and 151.5, 133.7 and 133.3, 133.3 and 132.9, 127.9 and 127.5, 126.8 and 126.7, 126.5, 126.2, 106.0 and 105.9, 47.3 and 47.0, 46.4, 44.1 and 42.3, 39.9 and 39.8, 37.8 and 36.4, 33.6, 33.2 and 33.1, 31.5 and 31.5, 25.9 and 25.9, 25.6 and 25.6, 25.5. ESI-MS (12b): $m / z 425.3[\mathrm{M}+\mathrm{H}]^{+}$. HRMS-ESI (12b): calcd. for $\mathrm{C}_{23} \mathrm{H}_{28} \mathrm{~N}_{4} \mathrm{O}_{4} \mathrm{Na}, 447.1997[\mathrm{M}+\mathrm{Na}]^{+}$; found: 447.1999. $[\alpha]^{23} \mathrm{D}(12 \mathrm{~b})-17.3\left(\mathrm{c} 0.46, \mathrm{CH}_{3} \mathrm{OH}\right)$. HPLC (12b, system 2$): t_{\mathrm{R}}=21.2 \mathrm{~min}$, purity $99 \%$.

\section{(S)-N-(1-\{[2-(2-Amino-2-oxoethyl)benzyl]amino\}-3-cyclohexyl-1-oxopropan-2-yl)-N-}

methylisoxazole-5-carboxamide (13). In analogy to previously described protocols, ${ }^{9}$ Fmoc-3-cyclohexyl- $L$ alanine (393 mg, $1.00 \mathrm{mmol})$, paraformaldehyde $(200 \mathrm{mg}, 6.66 \mathrm{mmol})$ and $p$-toluenesulfonic acid $(20.0 \mathrm{mg}$, $0.116 \mathrm{mmol})$ were suspended in toluene $(20.0 \mathrm{~mL})$ and heated under reflux in a Dean-Stark set up for $16 \mathrm{~h}$. The cooled mixture was washed with saturated, aqueous sodium bicarbonate solution and the organic layer 
was dried over $\mathrm{Na}_{2} \mathrm{SO}_{4}$. Evaporation of the solvent yielded (9H-fluoren-9-yl)methyl (S)-4-(cyclohexylmethyl)5-oxooxazolidine-3-carboxylate as light yellow oil (403 mg, 99\%) which was used without further purification. (9H-Fluoren-9-yl)methyl (S)-4-(cyclohexylmethyl)-5-oxooxazolidine-3-carboxylate (300 mg, $0.74 \mathrm{mmol})$ and aluminium chloride (197 mg, $1.48 \mathrm{mmol})$ were dissolved in anhydrous dichloromethane (15.0 mL). Triethylsilane $(0.24 \mathrm{~mL}, 1.48 \mathrm{mmol})$ was added and the mixture was stirred at ambient temperature for $16 \mathrm{~h}$. The crude mixture was diluted with dichloromethane $(5.00 \mathrm{~mL})$ and washed with $1 \mathrm{M} \mathrm{HCl}$. The organic layer was dried over $\mathrm{Na}_{2} \mathrm{SO}_{4}$ and evaporated to yield $(S)-2-(\{[(9 H$-fluoren-9-yl)methoxy $]$ carbonyl $\}$ (methyl)amino)3-cyclohexylpropanoic acid as beige oil (253 mg, 84\%) which was used without any further purification and loaded on a Rink Amide resin to synthesize $\mathbf{1 3}$ applying standard SPPS methods. Purification by preparative RP-HPLC (40 - 65\% $\mathrm{CH}_{3} \mathrm{CN} / 0.1 \%$ aq. trifluoroacetic acid) yielded 13 as white solid. IR (NaCl): 3318, 3208, 2925, 1667, 1532, 1400, $737 \mathrm{~cm}^{-1} .{ }^{1} \mathrm{H}$ NMR (DMSO- $d_{6}, 400 \mathrm{MHz}$, two rotamers were observed, $\delta$ ): 8.75 and $8.73(\mathrm{~d}, J=1.9 \mathrm{~Hz}, 1 \mathrm{H}), 8.66$ and $8.58(\mathrm{t}, J=5.7 \mathrm{~Hz}, 1 \mathrm{H}), 7.51($ br s, $1 \mathrm{H}), 7.27-7.13(\mathrm{~m}, 4 \mathrm{H}), 7.03$ and 6.80 (d, $J=1.9 \mathrm{~Hz}, 1 \mathrm{H}), 6.96($ br s, $1 \mathrm{H}), 5.11$ and $4.99(\mathrm{dd}, J=10.3,5.4 \mathrm{~Hz}, 1 \mathrm{H}), 4.40$ and 4.34 (dd, $J=11.4,5.7$ $\mathrm{Hz}, 2 \mathrm{H}), 3.49(\mathrm{~s}, 2 \mathrm{H}), 3.03$ and $2.92(\mathrm{~s}, 3 \mathrm{H}), 1.85-1.50(\mathrm{~m}, 7 \mathrm{H}), 1.37-0.69(\mathrm{~m}, 6 \mathrm{H}) .{ }^{13} \mathrm{C}$ NMR (DMSO- $d_{6}$, $101 \mathrm{MHz}$, two rotamers were observed, $\delta$ ): 172.3, 169.6 and 169.3, 162.4, 159.4 and 158.8, 151.0 and 150.9, 137.5 and 137.4, 134.6 and 134.5, 130.2, 127.8 and 127.6, 126.6 and 126.9, 126.8, 106.9 and 105.9, 58.5 and 54.4, 40.4 and 40.2, 39.2, 36.1 and 35.4, 33.9 and 33.7, 33.2 and 33.0, 32.5 and 29.7, 31.7 and 31.5, 26.0 and 25.9, 25.8, 25.6 and 25.4. ESI-MS: $m / z 427.1[\mathrm{M}+\mathrm{H}]^{+}$. HRMS-ESI: calcd. for $\mathrm{C}_{23} \mathrm{H}_{31} \mathrm{~N}_{4} \mathrm{O}_{4} 427.2340[\mathrm{M}+\mathrm{H}]^{+}$; found: 427.2331. $[\alpha]^{24}{ }_{D}-45.5\left(\mathrm{c} 0.68, \mathrm{CH}_{3} \mathrm{OH}\right)$. HPLC (system 1): $t_{\mathrm{R}}=19.5 \mathrm{~min}$, purity 98\%; (system 2): $t_{\mathrm{R}}=$ 22.1 min, purity $98 \%$.

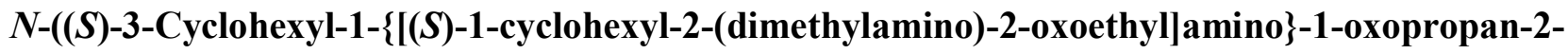

\section{yl)isoxazole-5-carboxamide}

(14).
(S)-2-Cyclohexyl-2-[(S)-3-cyclohexyl-2-(isoxazole-5carboxamido)propanamido]-acetic acid was synthesized applying standard Fmoc-based SPPS methods on a 2chlorotrityl resin and purified by preparative HPLC. A solution of $(S)-2$-cyclohexyl-2-[(S)-3-cyclohexyl-2(isoxazole-5-carboxamido)propanamido]-acetic acid $(40 \mathrm{mg}, 0.10 \mathrm{mmol})$ in dichloromethane/DMF (3:1, $2.0 \mathrm{~mL}$ ) was cooled to $0{ }^{\circ} \mathrm{C}$. TBTU $(48 \mathrm{mg}, 0.15 \mathrm{mmol})$ was dissolved in DMF $(0.5 \mathrm{~mL})$, DIPEA was added 
$(30 \mu 1,0.15 \mathrm{mmol})$ and the mixture was added dropwise. The reaction was stirred at $0{ }^{\circ} \mathrm{C}$ for 15 minutes before a $2 \mathrm{M}$ solution of dimethylamine in THF $(60 \mu \mathrm{L}, 0.12 \mathrm{mmol})$ was added. It was stirred for another 30 minutes at ambient temperature. After evaporation of the volatile components the crude product was purified by preparative HPLC (column 1; acetonitrile $/ \mathrm{H}_{2} \mathrm{O}+0.1 \%$ TFA, 40\% $1 \mathrm{~min}$, gradient $40-95 \%$ in $11 \mathrm{~min}$, $95 \% 2 \mathrm{~min}$, gradient $\left.95-40 \% 1 \mathrm{~min}, 40 \% 1 \mathrm{~min} ; \mathrm{t}_{\mathrm{R}}=8.3 \mathrm{~min}\right)$ to yield 14 as white solid $(17 \mathrm{mg}, 39 \%)$. IR (NaCl): 3318, 3208, 2925, 1667, 1532, 1400, $737 \mathrm{~cm}^{-1} .{ }^{1} \mathrm{H}$ NMR (DMSO- $\left.d_{6}, 400 \mathrm{MHz}, \delta\right): 8.92$ (d, J=8.3 Hz, 1H), $8.75(\mathrm{~d}, J=1.9 \mathrm{~Hz}, 1 \mathrm{H}), 8.04(\mathrm{~d}, J=8.6 \mathrm{~Hz}, 1 \mathrm{H}), 7.15(\mathrm{~d}, J=1.9 \mathrm{~Hz}, 1 \mathrm{H}), 4.60-4.49(\mathrm{~m}, 2 \mathrm{H}), 3.04(\mathrm{~s}$, $3 \mathrm{H}), 2.81(\mathrm{~s}, 3 \mathrm{H}), 1.78-1.45(\mathrm{~m}, 13 \mathrm{H}), 1.35-1.22(\mathrm{~m}, 1 \mathrm{H}), 1.23-1.04(\mathrm{~m}, 6 \mathrm{H}), 1.03-0.80(\mathrm{~m}, 4 \mathrm{H}) .{ }^{13} \mathrm{C}$ NMR (DMSO- $\left.d_{6}, 101 \mathrm{MHz}, \delta\right): 171.1,170.8,162.4,155.3,151.7,106.2,52.6,50.8,38.8,36.9,35.1,33.7$, 33.2, 31.7, 29.1, 28.1, 26.1, 25.8, 25.8, 25.7, 25.6, 25.5 (2C). ESI-MS: $m / z$ 433.2 [M+H] $]^{+}$. HRMS-ESI: calcd. for $\mathrm{C}_{23} \mathrm{H}_{37} \mathrm{~N}_{4} \mathrm{O}_{4}: m / z$ 433.2809 [M+H] $]^{+}$, found: 433.2806. [ $\left.\alpha\right]^{24} \mathrm{D}-14.0\left(\mathrm{c} 0.47, \mathrm{CH}_{3} \mathrm{OH}\right)$. HPLC (system 1) t $\mathrm{t}_{\mathrm{R}}=$ 20.7 min, purity $98 \%$; (system 2$) t_{R}=25.3$ min, purity: $97 \%$.

Cell culture. Cell culture reagents were obtained from gibco or Invitrogen LifeTechnologies GmbH. HEK-293T cells were grown in DMEM/F-12 medium supplemented with $10 \%$ fetal bovine serum, $100 \mu \mathrm{g} / \mathrm{mL}$ penicillin, $100 \mu \mathrm{g} / \mathrm{mL}$ streptomycin and $0.5 \mathrm{mg} / \mathrm{mL} L$-glutamine in culture dishes $(\varnothing 10 \mathrm{~cm})$ at $37^{\circ} \mathrm{C}$ and $5 \% \mathrm{CO}_{2}$ to a confluency of $70-100 \%$. Cells were split every three to four days and used for experiments between passages 3 and 14 .

$\beta$-Arrestin-HEK-293 cells were grown in DMEM/F-12 medium supplemented with $10 \%$ fetal bovine serum, $100 \mu \mathrm{g} / \mathrm{mL}$ penicillin, $100 \mu \mathrm{g} / \mathrm{mL}$ streptomycin, $150 \mu \mathrm{g} / \mathrm{mL}$ hygromycin and $0.5 \mathrm{mg} / \mathrm{mL} L$-glutamine in culture dishes $(\varnothing 10 \mathrm{~cm})$ at $37{ }^{\circ} \mathrm{C}$ and $5 \% \mathrm{CO}_{2}$ to a confluency of $70-100 \%$. Cells were split every three to four days and used for experiments between passages 3 and 16. For subcultivation of HEK-293T cells and $\beta$ Arrestin-HEK-293 cells, the medium was removed, and cells were detached with $2 \mathrm{~mL}$ of Versene. $8 \mathrm{~mL}$ of medium was added, and cells were gently pipetted up and down to separate aggregates. After centrifugation $\left(220 \mathrm{x} \mathrm{g}_{\mathrm{E}}, 6 \mathrm{~min}\right)$, cells were resuspended in $10 \mathrm{~mL}$ fresh medium and plated onto new culture dishes in the appropriate density. 
Transient transfection. HEK-293T cells or $\beta$-arrestin-HEK-293 cells were plated onto culture dishes and grown to a confluency of $50-80 \%$ at $37{ }^{\circ} \mathrm{C}$ and $5 \% \mathrm{CO}_{2} .1 \mathrm{~h}$ to $3 \mathrm{~h}$ prior to transfection the medium was renewed with DMEM/F-12 medium supplemented with $10 \%$ fetal bovine serum, $100 \mu \mathrm{g} / \mathrm{mL}$ penicillin and $100 \mu \mathrm{g} / \mathrm{mL}$ streptomycin and $0.5 \mathrm{mg} / \mathrm{mL} L$-glutamine. The transfection mix was prepared using $800 \mu \mathrm{L}$ serum free medium, $3 \mu \mathrm{g}$ cDNA and $9 \mu \mathrm{L}$ Mirus TransIT-293 (for $\varnothing 10 \mathrm{~cm}$ culture dishes), adding the components in the order indicated and only mixing it gently once Mirus TransIT was contained. After pre-incubation for $20-30 \mathrm{~min}$ at room temperature, the mix was added dropwisely. Medium was renewed $24 \mathrm{~h}$ after transfection and cultivation was continued for further $24 \mathrm{~h}$ at $5 \% \mathrm{CO}_{2}, 37^{\circ} \mathrm{C}$, before cells were used for experiments.

IP-One accumulation assay. Measurement of PAR2- respectively $\mathrm{G}_{\alpha q^{-}}$-stimulated IP1 formation was performed using the IP-One $\mathrm{HTRF}^{\circledR}$ assay (CisBio, Codolet, France) according to the manufacturer's protocol. In brief, HEK-293T cells transiently transfected with human PAR2 applying Mirus TransIT 293 as transfection reagent, were detached from the culture dish with Versene (Life Technologies, Darmstadt, Germany), seeded into black, clear flat bottom 384-well plates (Greiner, Frickenhausen, Germany) in assay medium at a density of 10,000 cells/well and maintained at $37^{\circ} \mathrm{C}, 5 \% \mathrm{CO}_{2}$ for $24 \mathrm{~h}$. The medium was exchanged with stimulation buffer and cells were incubated with dilutions of the test compounds in stimulation buffer for $2 \mathrm{~h}$ at $37^{\circ} \mathrm{C}$, $5 \% \mathrm{CO}_{2}$. For antagonist assays, cells were preincubated with the antagonists for $30 \mathrm{~min}$, before $2 \mathrm{f}-\mathrm{LIGRLO}-$ $\mathrm{NH}_{2}$ (final concentration300 nM) was added and the incubation was continued for $90 \mathrm{~min}$. After incubation, freshly prepared IP1 reagent mix (in lysis buffer), then freshly prepared AB reagent mix (in lysis buffer) was added and cells were further incubated in the dark for $60 \mathrm{~min}$ at ambient temperature. FRET ratios (emission at $620-10 \mathrm{~nm}$ and $665-10 \mathrm{~nm}$, respectively) were determined using the CLARIOstar II plate reader (BMG LabTech, Ortenberg, Germany). Results were analyzed by non-linear regression using the algorithms of PRISM 6.0 to obtain an $\mathrm{EC}_{50}$ and normalized to basal (0\%) and the maximal effect of $2 \mathrm{f}-\mathrm{LIGRLO}-\mathrm{NH}_{2}(100 \%)$ for the calculation of efficacy $\left(E_{\max }\right)$.

$\beta$-Arrestin-2 recruitment assay. Measurement of receptor stimulated $\beta$-arrestin- 2 recruitment was performed using the PathHunter assay (DiscoverX, Birmingham, U.K.) as described previously. ${ }^{10}$ In brief, 
(EA)- $\beta$-arrestin-2-HEK293 cells were transiently transfected with the ProLink tagged PAR2-PK1s construct, applying Mirus TransIT 293 as transfection reagent. $24 \mathrm{~h}$ after transfection, cells were detached from the culture dish using with Versene (Life Technologies, Darmstadt, Germany), seeded into white, clear flat bottom 384-well plates (Greiner, Frickenhausen, Germany) in assay medium at a density of 5,000 cells/well and maintained at $37{ }^{\circ} \mathrm{C}, 5 \% \mathrm{CO}_{2}$ for $24 \mathrm{~h}$. After incubation with the test compounds dissolved in PBS for $90 \mathrm{~min}$ at $37^{\circ} \mathrm{C}$, the detection mix was added, and incubation was continued in the dark for 60 min at room temperature. Chemiluminescence was determined using the CLARIOstar II plate reader (BMG LabTech, Ortenberg, Germany). Results were analyzed by non-linear regression using the algorithms of PRISM 6.0 to obtain an $\mathrm{EC}_{50}$ and normalized to basal luminescence $(0 \%)$ and the maximal effect of $2 \mathrm{f}-\mathrm{LIGRLO}^{-\mathrm{NH}_{2}}(100 \%)$ for the calculation of efficacy $\left(\mathrm{E}_{\max }\right)$.

Metabolic stability. Metabolic stability of the test compounds was assessed in analogy to previously described protocols. ${ }^{10}$ The test compounds or a positive control (imipramine) were incubated (compound concentration of $20 \mu \mathrm{M}$ from a $10 \mathrm{mM}$ stock solution in DMSO, total volume $500 \mu \mathrm{L}$ ) with pooled male rat liver microsomes (Sprague-Dawley, Sigma-Aldrich, Germany) at a concentration of $0.5 \mathrm{mg}$ microsomal protein/mL in Tris- $\mathrm{MgCl}_{2}$ buffer (48 mM Tris, $4.8 \mathrm{mM} \mathrm{MgCl}_{2}, \mathrm{pH}$ 7.4). Microsomal reactions were initiated by addition of $50 \mu \mathrm{L}$ of NADPH solution (Carl Roth, Germany, final concentration $1 \mathrm{mM}$ ) and carried out in polyethylene caps (Eppendorf, $1.5 \mathrm{~mL}$ ) in a shaker at $37{ }^{\circ} \mathrm{C}, 350 \mathrm{rpm}$. At $0,15,30$ and $60 \mathrm{~min}, 100 \mu 1$ were removed and $100 \mu \mathrm{L}$ of ice-cold $\mathrm{CH}_{3} \mathrm{CN}$ (containing $10 \mu \mathrm{M}$ internal standard 14) were added. Data were normalized using the internal standard and were plotted as \% peak area of samples at $\mathrm{t}=0$ min (analysis of extracted ion chromatogram)

Plasma stability. In analogy to previously described protocols,${ }^{6}$ compounds (10 $\mathrm{mM}$ stock solution in DMSO) were diluted to $100 \mu \mathrm{M}$ in PBS and $30 \mu \mathrm{L}$ of these dilutions were added to a mixture of rat plasma $(150 \mu \mathrm{L})$ and PBS $(120 \mu \mathrm{L})$ at $37^{\circ} \mathrm{C}$. At intervals of $0,5,15,30,60,120,180$ and $240 \mathrm{~min}, 30 \mu \mathrm{L}$ were removed and $90 \mu \mathrm{L}$ of an ice-cold internal standard solution in $\mathrm{CH}_{3} \mathrm{CN}$ was added ( $5 \mu \mathrm{M}$ internal standard 14). Samples were centrifuged $(13.000 \mathrm{rpm}, 1 \mathrm{~min})$ and the supernatant was analyzed by LC-MS. Data were 
normalized using the internal standard and were plotted as \% peak area of samples at $\mathrm{t}=0$ min (analysis of extracted ion chromatogram).

Cytotoxicity. Possible cytotoxic effects of ligand 5a were studied in non-transfected HEK 293T cells employing the trypan blue exclusion test in analogy to previously described protocols. ${ }^{11}$ In brief, cells were seeded at a density of 300.000 cells $/ \mathrm{mL}$ in 12 -well plates (Greiner) in complete growth medium and incubated with the test compounds (final concentration $1 \mu \mathrm{M}$ or $10 \mu \mathrm{M}$ concentration, diluted from a $10 \mathrm{mM}$ stock solution prepared in DMSO) at $37^{\circ} \mathrm{C}, 5 \% \mathrm{CO}_{2}$ for $24 \mathrm{~h}$. The medium was removed and the cells were detached with $1 \mathrm{~mL}$ Versene (Invitrogen). Cells from three wells were collected and resuspended in growth medium, and $20 \mu \mathrm{L}$ of the resulting suspension were mixed with an equal amount of $0.4 \%$ trypan blue solution (Molecular Probes, Eugene, OR). Cell numbers and the fraction of dead cells were determined using a hemocytometer employing the automated Countess II FL cell counter (Invitrogen) and compared to control conditions (treated with a solution containing an equal amount of DMSO). For each condition, eight independent experiments were performed. Cell lysis in presence of $0.005 \%$ (w/v) digitonine (Sigma Aldrich) for 5 min was used as a positive control for cytotoxicity.

PAINS screening. All target compounds were converted into SMILES using ChemDraw 18.0 (PerkinElmer) and screened for pan assay interference and aggregation liability using the tools and standard filters ${ }^{12}$ implemented in the ZINC 15 database. ${ }^{13}$ Results from the screening (Supplementary Table S1) indicate no liabilities for the target compounds.

Setup of MD simulations. The simulations are based on the PAR2 crystal structure in complex with the antagonist AZ8838 (PDB entry 5NDD) ${ }^{2}$. The coordinates of the ligands were removed, and missing side chains completed utilizing UCSF Chimera to create the starting structure for modeling. MODELLER 9v4 was used to add the N-terminal residues 37 - 58, add missing residues in ECL3 and add 2 C-terminal residues up to Cys361. A palmitoyl group was added to Cys361 according to the UniProt entry of human PAR2. The Cterminus was capped with a methylamide group. Protonation states of titratable residues at pH 7.0 were calculated by means of the $\mathrm{H}++$ server (http://biophysics.cs.vt.edu/H++) $)^{14}$. 
The protein structure was aligned to the Orientation of Proteins in Membranes (OPM $)^{15}$ structure of the PAR2 (PDB entry 5NDD).The complex was inserted into a solvated and pre-equilibrated membrane of dioleoylphosphatidylcholine (DOPC) lipids by means of the GROMACS tool g_membed ${ }^{16}$. Subsequently, water molecules were replaced by sodium and chloride ions to give a neutral system with $0.15 \mathrm{M} \mathrm{NaCl}$. The final system dimensions were roughly 90 x 90 x $150 \AA^{3}$, containing 221 lipids, 106 sodium ions, 116 chloride ions and about 27.000 water molecules.

Parameter topology and coordinate files were built up using the tleap module of AMBER $16^{17}$ and subsequently converted into GROMACS input files. The general AMBER force field (GAFF) ${ }^{18}$ was used for DOPC molecules and ff14SB ${ }^{19}$ for the protein residues. The SPC/E water model ${ }^{20}$ was applied.

Simulations were performed using GROMACS $2016.3^{21-22}$. The simulation systems were energy minimized and equilibrated in the NVT ensemble at $310 \mathrm{~K}$ for $1 \mathrm{~ns}$ followed by the NPT ensemble for $1 \mathrm{~ns}$ with harmonic restraints of $10.0 \mathrm{kcal} \cdot \mathrm{mol}^{-1}$ on protein and ligands. In the NVT ensemble the V-rescale thermostat was used. In the NPT ensemble the Berendsen barostat, a surface tension of $22 \mathrm{dyn} \cdot \mathrm{cm}^{-1}$, and a compressibility of $4.5 \times 10^{-5}$ bar $^{-1}$ was applied. The system was further equilibrated for $18 \mathrm{~ns}$ with restraints on protein backbone. Here, the restraints were reduced in a stepwise fashion with 5.0 and $1.0 \mathrm{kcal} \cdot \mathrm{mol}^{-1}$, respectively. $100 \mathrm{~ns}$ of unrestrained molecular dynamics simulation were performed to further equilibrate the system. Simulations were performed using periodic boundary conditions and time step of $2 \mathrm{fs}$ with bonds involving hydrogen constrained using LINCS. Long-range electrostatic interactions were computed using particle mesh Ewald $(\mathrm{PME})^{23}$ method with interpolation of order 4 and FFT grid spacing of $1.6 \AA$. Non-bonded interactions were cut off at $12.0 \AA \AA$.

Metadynamics simulations of $\mathbf{N}$-terminal signaling sequence binding. Metadynamics simulations were performed in order to obtain a binding mode of the trypsin activated $\mathrm{N}$-terminus to the receptor itself. The simulations were performed based on the recently described protocol by Saleh and coworkers to determine ligand binding modes at $\mathrm{GPCR}^{24}$. In brief, we used a combination of the well-tempered metadynamics (WT) ${ }^{25-}$ ${ }^{26}$ and funnel-shaped walls. A metadynamics-history-dependent bias was applied along the $\mathrm{z}$ component of the distance between the center of mass of the $\mathrm{C} \alpha$ atoms of Phe $155^{3.32}$, Tyr $156^{3.33}$ and Ser $333^{7.42}$, representing the 
center of the receptor, and center of mass of the N-terminal Ser37. This distance was used as the single collective variable. The funnel restraint was applied to the relative position on the xy plane to ensure better sampling for the relevant region. Gaussian hills with an initial height of $0.48 \mathrm{kcal} \cdot \mathrm{mol}^{-1}$ applied every $1 \mathrm{ps}$ were used. The hill width was chosen to be $1 \AA$. The Gaussian functions were rescaled in the WT scheme using a bias factor of 20. The free energies were calculated using the sum_hills function of the PLUMED plugin ${ }^{27}$. The lowest energy binding mode was equilibrated in a $1 \mu$ s long unrestrained MD simulation.

Molecular Docking. Docking studies were performed using the PAR2 model of Kennedy et al. ${ }^{3}$ and the equilibrated model of the N-terminal bound PAR2 proposed by the metadynamics simulations. For the latter, the N-terminal sequence SLIGKVD of the receptor was removed to expose the cavity used for docking. The peptide sequence SLIGKV was removed from the PAR2 model of Kennedy et al. ${ }^{3}$ for the same purpose. The 3D coordinates of the compounds were created and optimized using Avogadro ${ }^{28}$, an open-source molecular builder and visualization tool (Version 1.2.0). Docking was performed using AutoDock Vina ${ }^{29}$ applying a search space of $20 \times 20 \times 20 \AA$ and an exhaustiveness value of 32 . Twenty conformations of each ligand were obtained and inspected manually.

Subsequently, the selected ligand-receptor complexes of $\mathbf{4 b}$ (IK109), 5a (IK187) and $\mathbf{2}$ were submitted to an energy minimization using the PMEMD module of the AMBER18 program package ${ }^{30}$. The general AMBER force field $2(\mathrm{GAFF} 2)^{30}$ was used for small molecules and ff $14 \mathrm{SB}^{19}$ for protein residues. Parameters for $\mathbf{4 b}$ (IK109), 5a (IK187) and $\mathbf{2}$ were assigned using antechamber ${ }^{30}$. Structures of the ligands were optimized by means of Gaussian $16^{31}$ at the B3LYP/6-31G* level and charges were calculated at the HF/6-31G* level of theory. Atom point charges were assigned according to the RESP procedure described in literature ${ }^{20}$. No formal charge was assigned to the ligands. The minimization protocol includes 500 steps of steepest descent minimization, followed by 4500 steps of conjugate gradient minimization. The energy minimizations were carried out in a water box with periodic boundary conditions and a non-bonded cutoff of $10.0 \AA$.

Visualization was performed using the PyMOL Molecular Graphics System, Version 2.1.1 (Schrödinger, LLC). 
Supplementary Data. ${ }^{1} \mathrm{H}$ and ${ }^{13} \mathrm{C}$ NMR spectra of the key compounds.

4b, ${ }^{1} \mathrm{H}-\mathrm{NMR}, \mathrm{DMSO}_{-} \mathrm{d}_{6}, 400 \mathrm{MHz}$<smiles>NC(=O)Cc1ccccc1CNC(=O)C(CC1CCCCC1)NC(=O)c1ccno1</smiles>

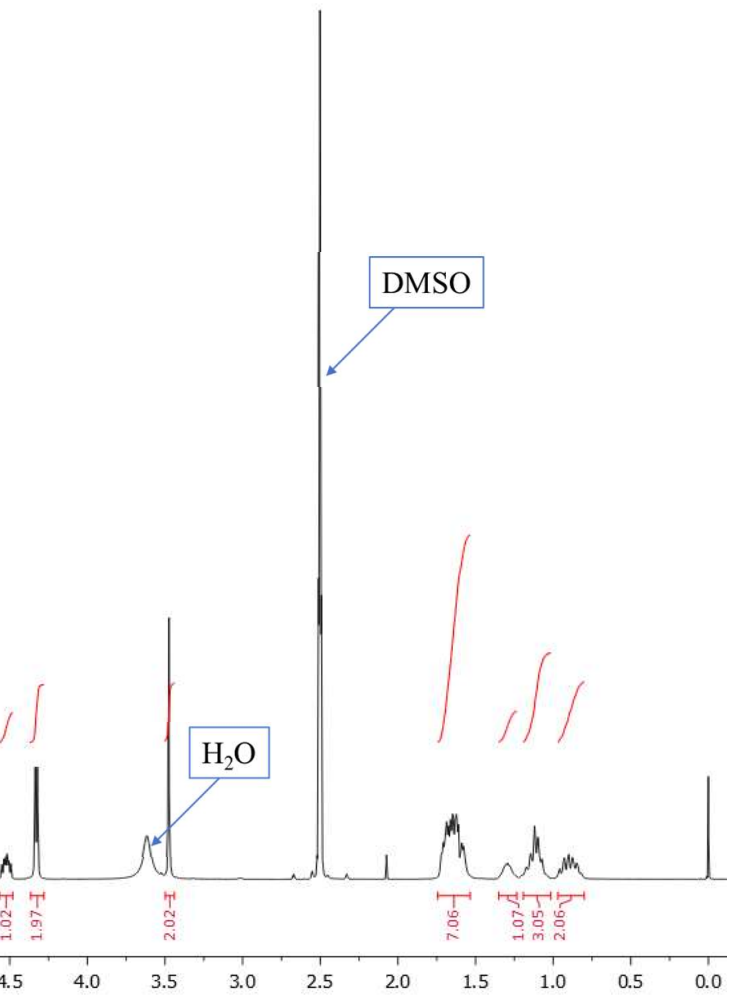

4b, ${ }^{13} \mathrm{C}-\mathrm{NMR}$, DMSO-d 6 , $101 \mathrm{MHz}$
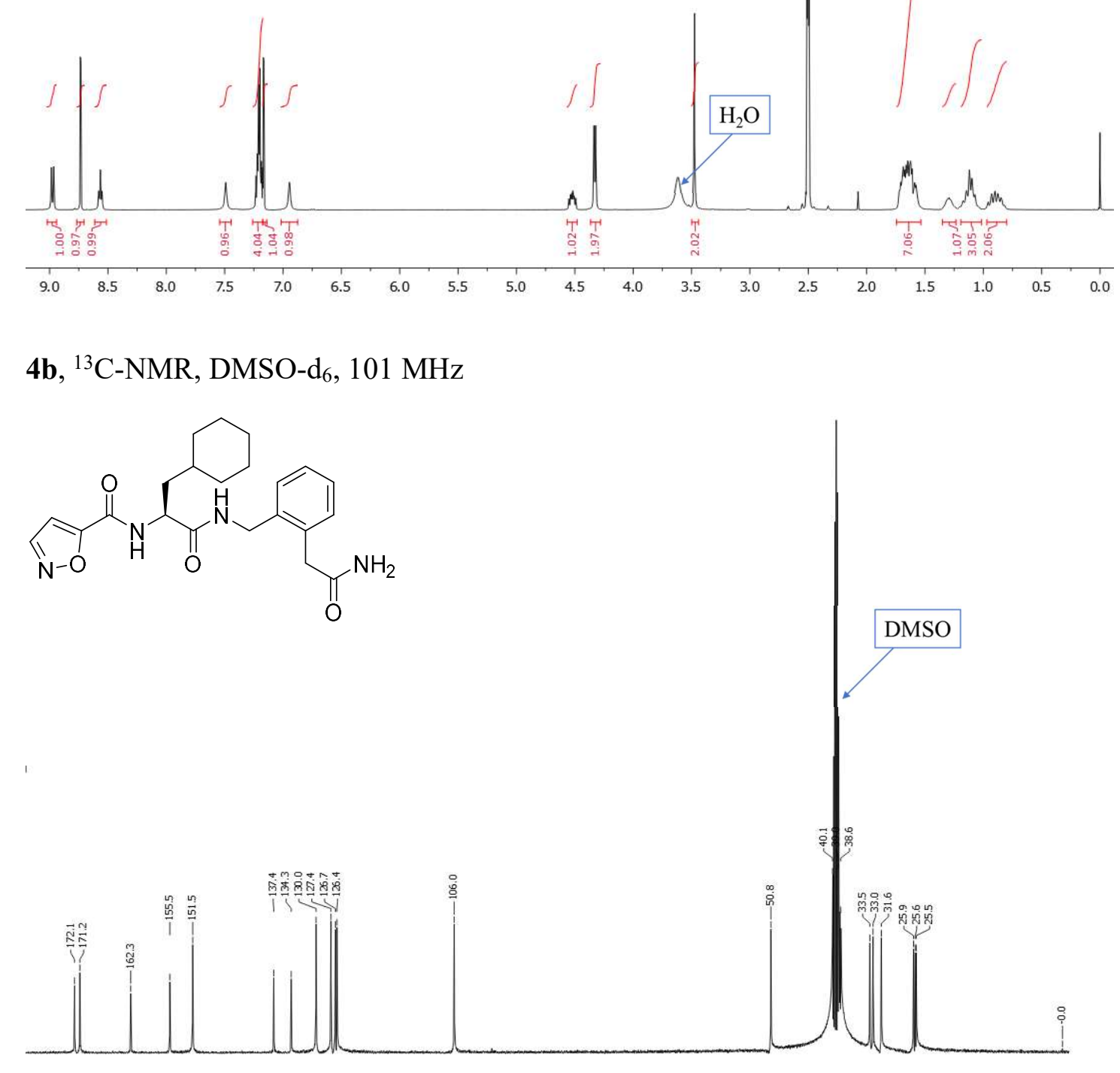
5a, ${ }^{1} \mathrm{H}-\mathrm{NMR}, \mathrm{DMSO}-\mathrm{d}_{6}, 400 \mathrm{MHz}$<smiles>Cc1cc(C(=O)NC(CC2CCCCC2)C(=O)NCc2ccccc2CC(N)=O)on1</smiles>
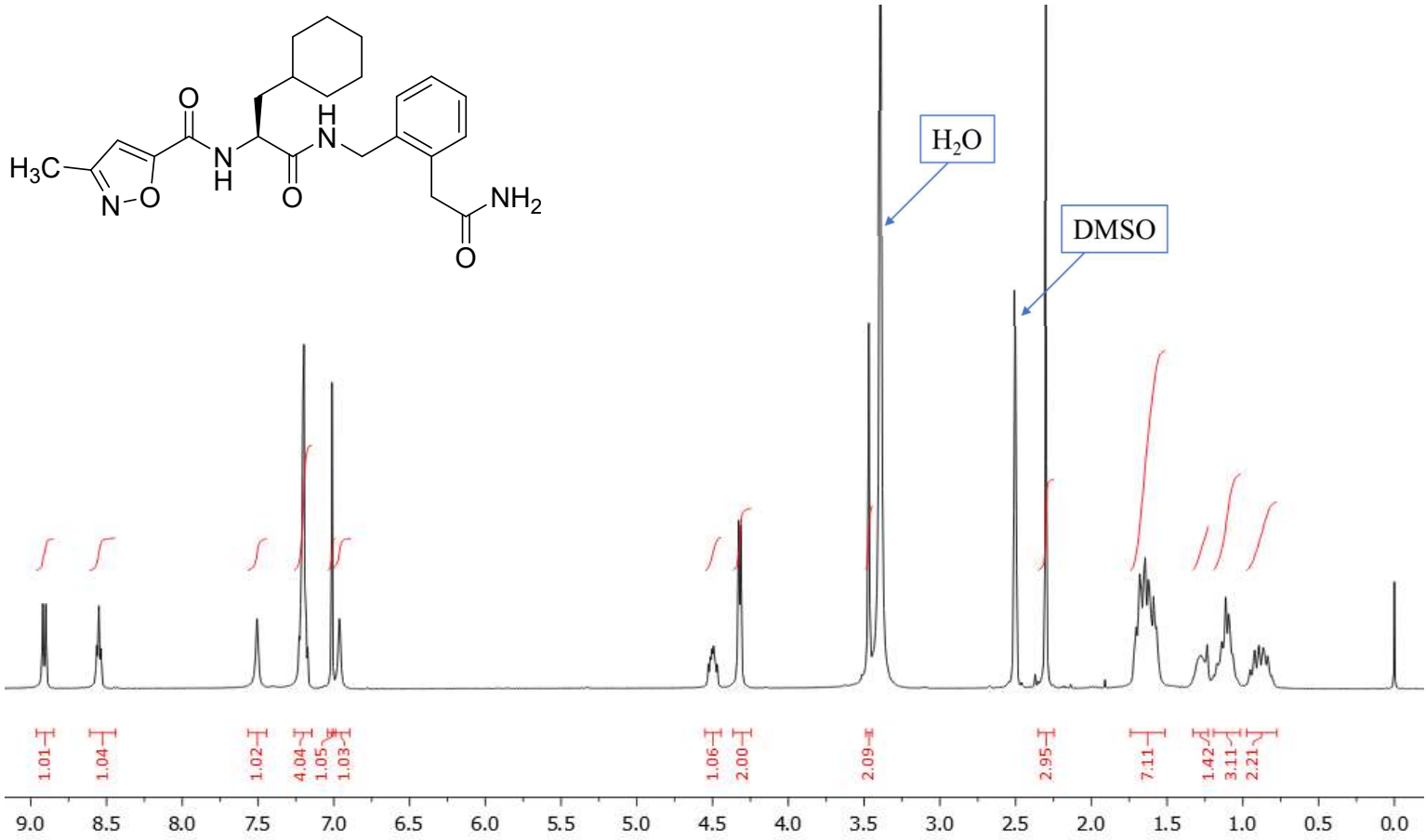

5a, ${ }^{13} \mathrm{C}-\mathrm{NMR}, \mathrm{DMSO}-\mathrm{d}_{6}, 101 \mathrm{MHz}$<smiles>Cc1cc(C(=O)NC(CC2CCCCC2)C(=O)NCc2ccccc2CC(N)=O)on1</smiles>

DMSO

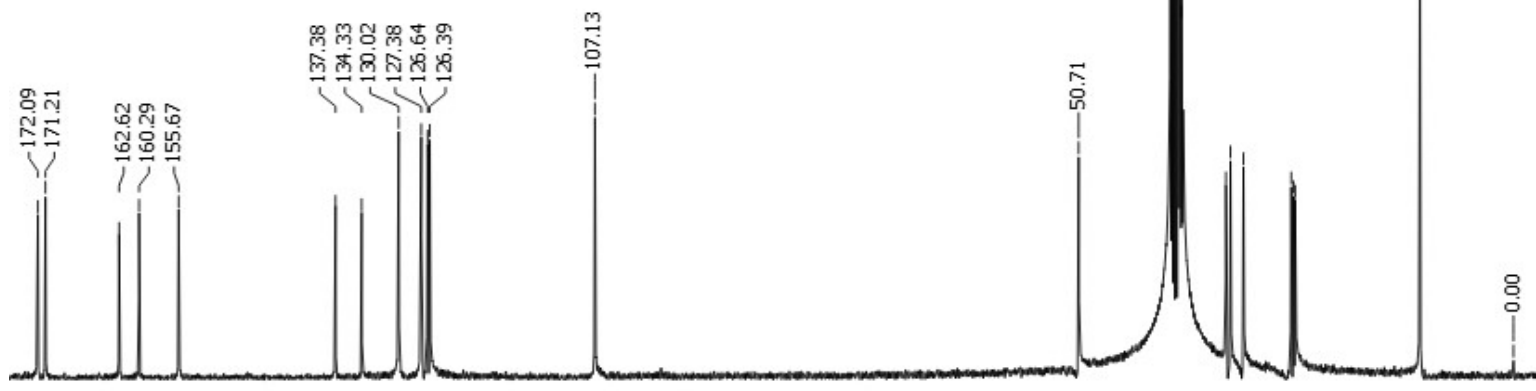


5b, ${ }^{1} \mathrm{H}-\mathrm{NMR}$, DMSO-d $6,400 \mathrm{MHz}$

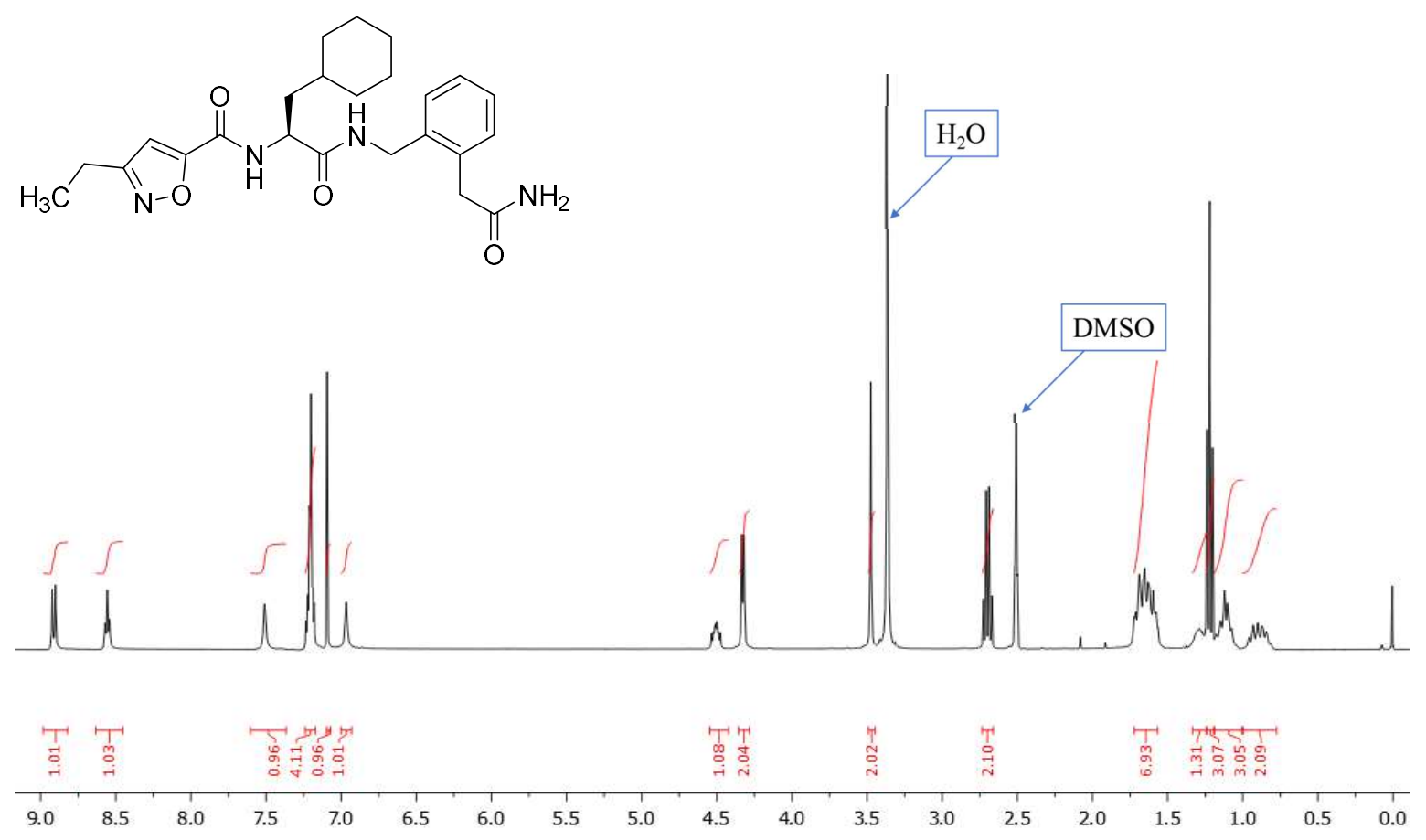

5b, ${ }^{13} \mathrm{C}-\mathrm{NMR}$, DMSO-d $6,101 \mathrm{MHz}$

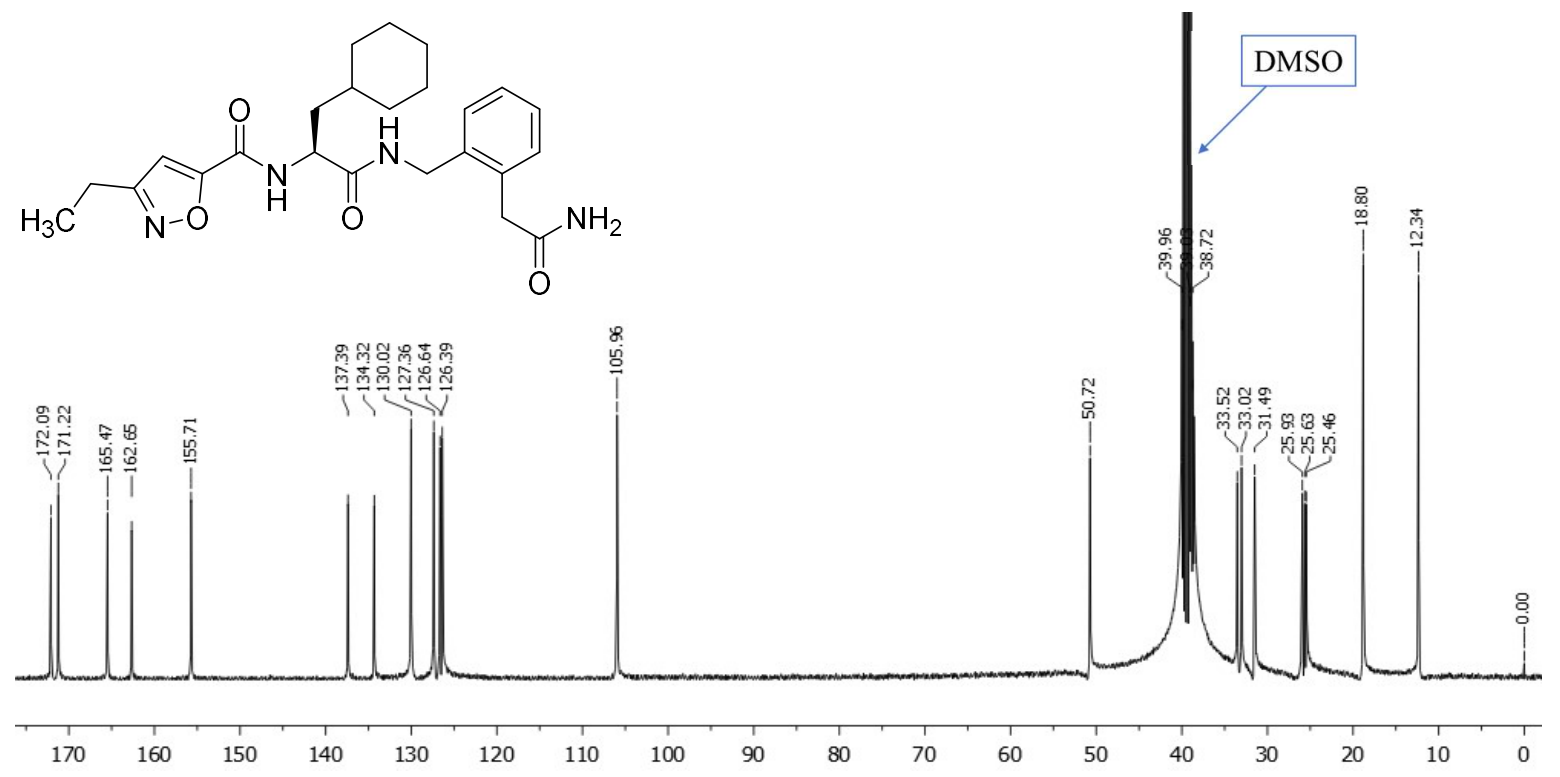


6, ${ }^{1} \mathrm{H}-\mathrm{NMR}, \mathrm{DMSO}-\mathrm{d}_{6}, 600 \mathrm{MHz}$
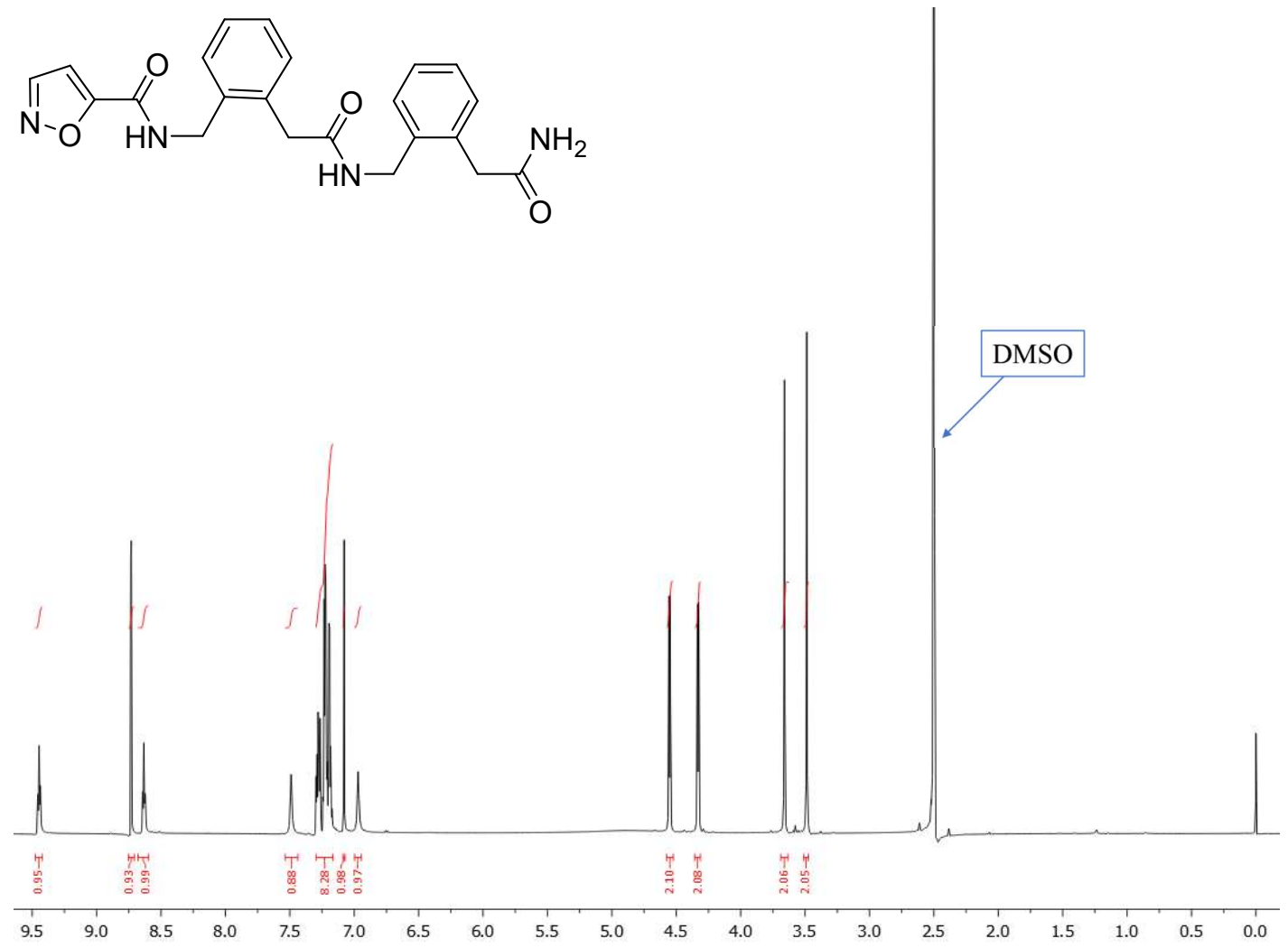

6, ${ }^{13} \mathrm{C}-\mathrm{NMR}, \mathrm{DMSO}-\mathrm{d}_{6}, 101 \mathrm{MHz}$

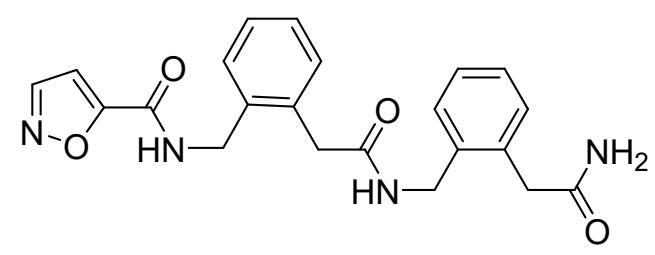

DMSO

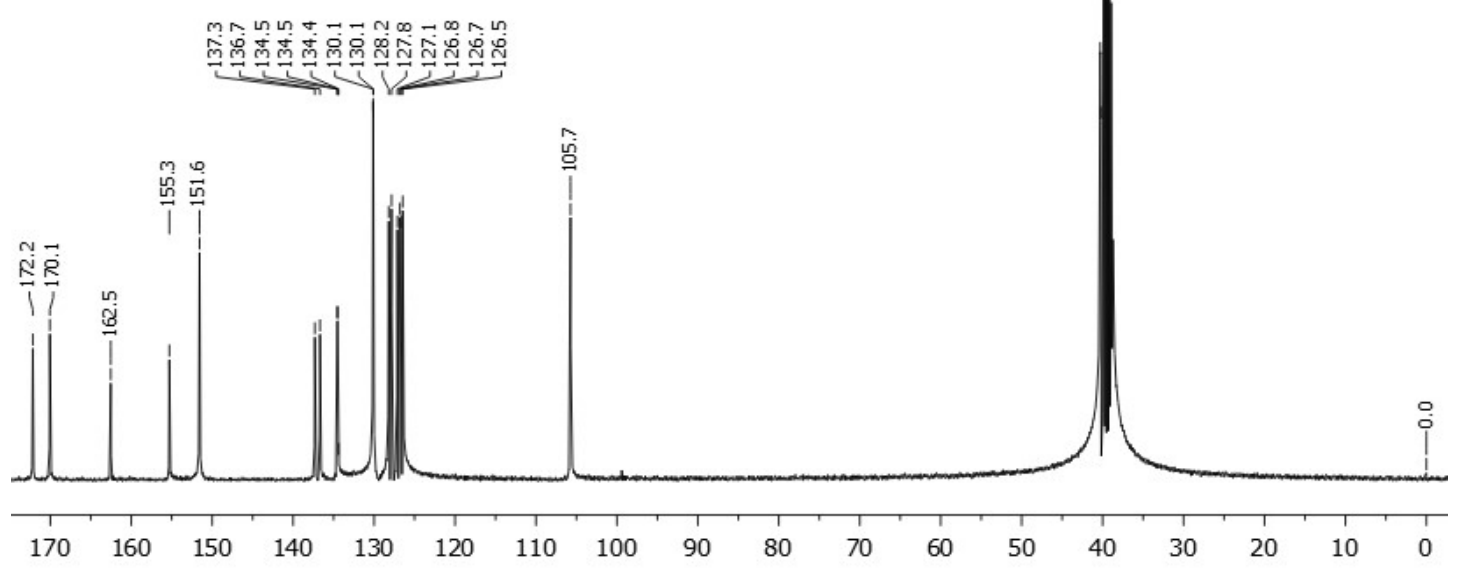


7, ${ }^{1} \mathrm{H}-\mathrm{NMR}, \mathrm{DMSO}-\mathrm{d}_{6}, 400 \mathrm{MHz}$

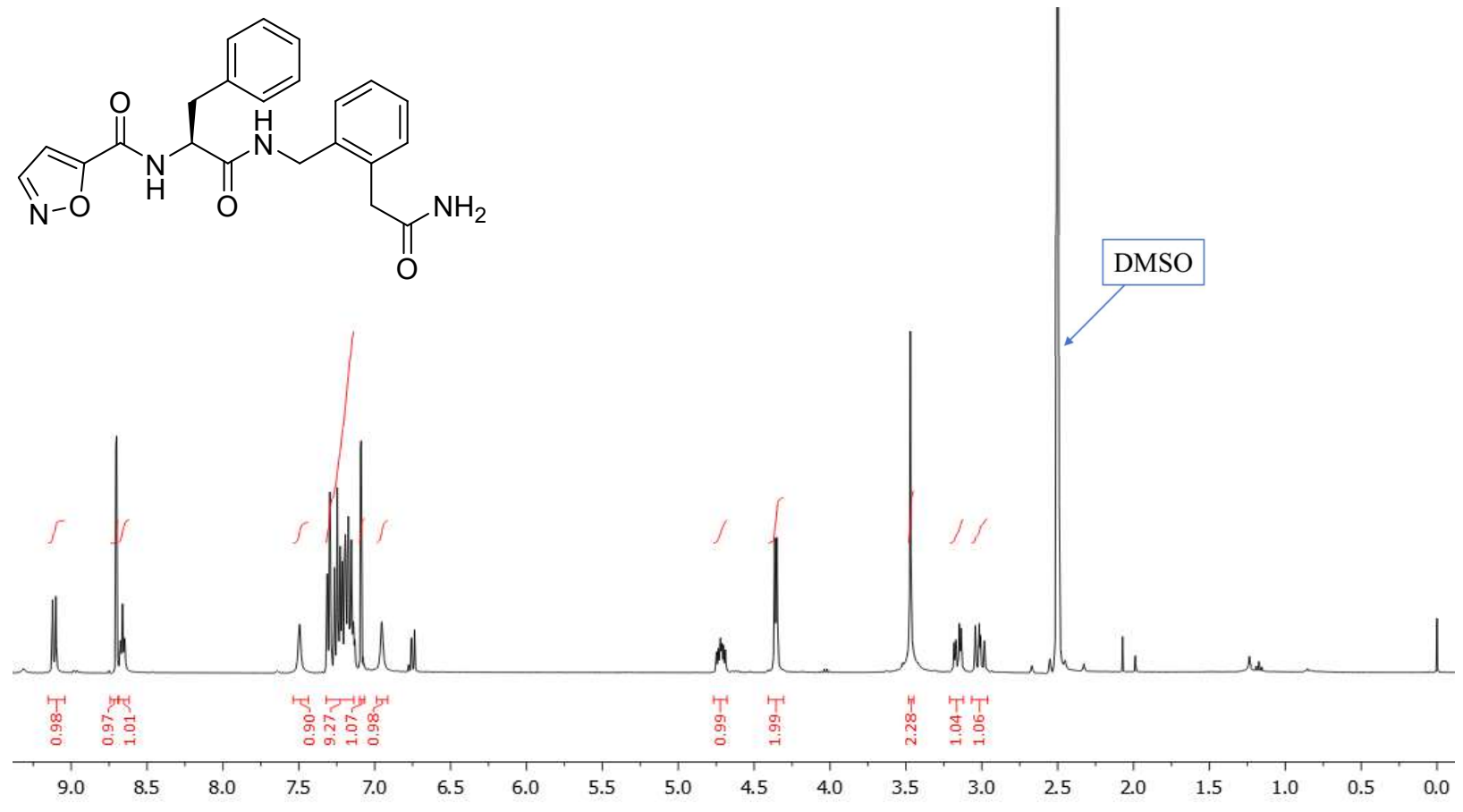

7, ${ }^{13} \mathrm{C}-\mathrm{NMR}, \mathrm{DMSO}-\mathrm{d}_{6}, 101 \mathrm{MHz}$<smiles>NC(=O)Cc1ccccc1CNC(=O)C(Cc1ccccc1)NC(=O)c1ccno1</smiles>

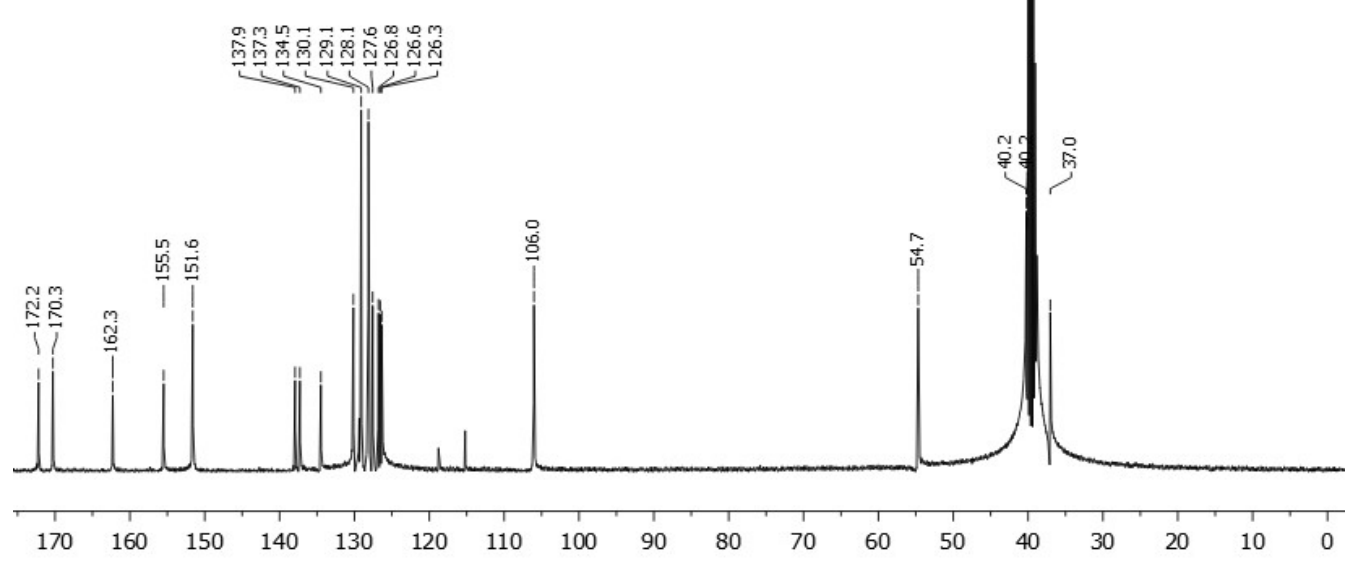


8a, ${ }^{1} \mathrm{H}-\mathrm{NMR}$, DMSO-d 6 , $400 \mathrm{MHz}$

(= first eluting enantiomer, absolute configuration not known)<smiles>Cc1ccccc1CNC(=O)[C@H](CC1CCCCC1)NC(=O)c1ccno1</smiles>

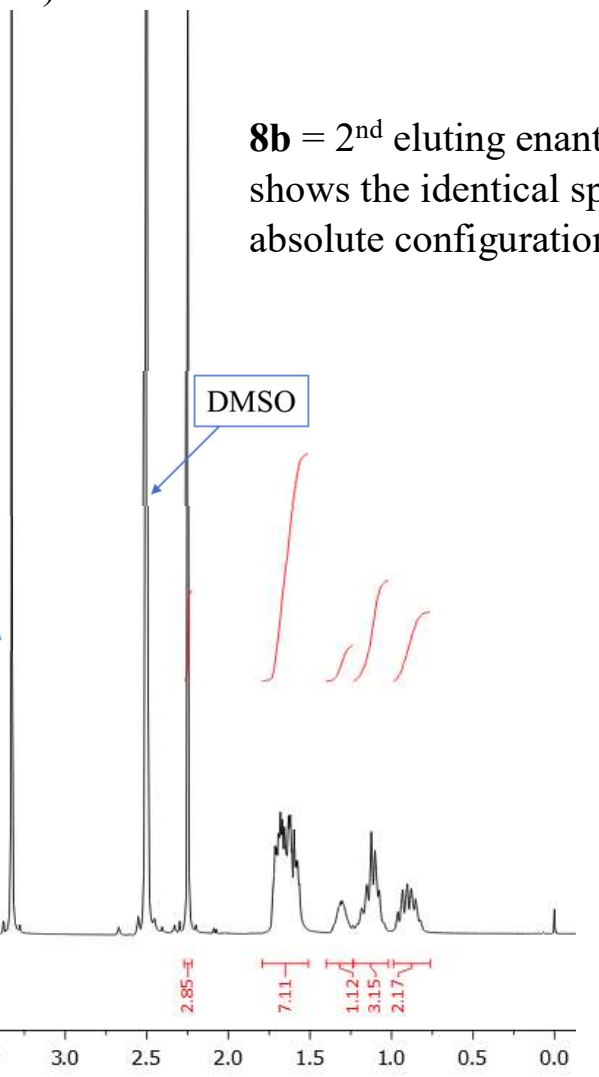

8a, ${ }^{13} \mathrm{C}-\mathrm{NMR}$, DMSO-d $6,151 \mathrm{MHz}$

(= first eluting enantionmer, absolute configuration not known)<smiles>Cc1ccccc1CNC(=O)C(CC1CCCCC1)NC(=O)c1ccno1</smiles>

$\mathbf{8 b}=2^{\text {nd }}$ eluting enantiomer: shows the identical spectrum as $\mathbf{8 a}$, absolute configuration is not known

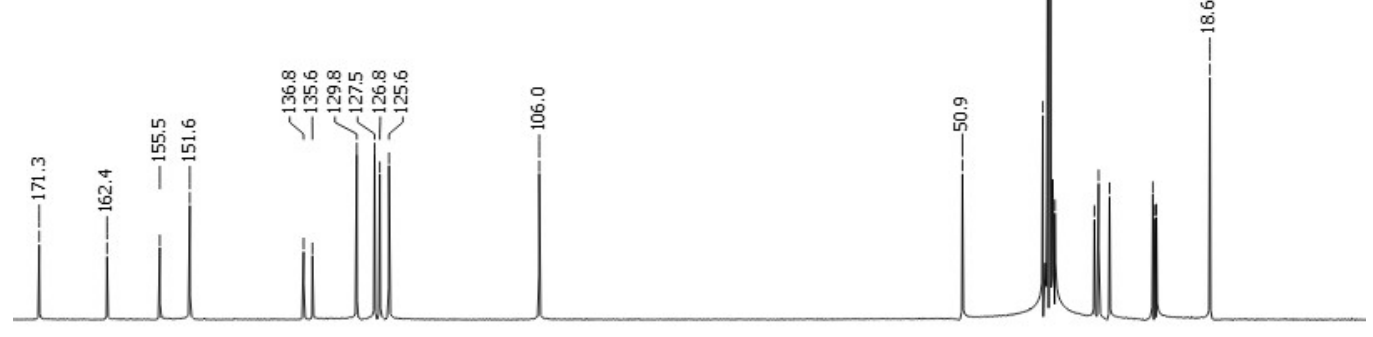


9, ${ }^{1} \mathrm{H}-\mathrm{NMR}, \mathrm{DMSO}-\mathrm{d}_{6}, 400 \mathrm{MHz}$<smiles>NC(=O)Cc1ccccc1CNC(=O)C(CC1CCCCC1)NC(=O)c1ccccc1</smiles>

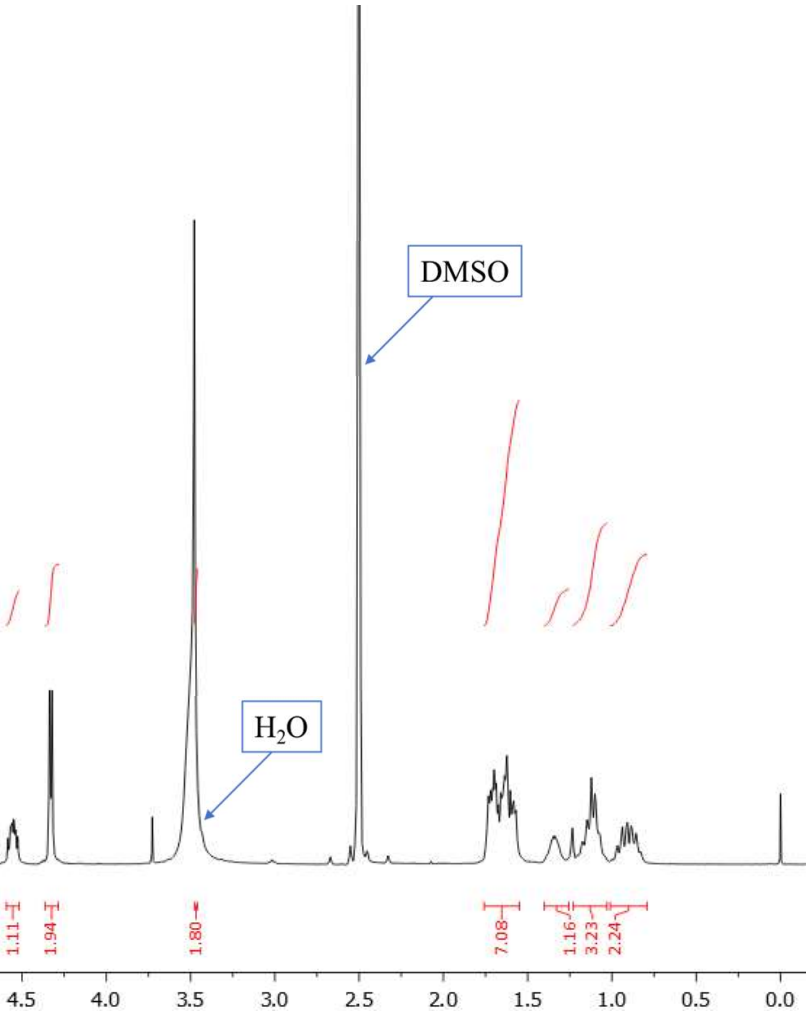

9, ${ }^{13} \mathrm{C}-\mathrm{NMR}, \mathrm{DMSO}-\mathrm{d}_{6}, 101 \mathrm{MHz}$<smiles>NC(=O)Cc1ccccc1CNC(=O)C(CC1CCCCC1)NC(=O)c1ccccc1</smiles>

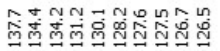

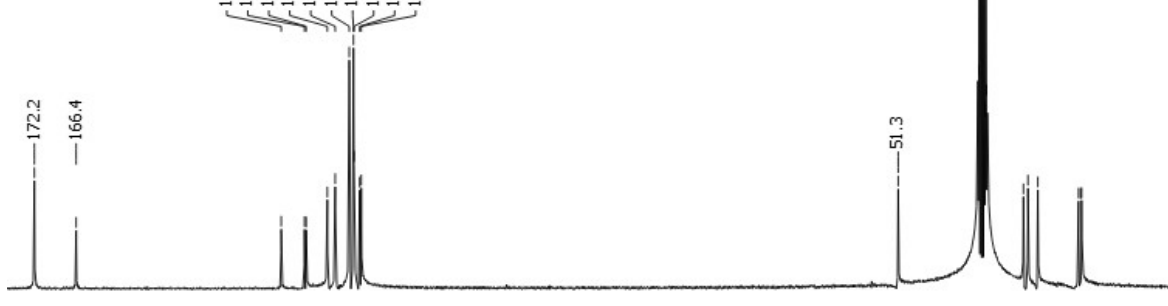

170
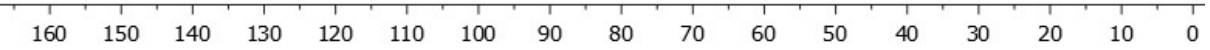
10a, ${ }^{1} \mathrm{H}-\mathrm{NMR}, \mathrm{DMSO}-\mathrm{d}_{6}, 400 \mathrm{MHz}$

$\left(=1^{\text {st }}\right.$ eluting diastereomer, absolute configuration not known)<smiles>NC(=O)CC1CCCCC1CNC(=O)C(CC1CCCCC1)NC(=O)c1ccno1</smiles>

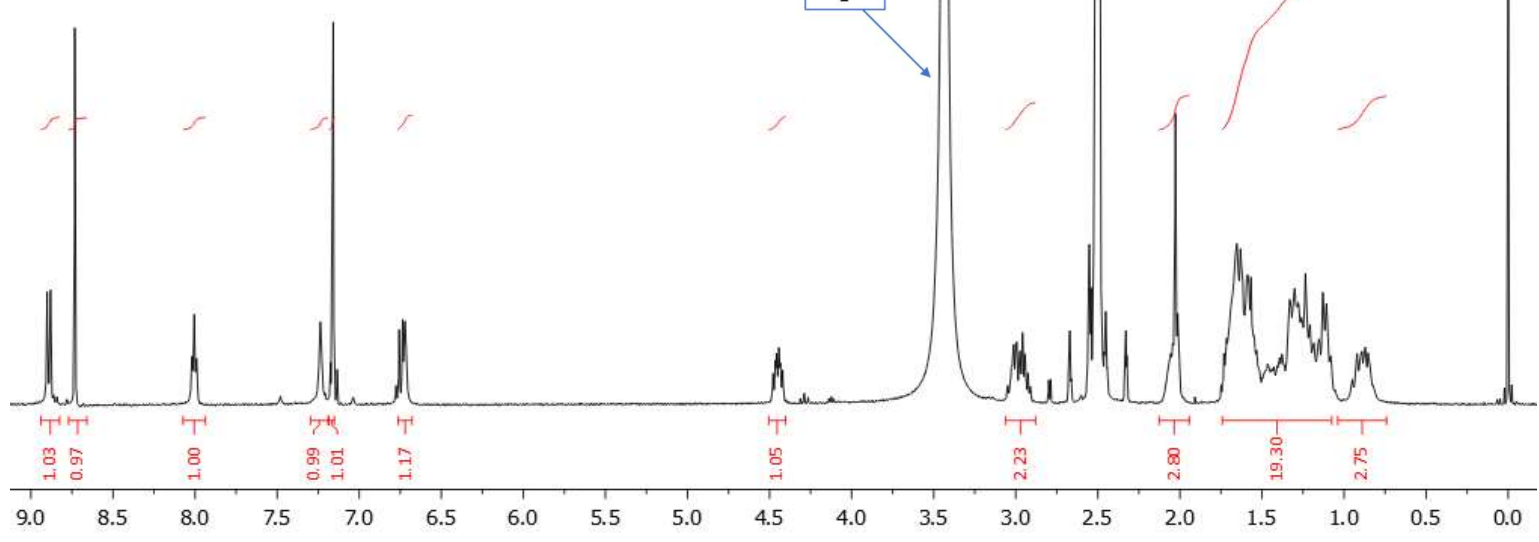

10a, ${ }^{13} \mathrm{C}-\mathrm{NMR}, \mathrm{DMSO}-\mathrm{d}_{6}, 151 \mathrm{MHz}$

$\left(=1^{\text {st }}\right.$ eluting diastereomer, absolute configuration not known $)$<smiles>NC(=O)C[C]1CCCC[C]1CNC(=O)[C@H](CC1CCCCC1)NC(=O)c1ccno1</smiles>

DMSO

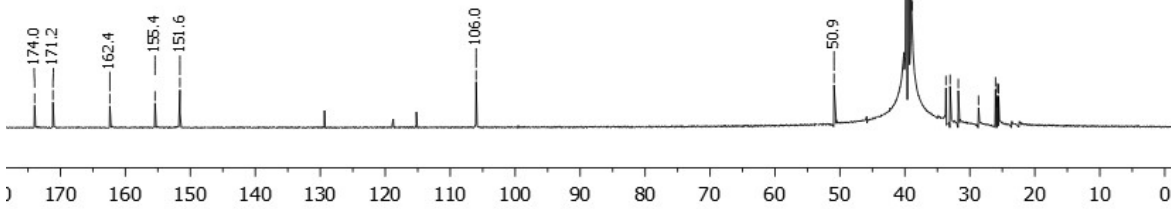


10b, ${ }^{1} \mathrm{H}-\mathrm{NMR}, \mathrm{DMSO}-\mathrm{d}_{6}, 400 \mathrm{MHz}$

(=2nd eluting diastereomer, absolute configuration not known)

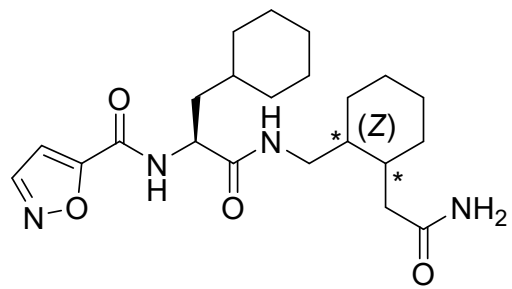

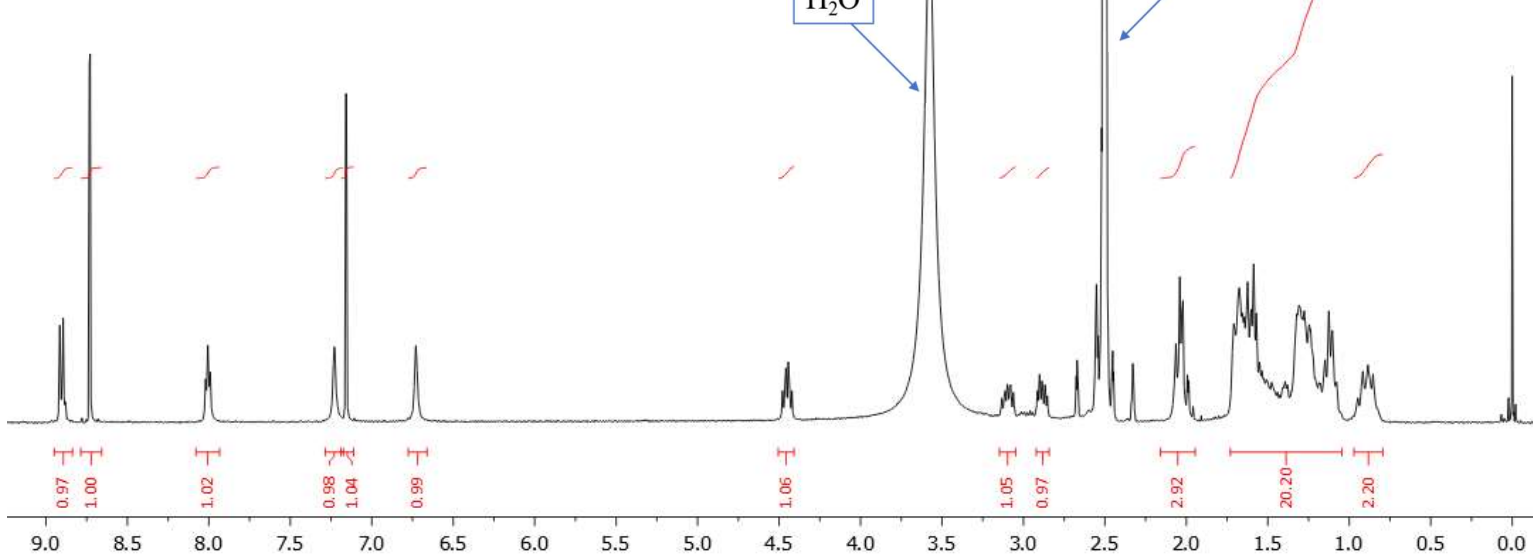

10b, ${ }^{13} \mathrm{C}-\mathrm{NMR}, \mathrm{DMSO}-\mathrm{d}_{6}, 151 \mathrm{MHz}$

(=2nd eluting diastereomer, absolute configuration not known)<smiles>NC(=O)C[C]1[CH]CCCC1</smiles>

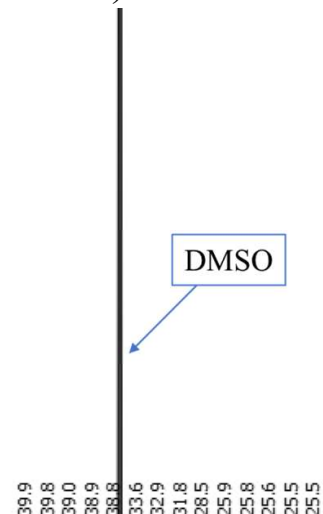

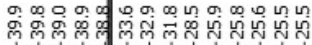

प11 12

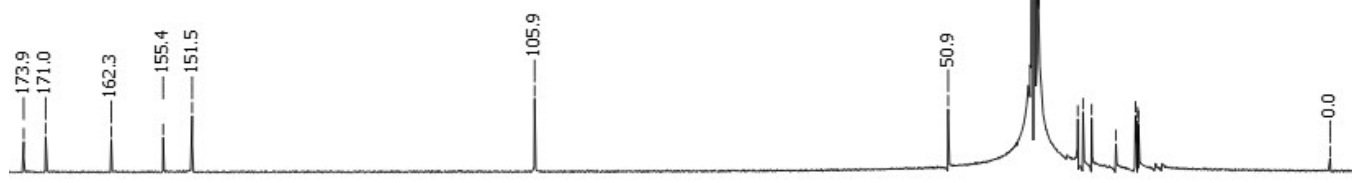

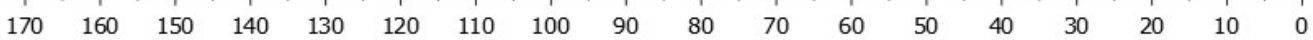


11, ${ }^{1} \mathrm{H}-\mathrm{NMR}, \mathrm{DMSO}-\mathrm{d}_{6}, 600 \mathrm{MHz}$

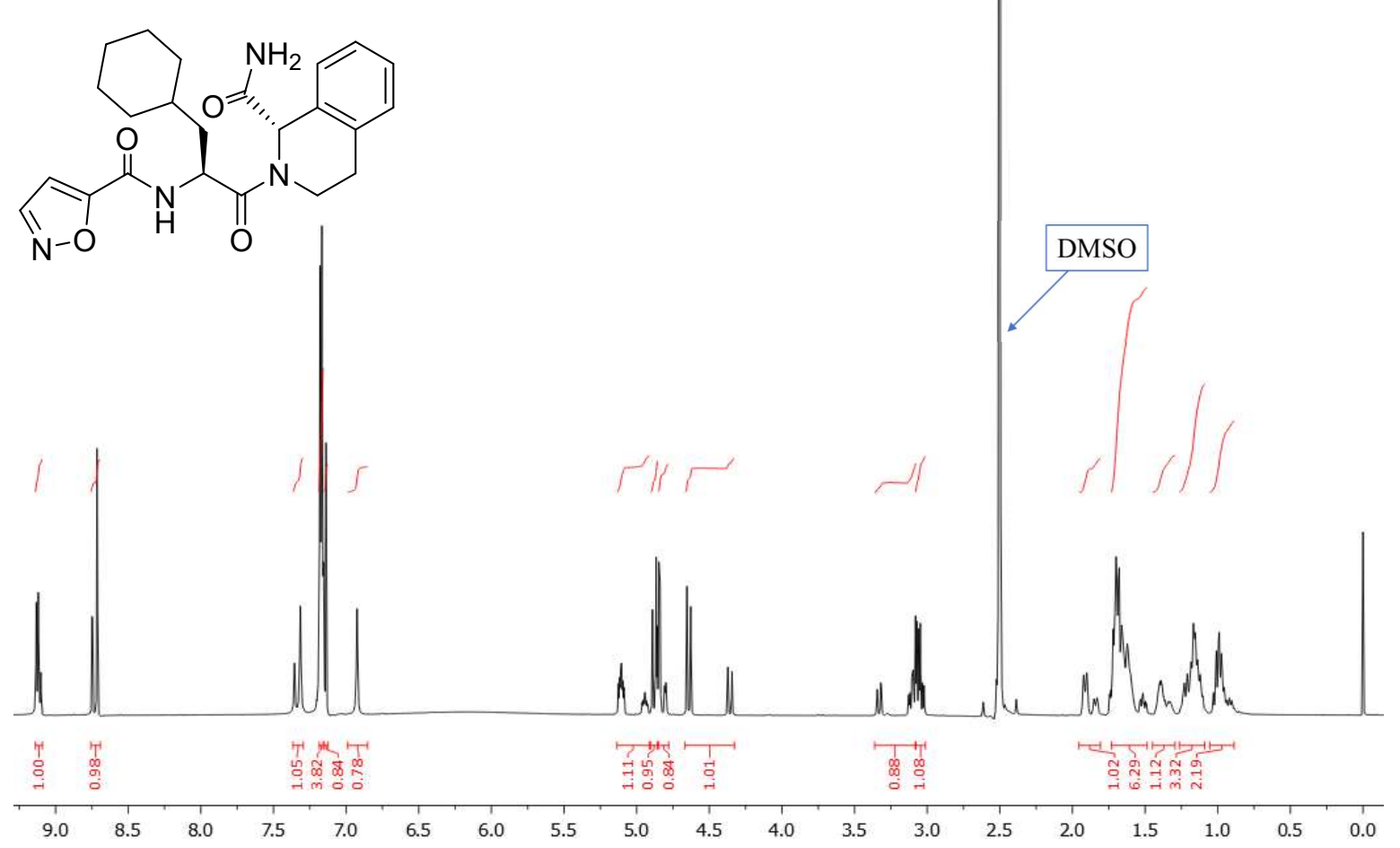

11, ${ }^{13} \mathrm{C}-\mathrm{NMR}$, DMSO-d $6,101 \mathrm{MHz}$

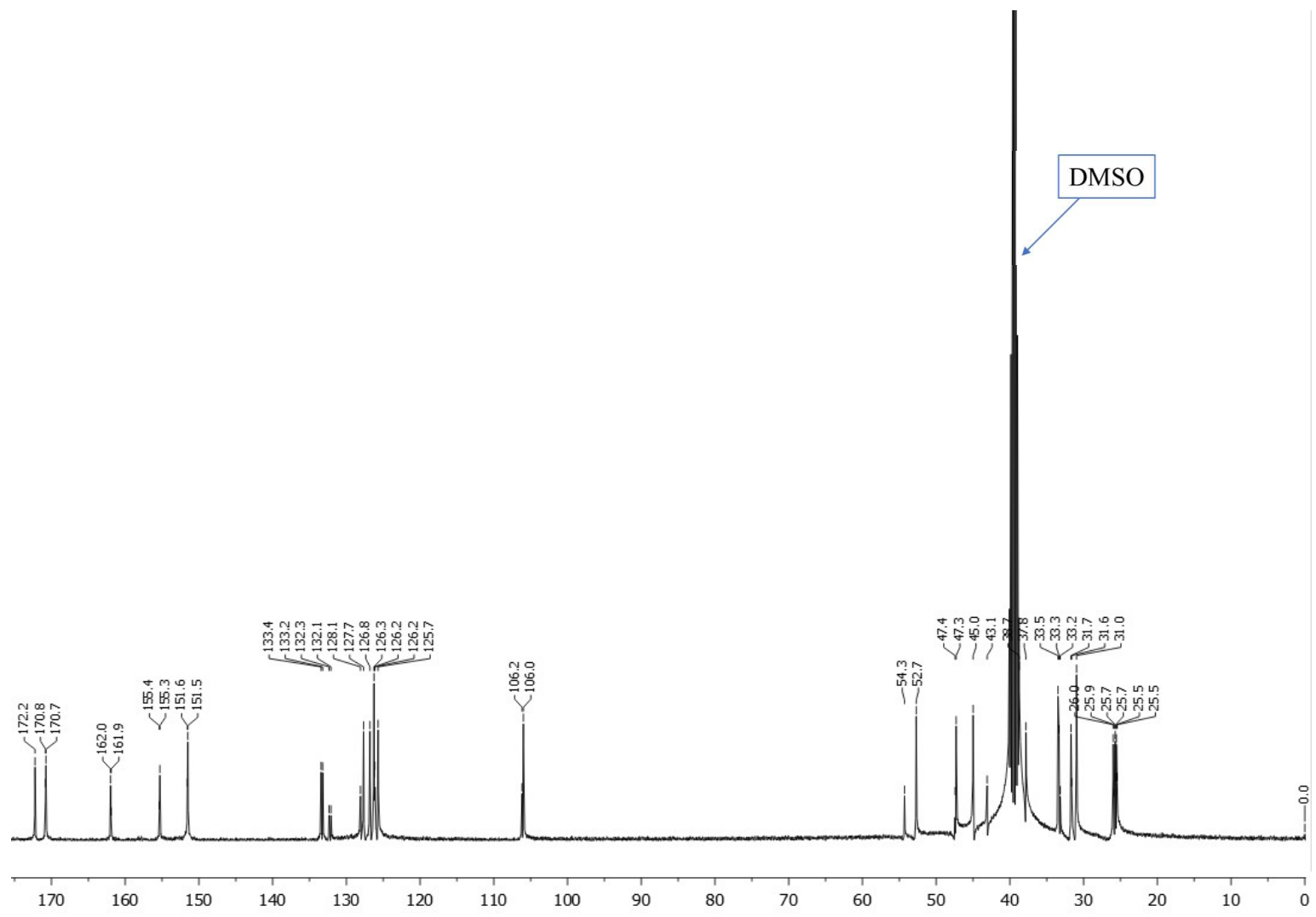


12a, ${ }^{1} \mathrm{H}-\mathrm{NMR}$, DMSO-d $6,400 \mathrm{MHz}$

$\left(=1^{\text {st }}\right.$ eluting diastereomer, absolute configuration not known)<smiles>NC(=O)C1=CN(C(=O)[C@H](CC2CCCCC2)NC(=O)c2ccno2)Cc2ccccc21</smiles>
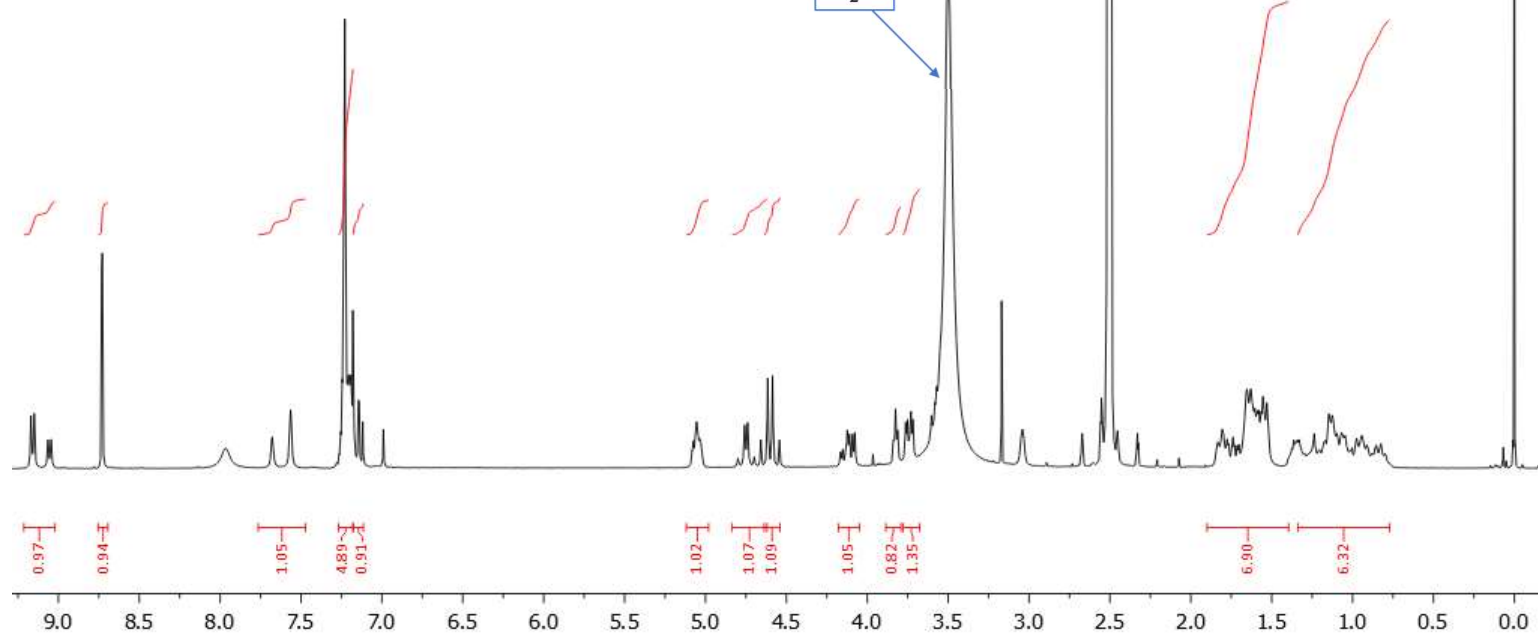

12a, ${ }^{13} \mathrm{C}-\mathrm{NMR}, \mathrm{DMSO}-\mathrm{d}_{6}, 151 \mathrm{MHz}$

$\left(=1^{\text {st }}\right.$ eluting diastereomer, absolute configuration not known)<smiles>NC(=O)C1=CN(C(=O)[C@H](CC2CCCCC2)NC(=O)c2ccno2)Cc2ccccc21</smiles>
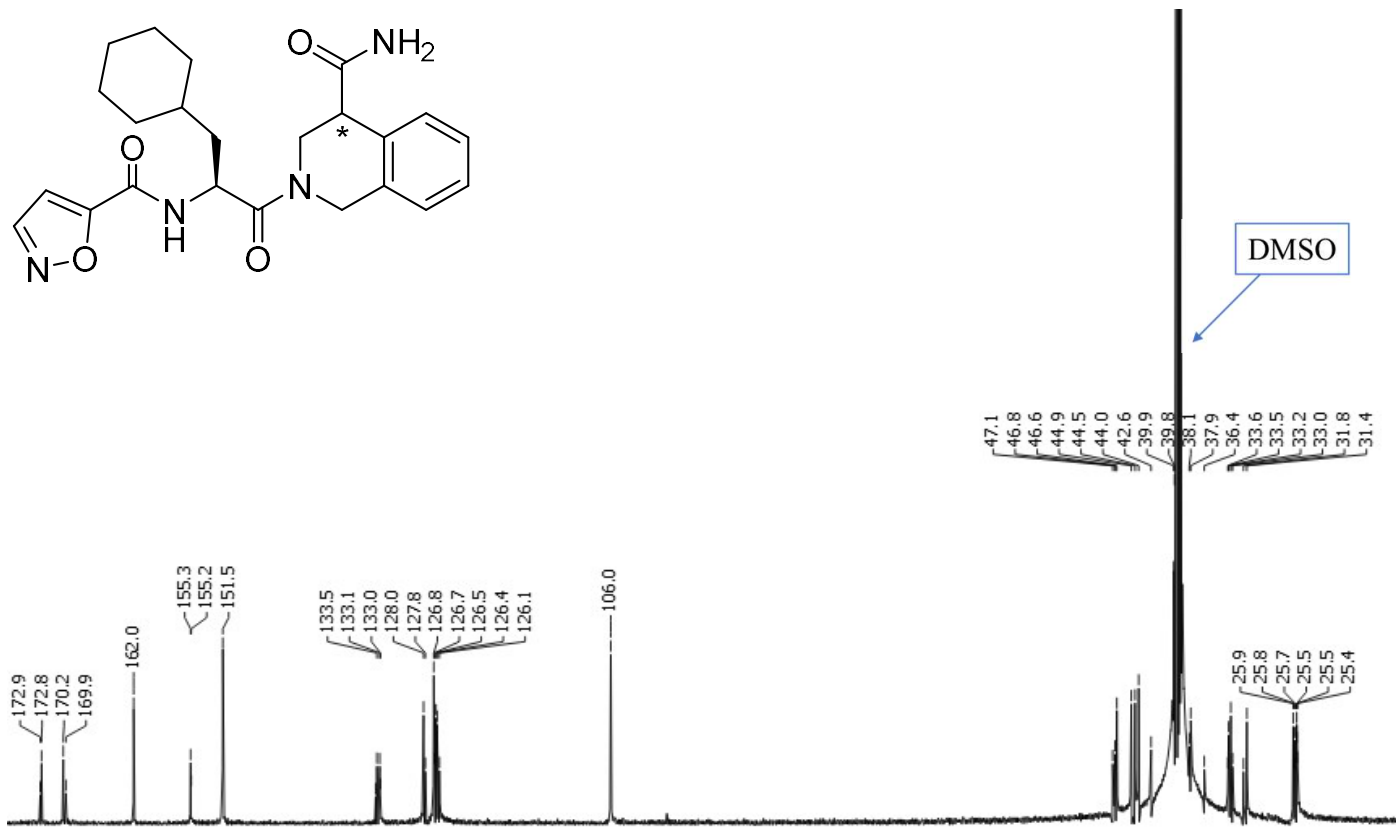

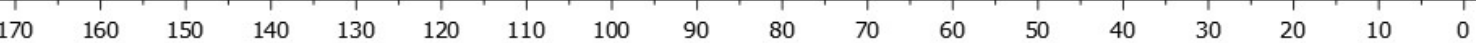


12b, ${ }^{1} \mathrm{H}-\mathrm{NMR}, \mathrm{DMSO}-\mathrm{d}_{6}, 400 \mathrm{MHz}$

(=2nd eluting diastereomer, absolute configuration not known)<smiles>NC(=O)C1=CN(C(=O)[C@H](CC2CCCCC2)NC(=O)c2ccno2)Cc2ccccc21</smiles>

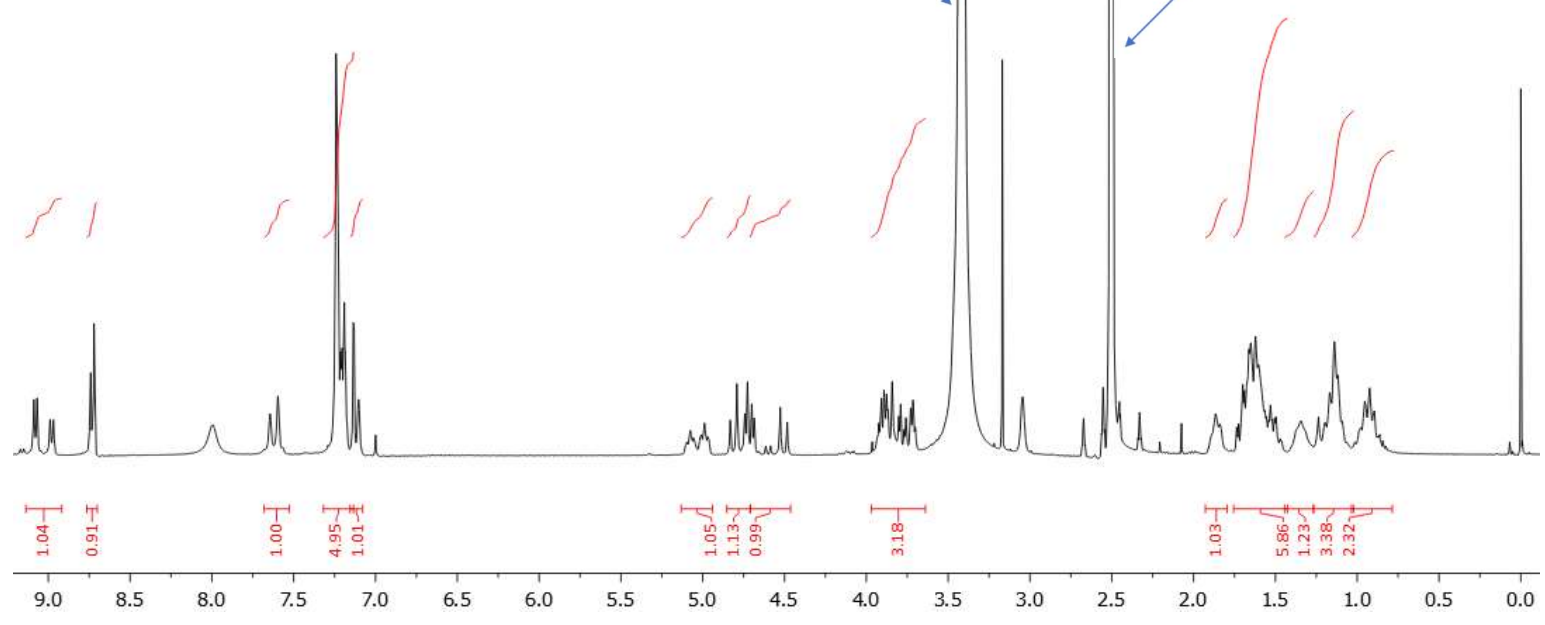

12b, ${ }^{13} \mathrm{C}-\mathrm{NMR}$, DMSO-d $6,151 \mathrm{MHz}$

$\left(=2^{\text {nd }}\right.$ eluting diastereomer, absolute configuration not known)<smiles>NC(=O)C1=CN(C(=O)[C@H](CC2CCCCC2)NC(=O)c2ccno2)Cc2ccccc21</smiles>

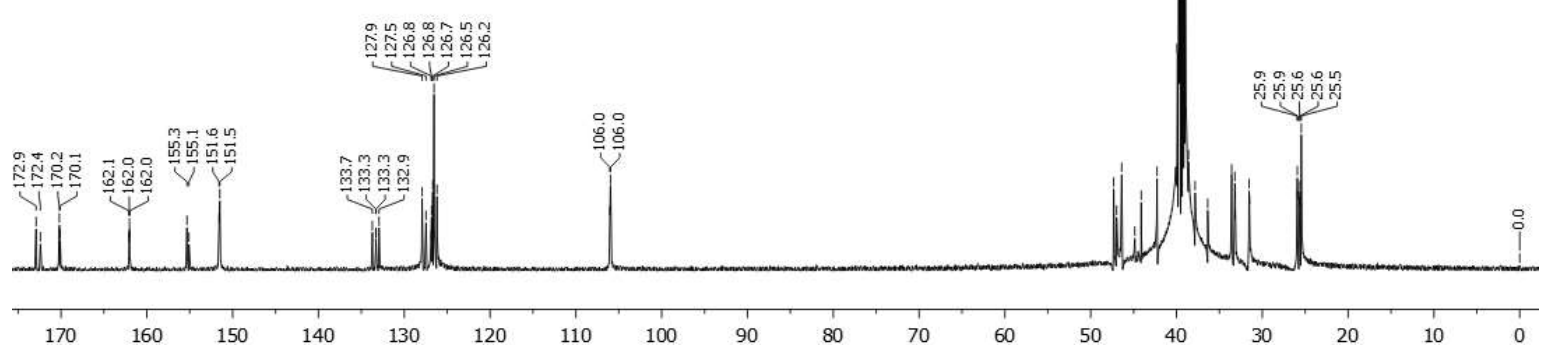


13, ${ }^{1} \mathrm{H}-\mathrm{NMR}$, DMSO-d 6 , $400 \mathrm{MHz}$

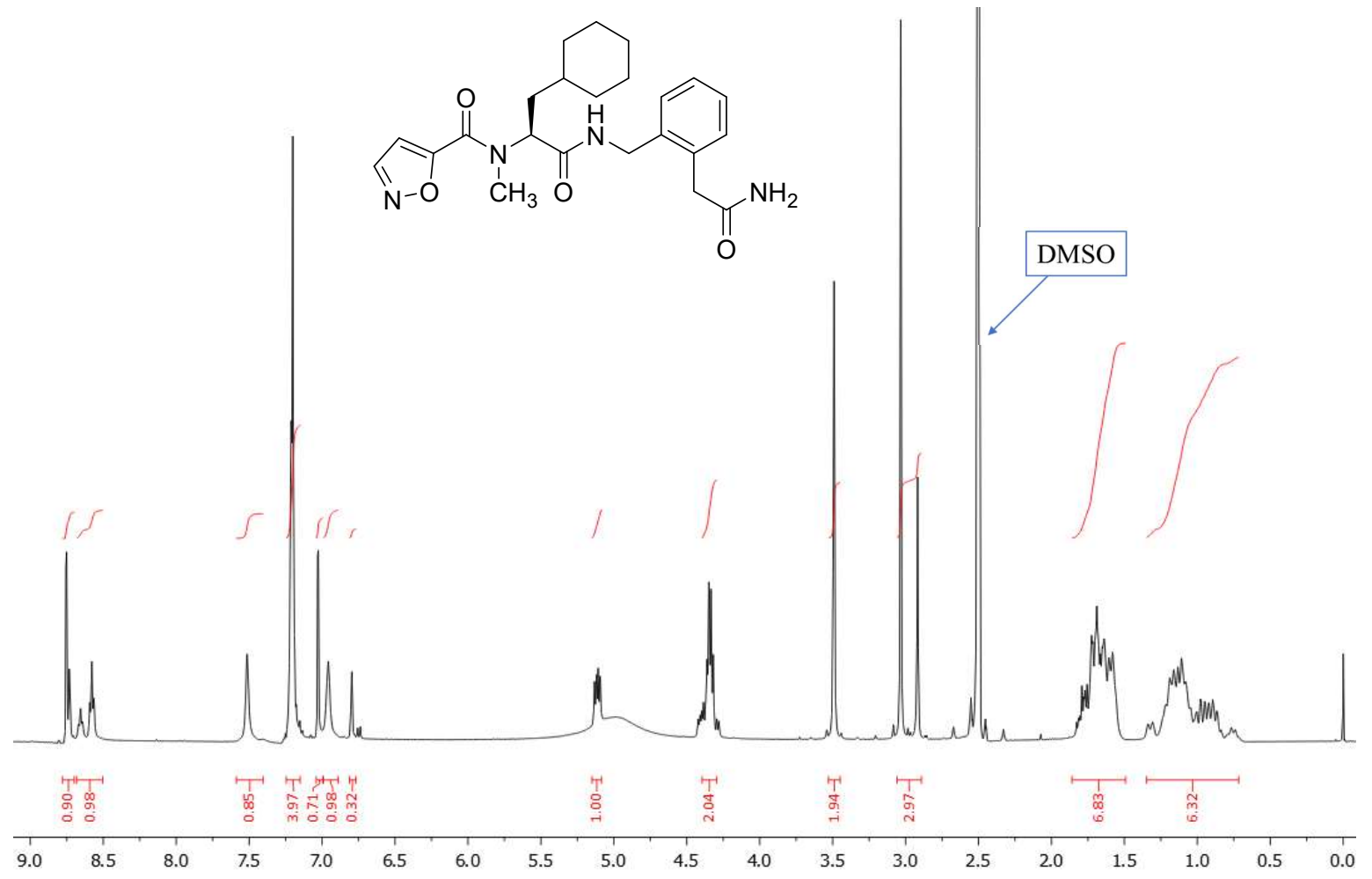

13, ${ }^{13} \mathrm{C}-\mathrm{NMR}$, DMSO-d $6,101 \mathrm{MHz}$

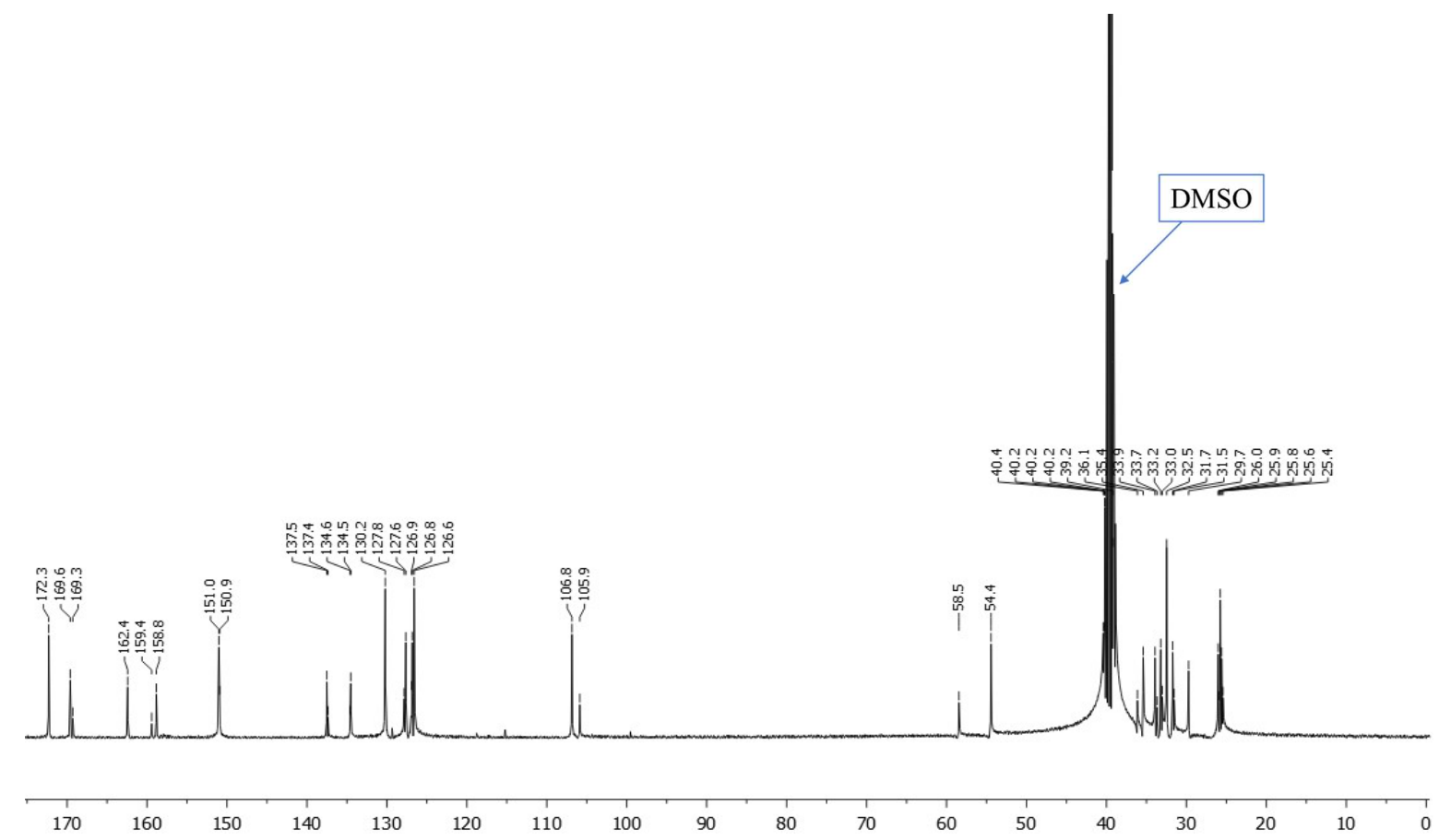


Supplementary Data. HPLC traces of the key compounds.

4b, HPLC system $1, \lambda=254 \mathrm{~nm}$

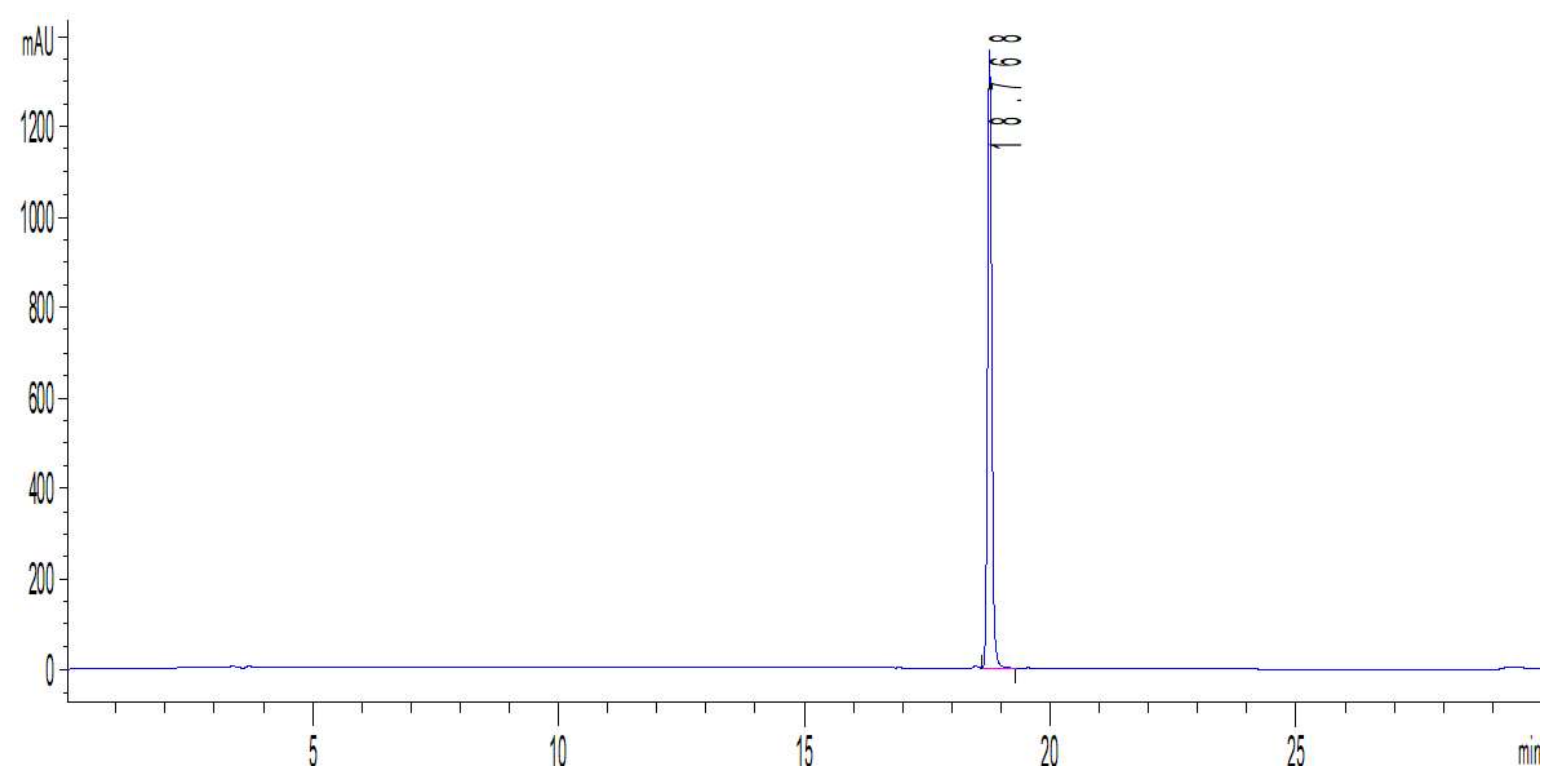

5a, HPLC system $2, \lambda=254 \mathrm{~nm}$

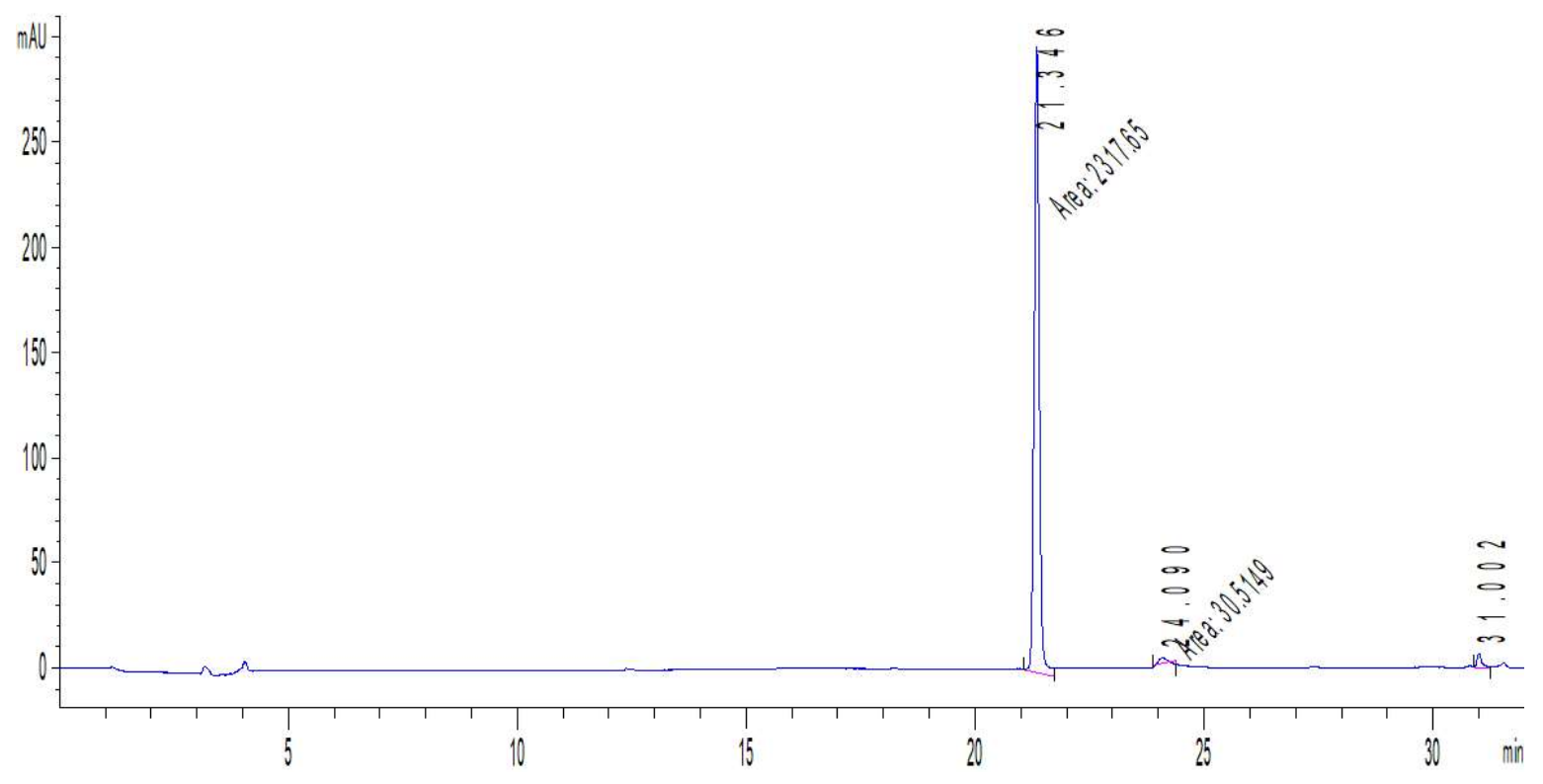


5b, HPLC system $2, \lambda=254 \mathrm{~nm}$

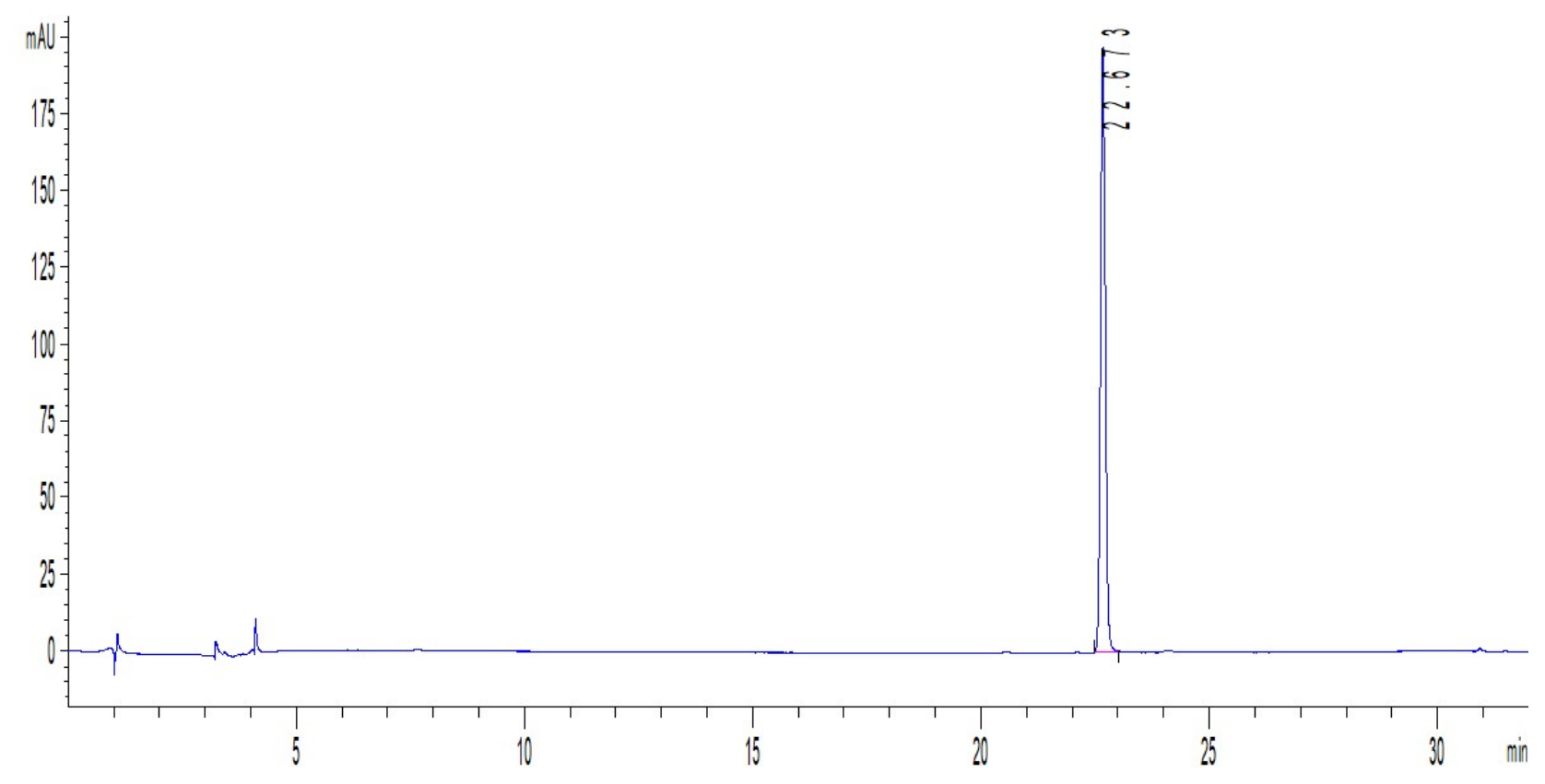

6, HPLC system $1, \lambda=254 \mathrm{~nm}$

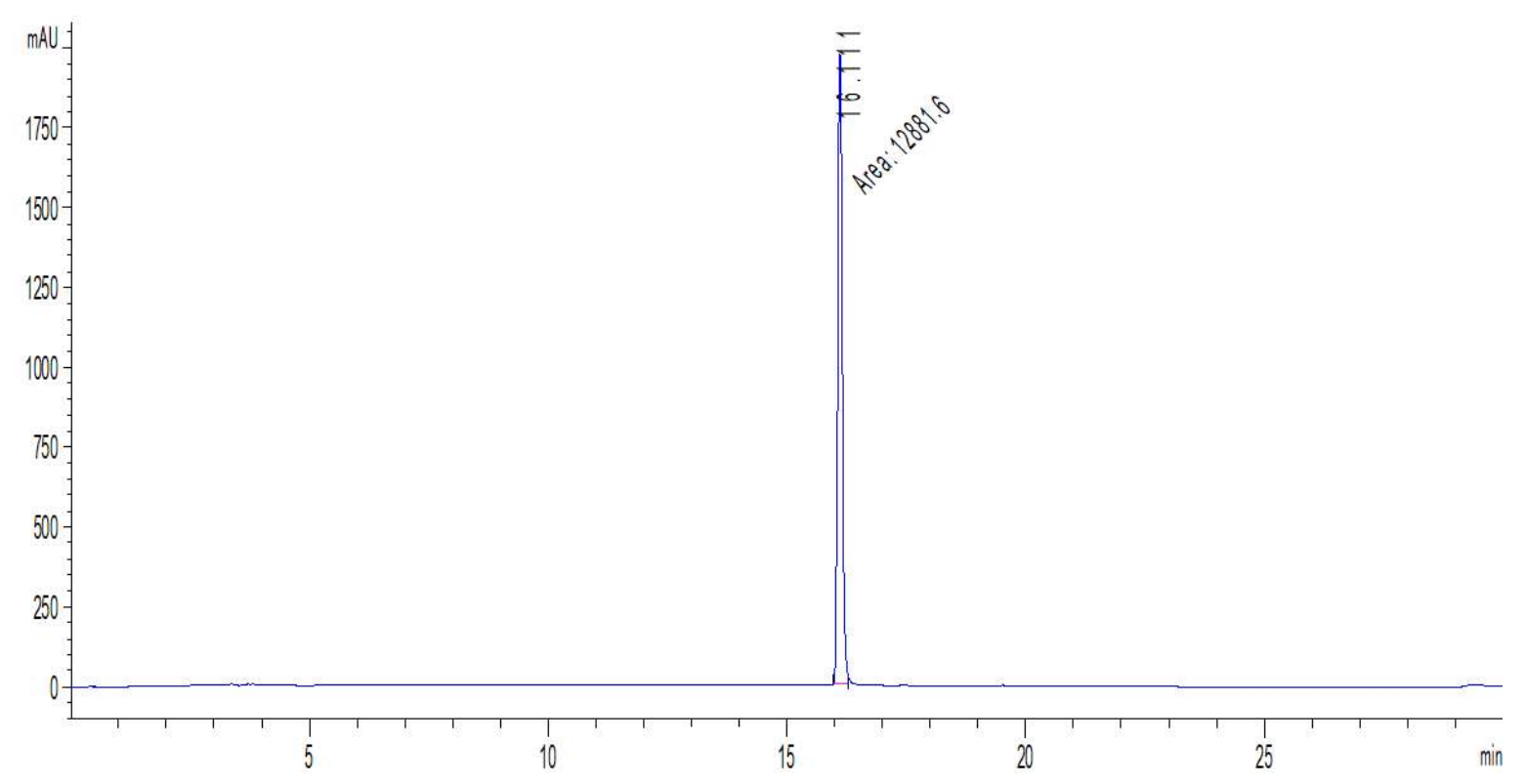


7, HPLC system $1, \lambda=254 \mathrm{~nm}$

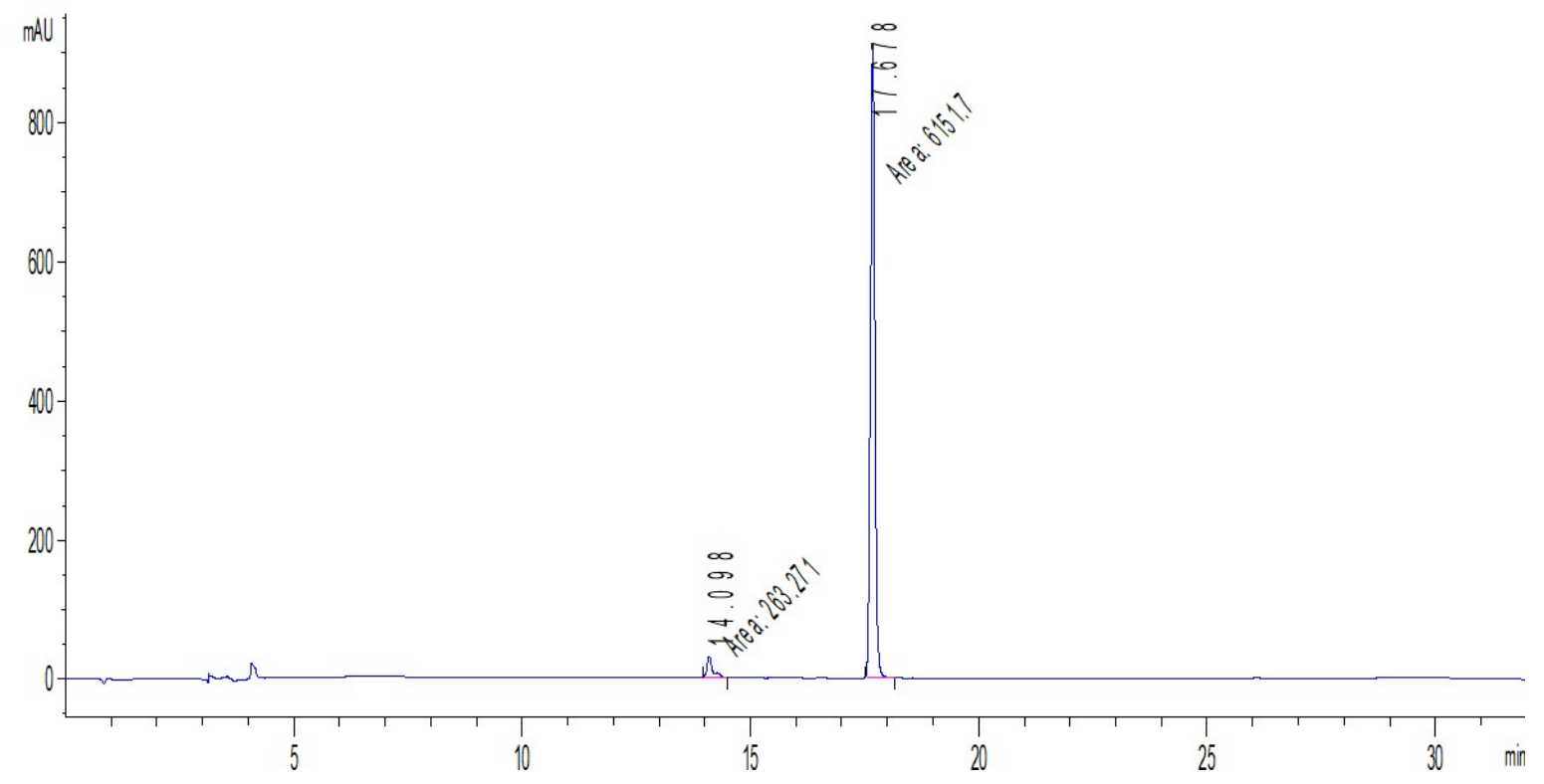

8a/8b, chiral HPLC, hexane/isopropanol $+0,1 \%$ EDA, $\lambda=254 \mathrm{~nm}$

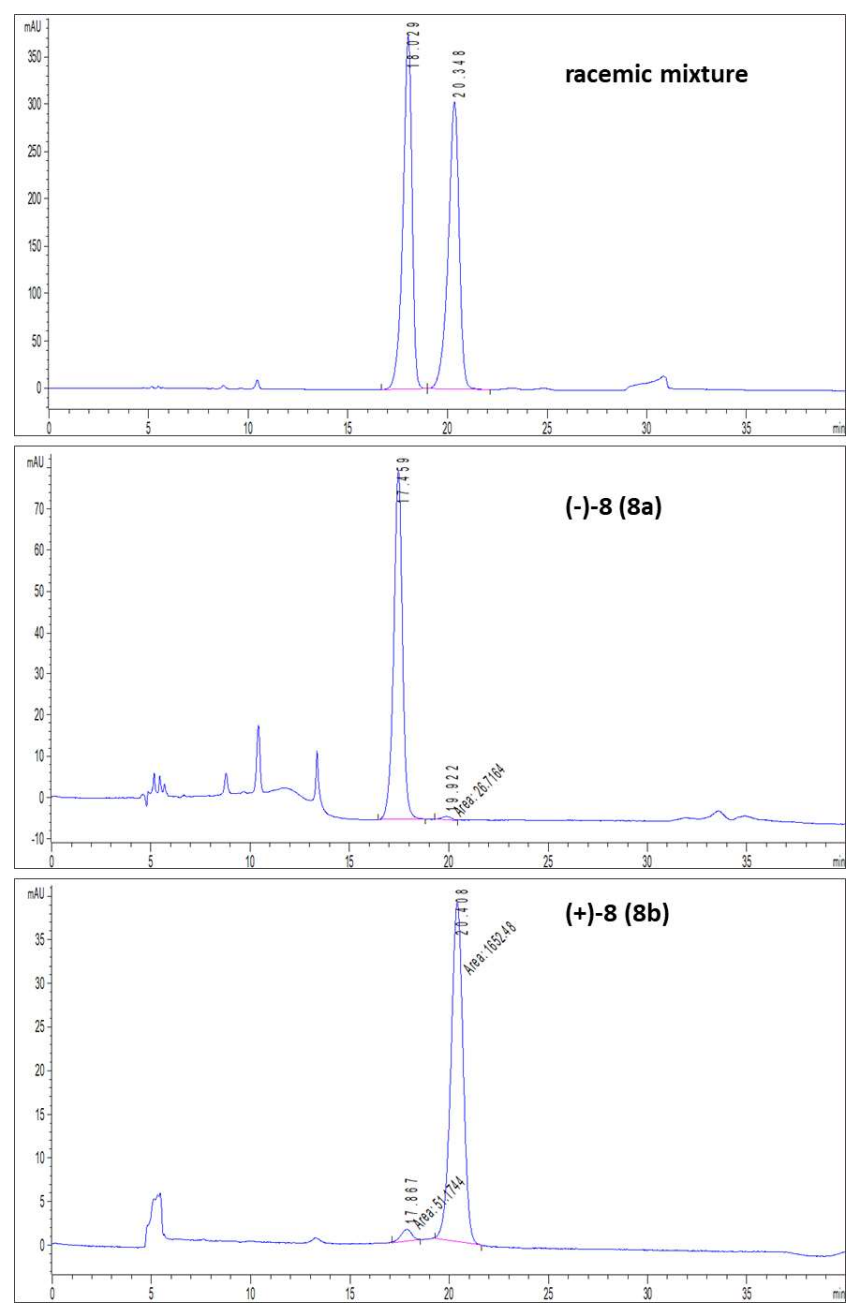


$\mathbf{8 a} / \mathbf{8 b}$, HPLC system $1, \lambda=254 \mathrm{~nm}$

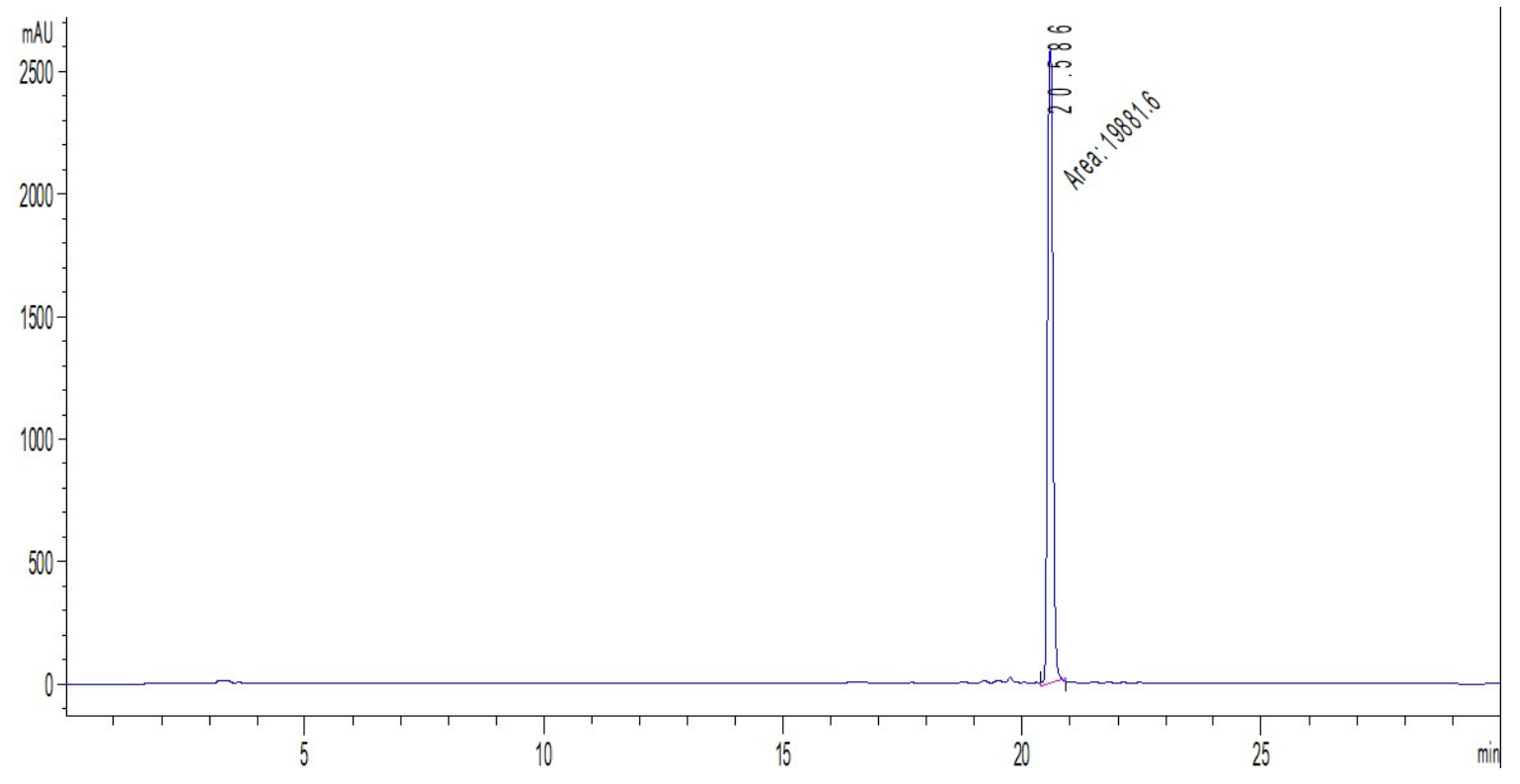

9, HPLC system $2, \lambda=254 \mathrm{~nm}$

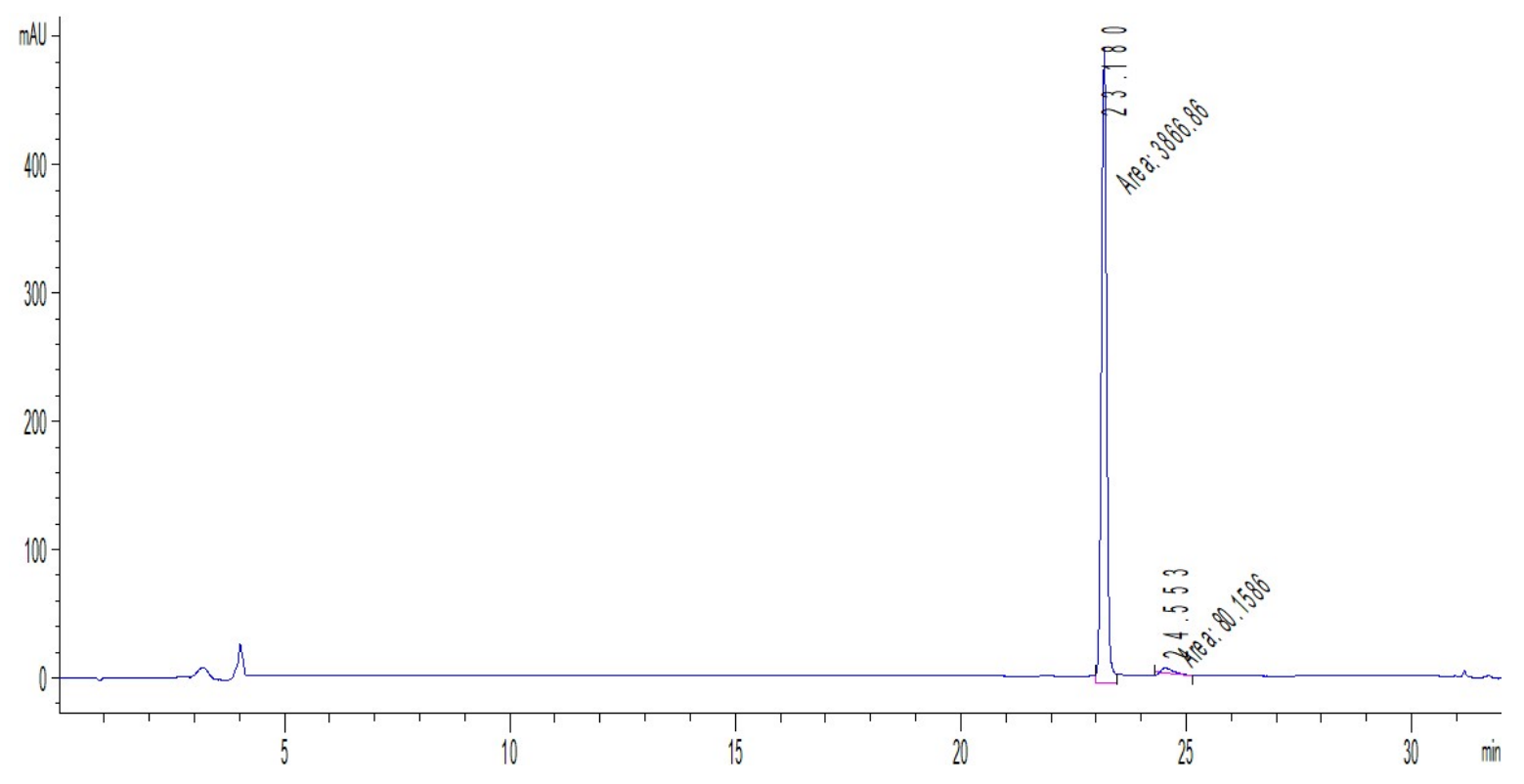


10a, HPLC system $2, \lambda=254 \mathrm{~nm}$

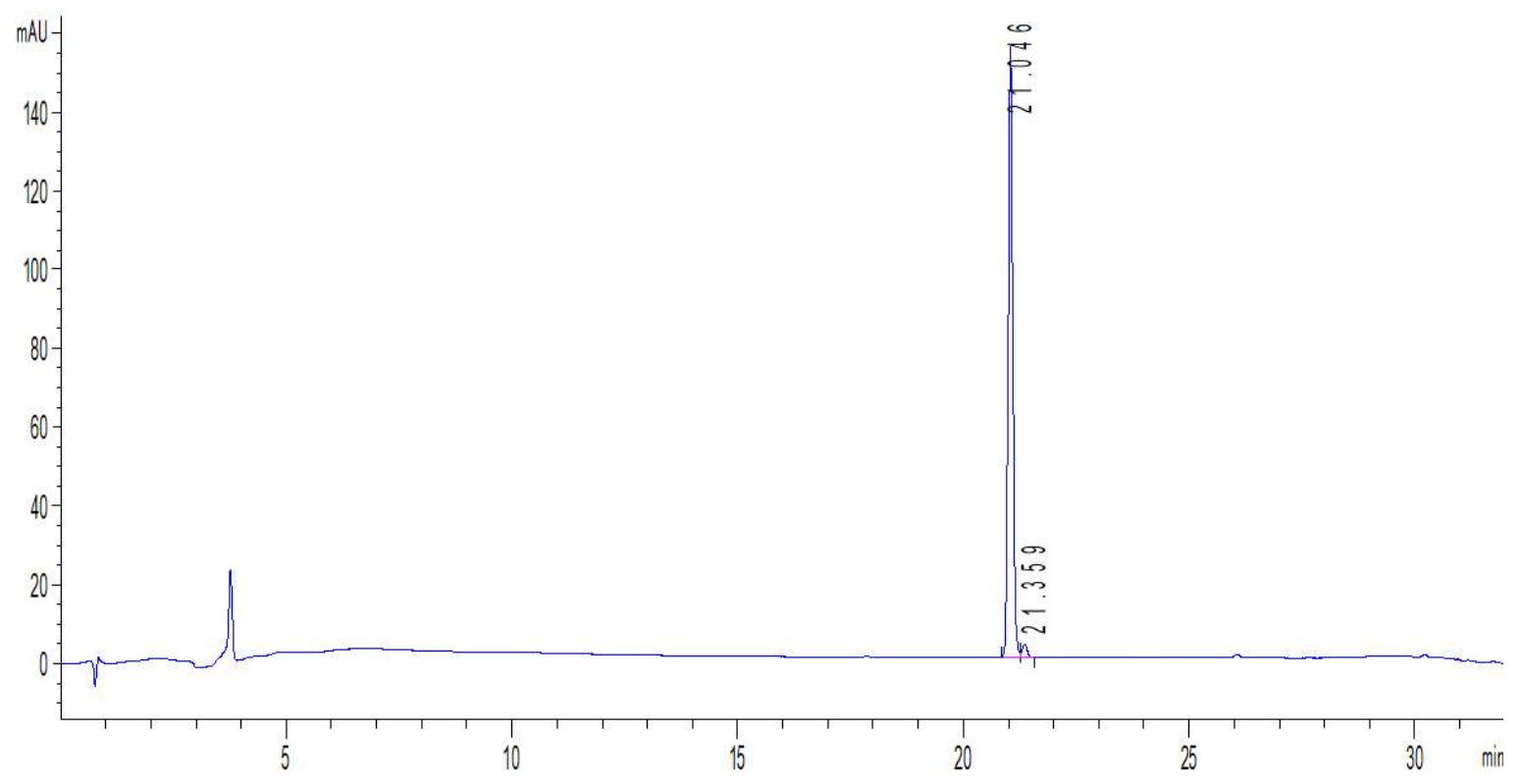

10b, HPLC system $2, \lambda=254 \mathrm{~nm}$

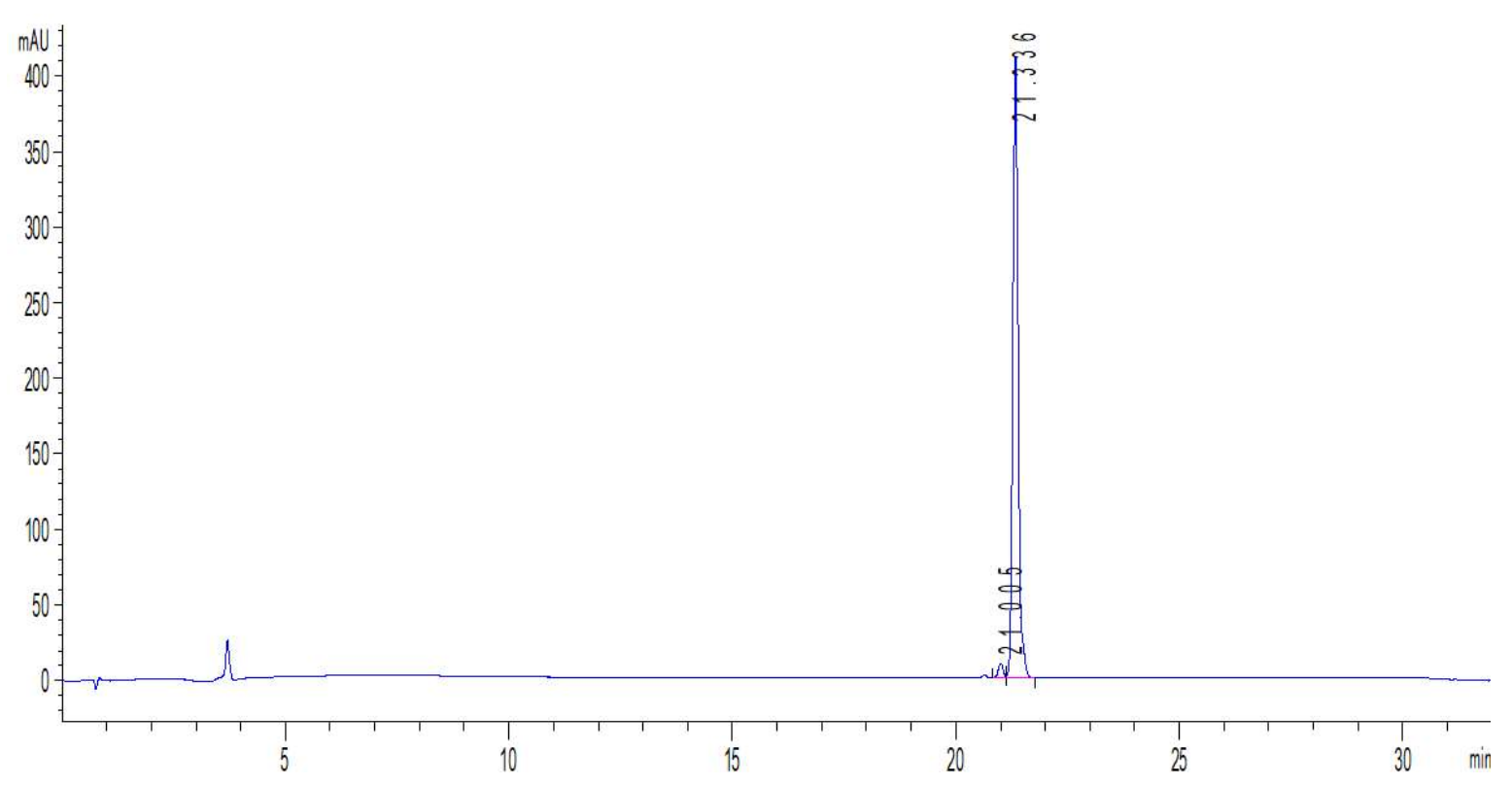


11, HPLC system $1, \lambda=254 \mathrm{~nm}$

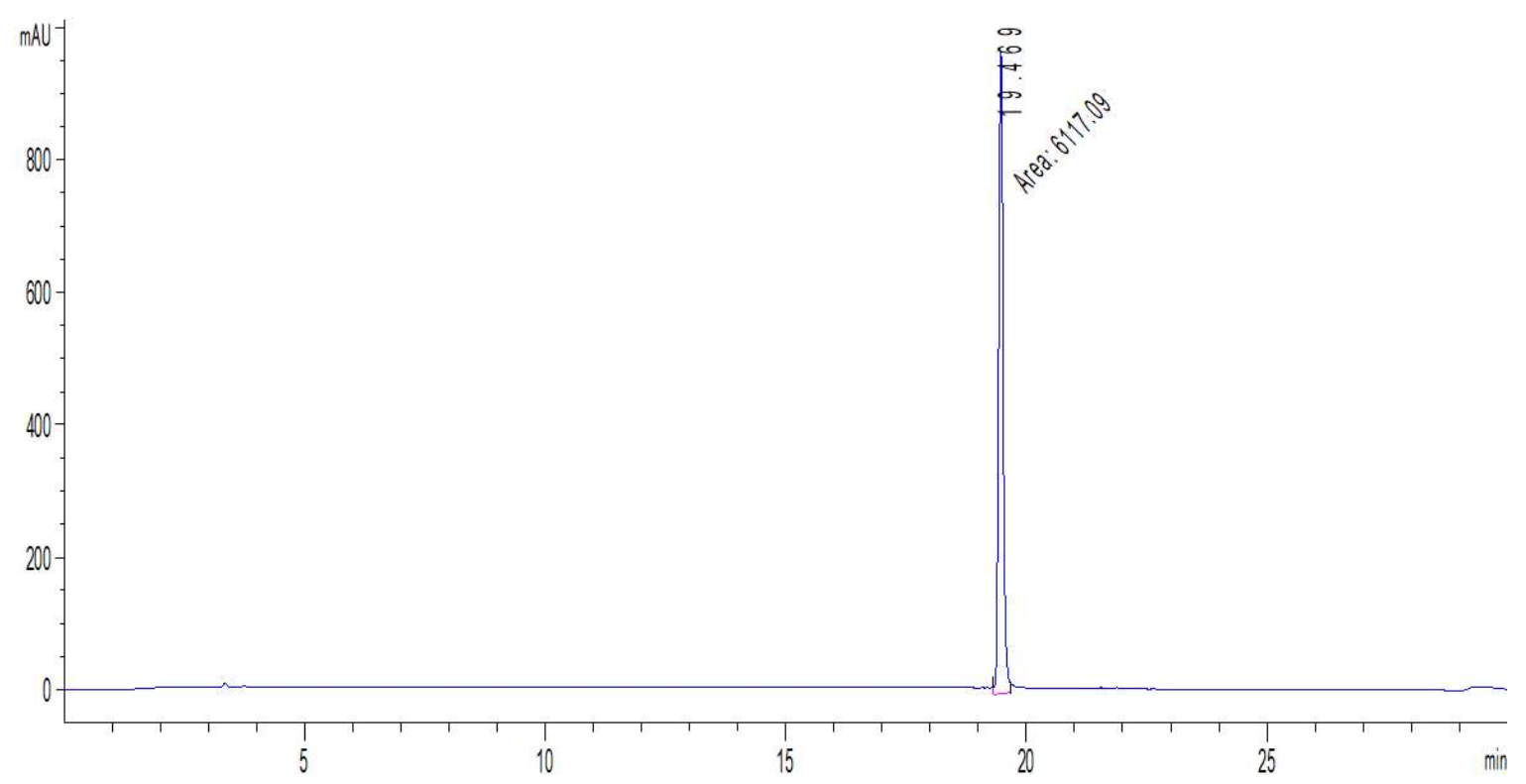

12a, HPLC system $2, \lambda=254 \mathrm{~nm}$

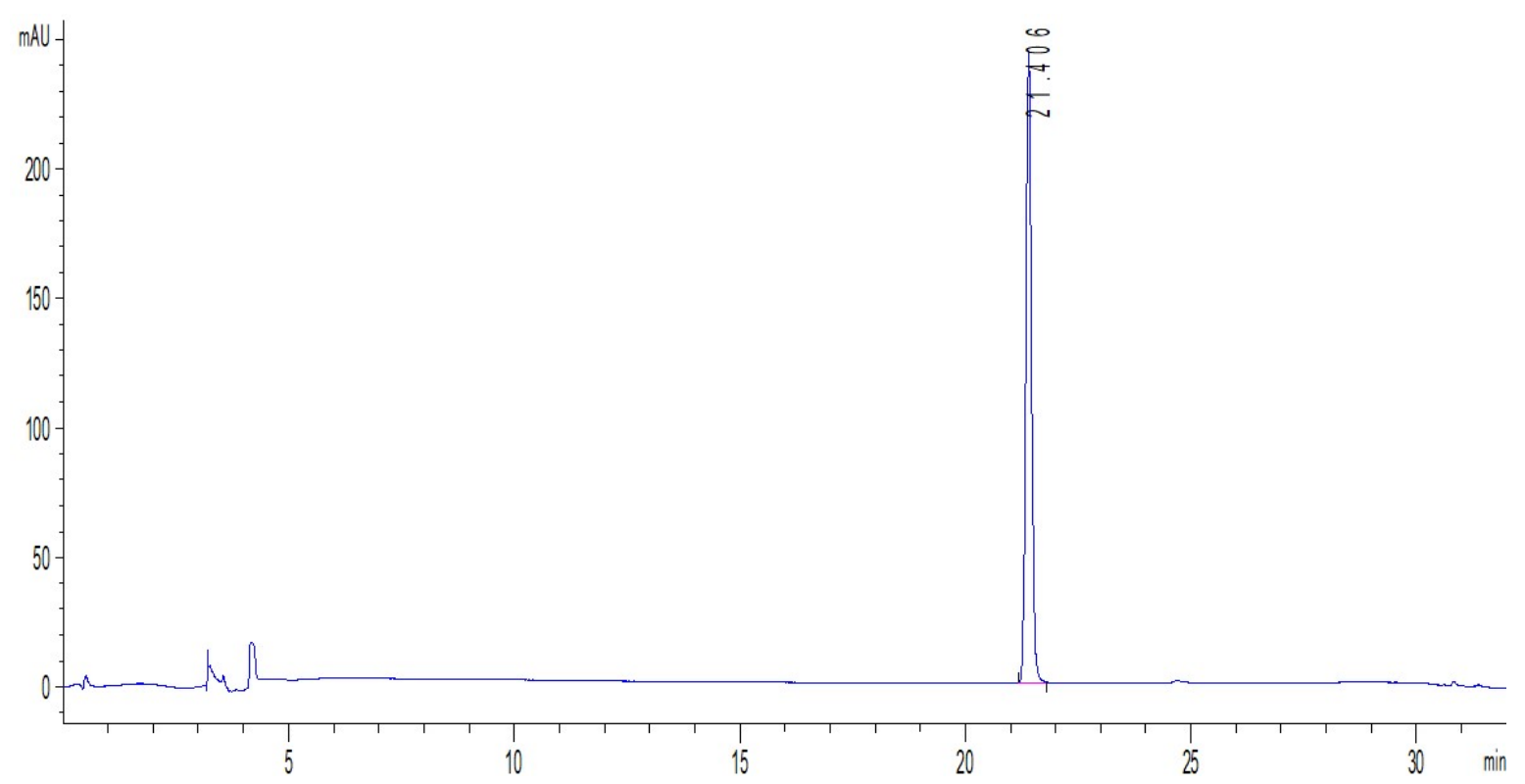


12b, HPLC system $2, \lambda=254 \mathrm{~nm}$

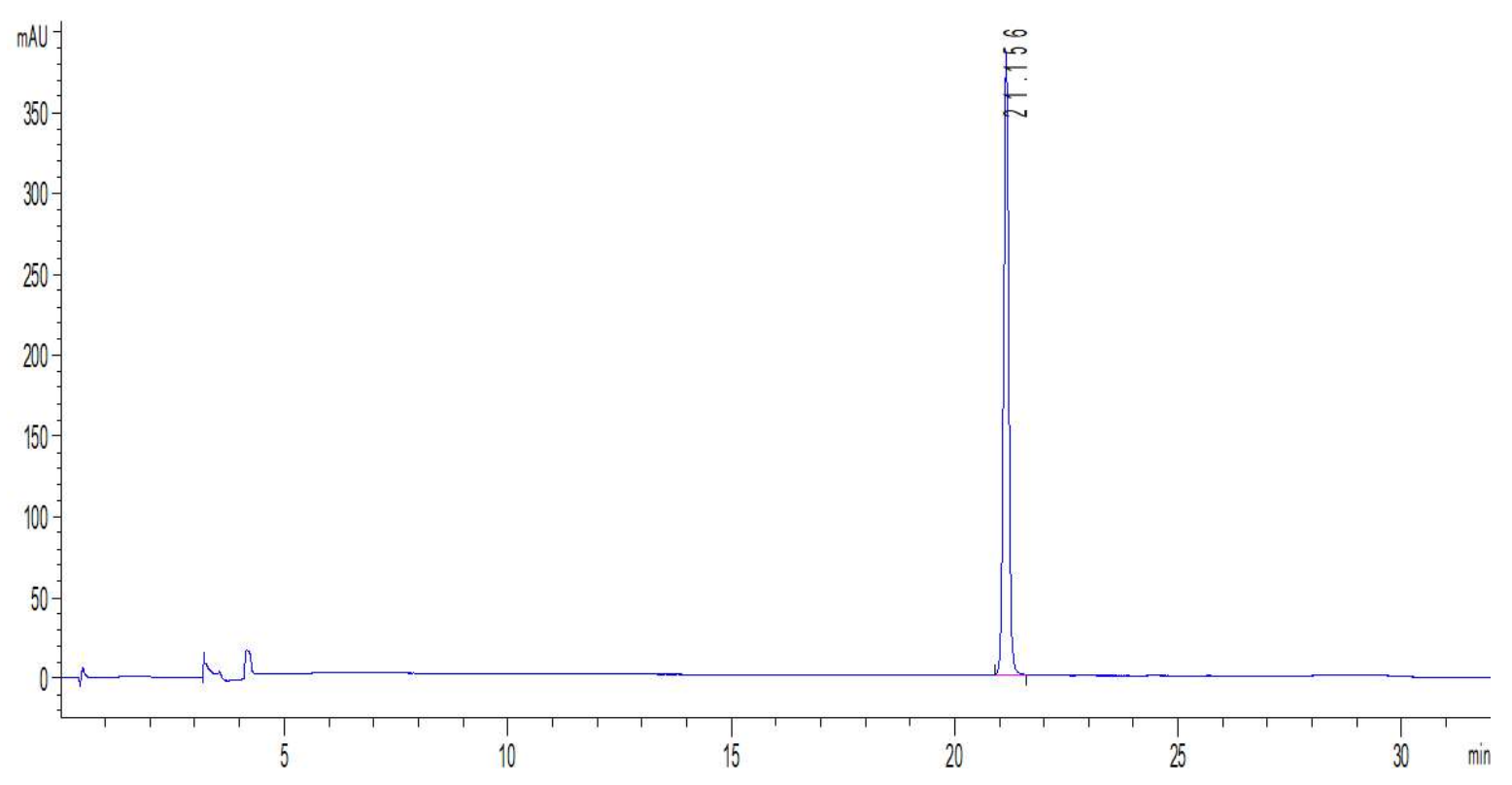

13, HPLC system $1, \lambda=254 \mathrm{~nm}$

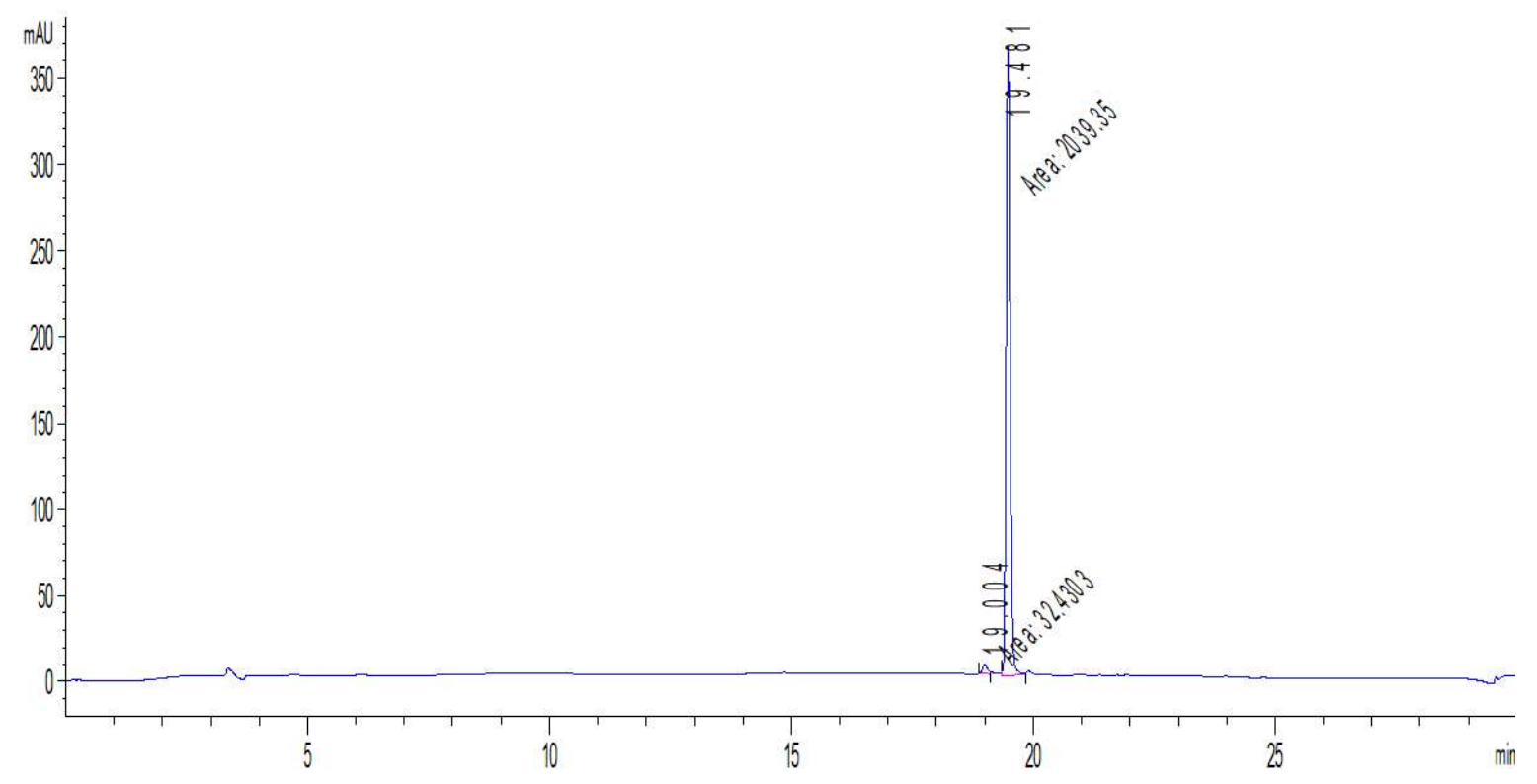




\section{Supplementary References.}

1. Zhang, C.; Srinivasan, Y.; Arlow, D. H.; Fung, J. J.; Palmer, D.; Zheng, Y.; Green, H. F.; Pandey, A.; Dror, R. O.; Shaw, D. E.; Weis, W. I.; Coughlin, S. R.; Kobilka, B. K. High-Resolution Crystal Structure of Human Protease-Activated Receptor 1. Nature 2012, 492, 387-392.

2. Cheng, R. K. Y.; Fiez-Vandal, C.; Schlenker, O.; Edman, K.; Aggeler, B.; Brown, D. G.; Brown, G. A.; Cooke, R. M.; Dumelin, C. E.; Dore, A. S.; Geschwindner, S.; Grebner, C.; Hermansson, N. O.; Jazayeri, A.; Johansson, P.; Leong, L.; Prihandoko, R.; Rappas, M.; Soutter, H.; Snijder, A.; Sundstrom, L.; Tehan, B.; Thornton, P.; Troast, D.; Wiggin, G.; Zhukov, A.; Marshall, F. H.; Dekker, N. Structural Insight into Allosteric Modulation of Protease-Activated receptor 2. Nature 2017, 545, 112-115.

3. Kennedy, A. J.; Ballante, F.; Johansson, J. R.; Milligan, G.; Sundström, L.; Nordqvist, A.; Carlsson, J. Structural Characterization of Agonist Binding to Protease-Activated Receptor 2 Through Mutagenesis and Computational Modeling. ACS Pharmacol. Transl. Sci. 2018, 1, 119-133.

4. Maschauer, S.; Einsiedel, J.; Huebner, H.; Gmeiner, P.; Prante, O. 18F- and 68Ga-Labeled Neurotensin Peptides for PET Imaging of Neurotensin Receptor 1. J. Med. Chem. 2016, 59, 6480-6492.

5. McGuire, J. J.; Saifeddine, M.; Triggle, C. R.; Sun, K.; Hollenberg, M. D. 2-Furoyl-LIGRLO-Amide: A Potent and Selective Proteinase-Activated Receptor 2 Agonist. J. Pharmacol. Exp. Ther. 2004, 309, 11241131.

6. Yau, M. K.; Suen, J. Y.; Xu, W.; Lim, J.; Liu, L.; Adams, M. N.; He, Y.; Hooper, J. D.; Reid, R. C.; Fairlie, D. P. Potent Small Agonists of Protease Activated Receptor 2. ACS Med. Chem. Lett. 2016, 7, 105-110.

7. Behnam, M. A. M.; Nitsche, C.; Vechi, S. M.; Klein, C. D. C-Terminal Residue Optimization and Fragment Merging: Discovery of a Potent Peptide-Hybrid Inhibitor of Dengue Protease. ACS Med. Chem. Lett. 2014, 5, 1037-1042.

8. Ager, D. J.; Prakash, I. Reductions of Aromatic Amino Acids and Derivatives. Org. Process Res. Dev. 2003, 7, 164-167.

9. Zhang, S.; Govender, T.; Norstroem, T.; Arvidsson, P. I. An Improved Synthesis of Fmoc-N-Methyl- $\alpha-$ Amino Acids. J. Org. Chem. 2005, 70, 6918-6920.

10. Maennel, B.; Dengler, D.; Shonberg, J.; Huebner, H.; Moeller, D.; Gmeiner, P. Hydroxy-Substituted heteroarylpiperazines: Novel Scaffolds for $\beta$-Arrestin-Biased D2R Agonists. J. Med. Chem. 2017, 60, 4693-4713.

11. Strober, W. Trypan Blue Exclusion Test of Cell Viability. Curr. Protoc. Immunol. 1997, 21, A.3B.1A.3B.2.

12. Baell, J. B.; Holloway, G. A. New Substructure Filters for Removal of Pan Assay Interference Compounds (PAINS) from Screening Libraries and for Their Exclusion in Bioassays. J. Med. Chem. 2010, 53, 27192740 . 
13. Sterling, T.; Irwin, J. J. ZINC 15 - Ligand Discovery for Everyone. J. Chem. Inf. Model. 2015, 55, 23242337.

14. Anandakrishnan, R.; Aguilar, B.; Onufriev, A. V. H++ 3.0: Automating pK Prediction and the Preparation of Biomolecular Structures for Atomistic Molecular Modeling and Simulations. Nucleic. Acids. Res. 2012, 40, W537-W541.

15. Lomize, M. A.; Lomize, A. L.; Pogozheva, I. D.; Mosberg, H. I. OPM: Orientations of Proteins in Membranes Database. Bioinformatics 2006, 22, 623-625.

16. Wolf, M. G.; Hoefling, M.; Aponte-Santamaria, C.; Grubmuller, H.; Groenhof, G. G_membed: Efficient Insertion of a Membrane Protein into an Equilibrated Lipid Bilayer with Minimal Perturbation. J. Comput. Chem. 2010, 31, 2169-2174.

17. Case, D. A.; Cerutti, D. S.; Cheatham, I., T. E. ; Darden, T. A.; Duke, R. E.; Giese, T. J.; Gohlke, H.; Goetz, A. W.; Greene, D.; Homeyer, N.; Izadi, S.; Kovalenko, A.; Lee, T. S.; LeGrand, S.; Li, P.; Lin, C.; Liu, J.; Luchko, T.; Luo, R.; Mermelstein, D.; Merz, K. M.; Monard, G.; Nguyen, H.; Omelyan, I.; Onufriev, A.; Pan, F.; Qi, R.; Roe, D. R.; Roitberg, A.; Sagui, C.; Simmerling, C. L.; Botello-Smith, W. M.; Swails, J.; Walker, R. C.; Wang, J.; Wolf, R. M.; Wu, X.; Xiao, L.; York, D. M.; Kollman, P. A. AMBER17. University of California, San Francisco 2017.

18. Wang, J.; Wolf, R. M.; Caldwell, J. W.; Kollman, P. A.; Case, D. A. Development and Testing of a General Amber Force Field. J. Comput. Chem. 2004, 25, 1157-1174.

19. Maier, J. A.; Martinez, C.; Kasavajhala, K.; Wickstrom, L.; Hauser, K. E.; Simmerling, C. ff14SB: Improving the Accuracy of Protein Side Chain and Backbone Parameters from ff99SB. J. Chem. Theory. Comput. 2015, 11, 3696-3713.

20. Bayly, C. I.; Cieplak, P.; Cornell, W.; Kollman, P. A. A Well-Behaved Electrostatic Potential Based Method Using Charge Restraints for Deriving Atomic Charges: the RESP Model. J. Phys. Chem. 1993, 97, 10269-10280.

21. Van Der Spoel, D.; Lindahl, E.; Hess, B.; Groenhof, G.; Mark, A. E.; Berendsen, H. J. GROMACS: Fast, Flexible, and Free. J. Comput. Chem. 2005, 26, 1701-1718.

22. Abraham, M. J.; Murtola, T.; Schulz, R.; Páll, S.; Smith, J. C.; Hess, B.; Lindahl, E. GROMACS: High Performance Molecular Simulations Through Multi-Level Parallelism from Laptops to Supercomputers. SoftwareX 2015, 1-2, 19-25.

23. Darden, T.; York, D.; Pedersen, L. Particle Mesh Ewald - an N.Log(N) Method for Ewald Sums in Large Systems. J Chem Phys 1993, 98, 10089-10092.

24. Saleh, N.; Ibrahim, P.; Saladino, G.; Gervasio, F. L.; Clark, T. An Efficient Metadynamics-Based Protocol to Model the Binding Affinity and the Transition State Ensemble of G-Protein-Coupled Receptor Ligands. J. Chem. Inf. Model. 2017, 57, 1210-1217. 
25. Laio, A.; Parrinello, M. Escaping Free-Energy Minima. Proc. Natl. Acad. Sci. U.S.A. 2002, 99, 1256212566.

26. Barducci, A.; Bussi, G.; Parrinello, M. Well-Tempered Metadynamics: a Smoothly Converging and Tunable Free-Energy Method. Phys. Rev. Lett. 2008, 100, 020603.

27. Tribello, G. A.; Bonomi, M.; Branduardi, D.; Camilloni, C.; Bussi, G. PLUMED 2: New Feathers for an Old Bird. Comput. Phys. Commun. 2014, 185, 604-613.

28. Hanwell, M. D.; Curtis, D. E.; Lonie, D. C.; Vandermeersch, T.; Zurek, E.; Hutchison, G. R. Avogadro: an Advanced Semantic Chemical Editor, Visualization, and Analysis Platform. J. Cheminform. 2012, 4, 17.

29. Trott, O.; Olson, A. J. AutoDock Vina: Improving the Speed and Accuracy of Docking with a New Scoring Function, Efficient Optimization, and Multithreading. J. Comput. Chem. 2010, 31, 455-461.

30. Case, D. A.; Ben-Shalom, I. Y.; Brozell, S. R.; Cerutti, D. S.; Cheatham, T. E.; III; Cruzeiro, V. W. D.; Darden, T. A.; Duke, R. E.; Ghoreishi, D.; Gilson, M. K.; Gohlke, H.; Goetz, A. W.; Greene, D.; Harris, R.; Homeyer, N.; Izadi, S.; Kovalenko, A.; Kurtzman, T.; Lee, T. S.; LeGrand, S.; P. Li, C. L.; Liu, J.; Luchko, T.; Luo, R.; Mermelstein, D. J.; Merz, K. M.; Miao, Y.; Monard, G.; Nguyen, C.; Nguyen, H.; Omelyan, I.; Onufriev, A.; Pan, F.; Qi, R.; Roe, D. R.; Roitberg, A.; Sagui, C.; Schott-Verdugo, S.; Shen, J.; Simmerling, C. L.; Smith, J.; Salomon-Ferrer, R.; Swails, J.; Walker, R. C.; Wang, J.; Wei, H.; Wolf, R. M.; Wu, X.; Xiao, L.; York, D. M.; Kollman, P. A. AMBER 2018. University of California, San Francisco 2018.

31. Frisch, M. J.; Trucks, G. W.; Schlegel, H. B.; Scuseria, G. E.; Robb, M. A.; Cheeseman, J. R.; Scalmani, G.; Barone, V.; Petersson, G. A.; Nakatsuji, H.; Li, X.; Caricato, M.; Marenich, A. V.; Bloino, J.; Janesko, B. G.; Gomperts, R.; Mennucci, B.; Hratchian, H. P.; Ortiz, J. V.; Izmaylov, A. F.; Sonnenberg, J. L.; Williams-Young, D.; Ding, F.; Lipparini, F.; Egidi, F.; Goings, J.; Peng, B.; Petrone, A.; Henderson, T.; Ranasinghe, D.; Zakrzewski, V. G.; Gao, J.; Rega, N.; Zheng, G.; Liang, W.; Hada, M.; Ehara, M.; Toyota, K.; Fukuda, R.; Hasegawa, J.; Ishida, M.; Nakajima, T.; Honda, Y.; Kitao, O.; Nakai, H.; Vreven, T.; Throssell, K.; Montgomery, J. A., Jr.; Peralta, J. E.; Ogliaro, F.; Bearpark, M. J.; Heyd, J. J.; Brothers, E. N.; Kudin, K. N.; Staroverov, V. N.; Keith, T. A.; Kobayashi, R.; Normand, J.; Raghavachari, K.; Rendell, A. P.; Burant, J. C.; Iyengar, S. S.; Tomasi, J.; Cossi, M.; Millam, J. M.; Klene, M.; Adamo, C.; Cammi, R.; Ochterski, J. W.; Martin, R. L.; Morokuma, K.; Farkas, O.; Foresman, J. B.; Fox, D. J. Gaussian 16. 2016. 